Portland State University

PDXScholar

\title{
The Effects of Utility Pole Placement and Characteristics on Pentachlorophenol Concentrations Entering Underground Injection Control (UIC) Devices: City of Gresham, Oregon
}

Katie Bohnren

Portland State University

Follow this and additional works at: https://pdxscholar.library.pdx.edu/mem_gradprojects

Part of the Other Environmental Sciences Commons, and the Water Resource Management Commons Let us know how access to this document benefits you.

Recommended Citation

Bohnren, Katie, "The Effects of Utility Pole Placement and Characteristics on Pentachlorophenol Concentrations Entering Underground Injection Control (UIC) Devices: City of Gresham, Oregon" (2012). Master of Environmental Management Project Reports. 25.

https://pdxscholar.library.pdx.edu/mem_gradprojects/25

https://doi.org/10.15760/mem.15

This Project is brought to you for free and open access. It has been accepted for inclusion in Master of Environmental Management Project Reports by an authorized administrator of PDXScholar. Please contact us if we can make this document more accessible: pdxscholar@pdx.edu. 
The effects of utility pole placement and characteristics on

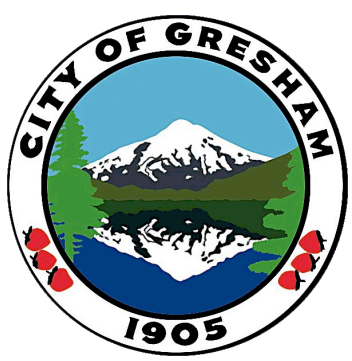
pentachlorophenol concentrations entering Underground Injection Control (UIC) devices: City of Gresham, Oregon

\section{Prepared by: Katie Bohren}

In partial fulfillment of the requirements of the Masters of Environmental Management Degree Portland State University, June 2012

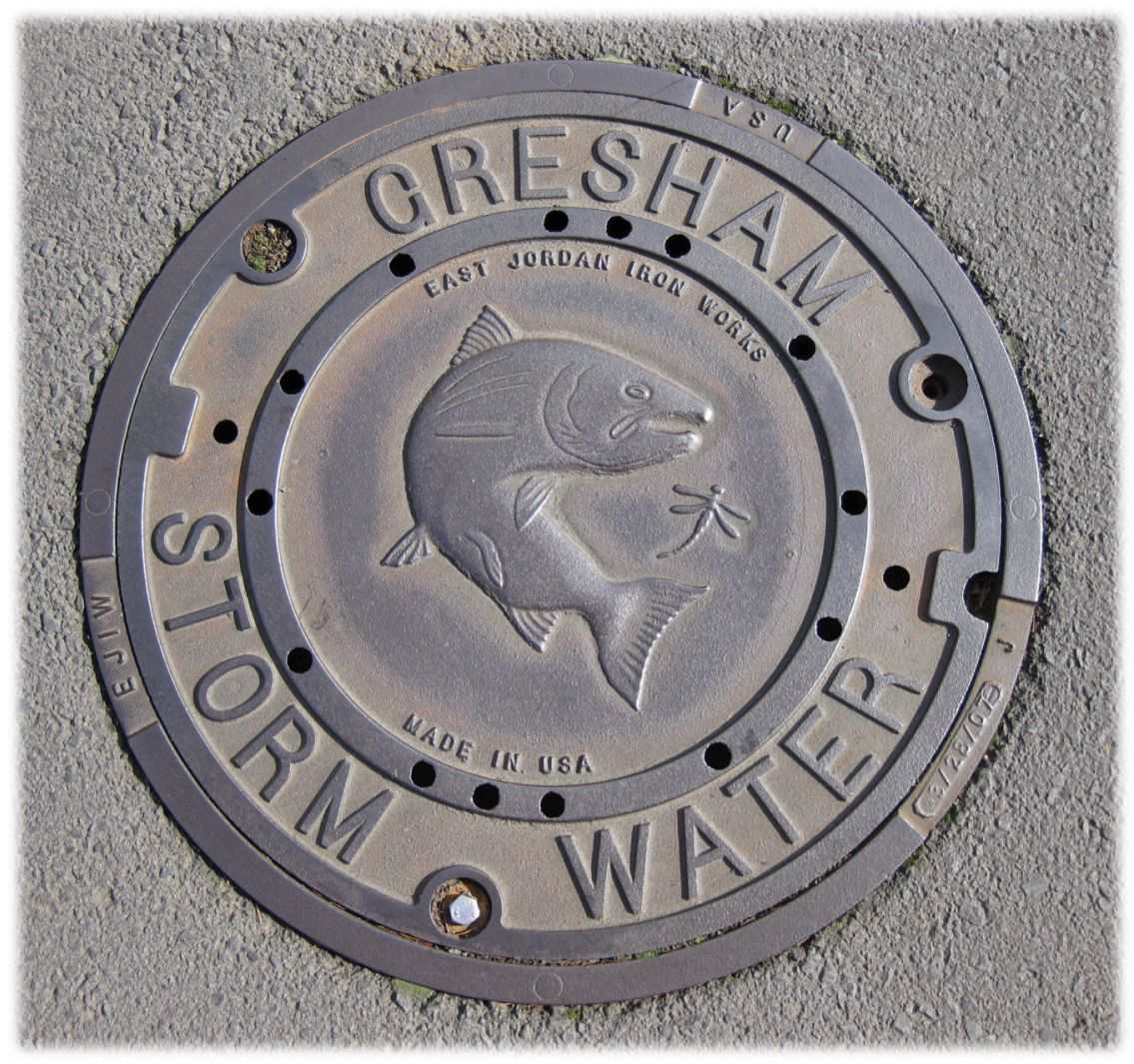

Academic Advisor: Dr. Joseph Maser

Community Partner: Torrey Lindbo \& Lynne Kennedy, City of Gresham 


\section{TABLE OF CONTENTS}

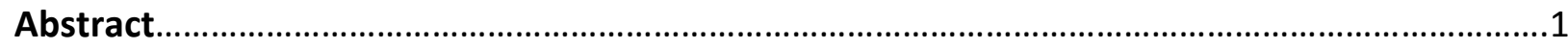

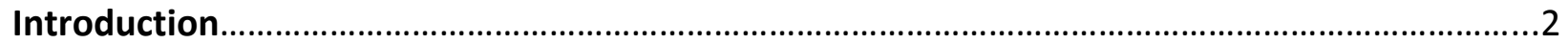

Underground Injection Control (UIC) Device \& WPCF Permit Background..........................4

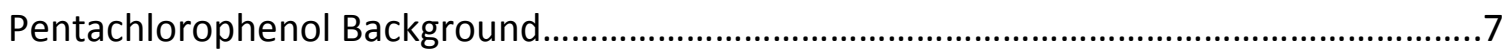

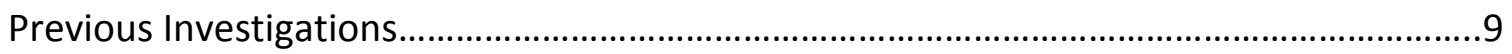

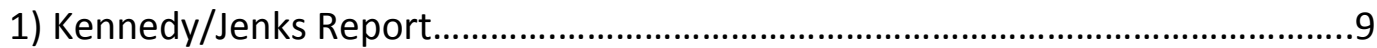

2) City of Gresham UIC Priority Pollutant Wet Weather Study (2009-2010).........10

3) GSI Water Resources, Inc. Report......................................................................14

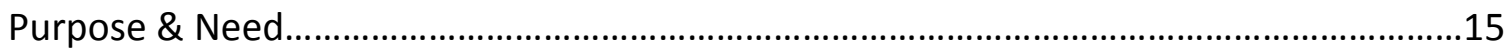

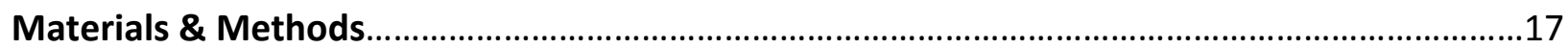

Site Description \& Gresham Hydrogeology.......................................................................17

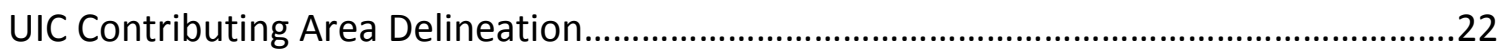

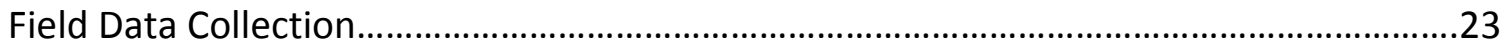

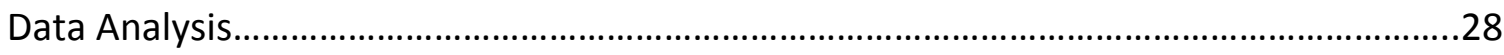

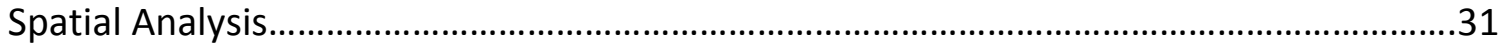

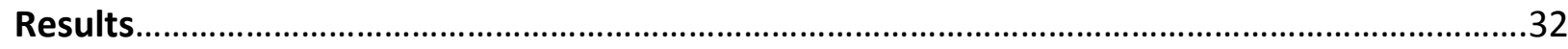

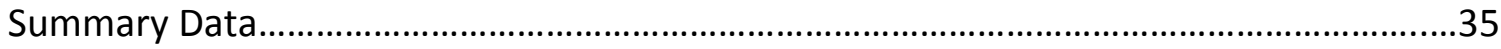

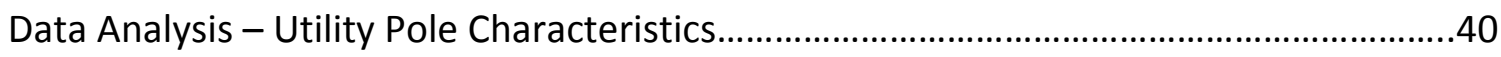

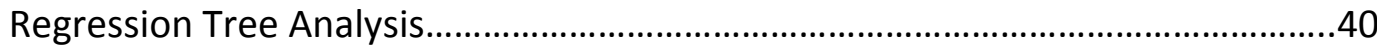

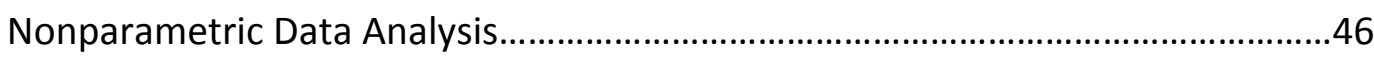

Data Analysis - Contributing Area Characteristics............................................................50

Regression Tree Analysis...................................................................................50

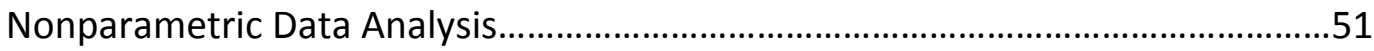

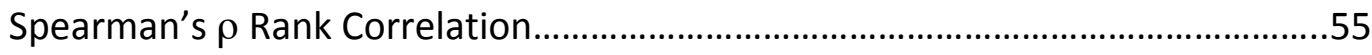

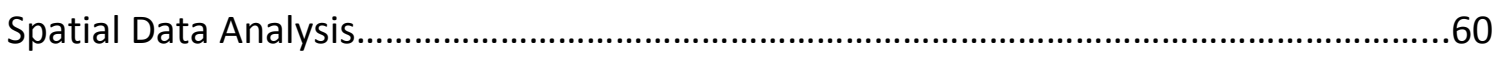

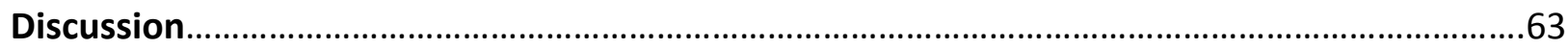

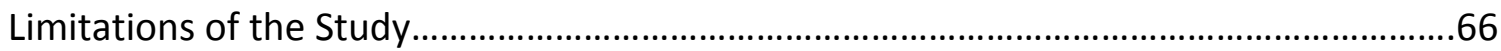

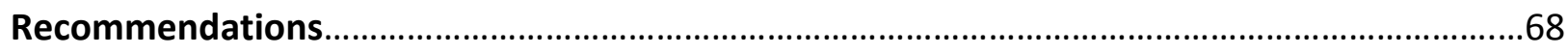


Acknowledgements.

Appendix A: City of Portland Exploratory Study \& Current Compliance Monitoring...................73

Appendix B: Contributing Area Delineation Procedure in ArcGIS \& Example of

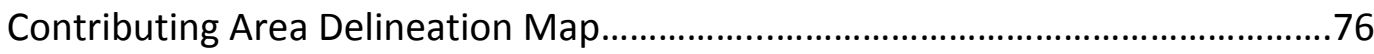

Appendix C: Field Data Collection Sheet \& Instructions............................................................79

Appendix D: Comprehensive Utility Pole Data for 60 UIC Contributing Areas

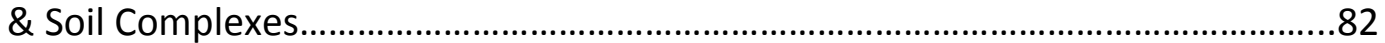

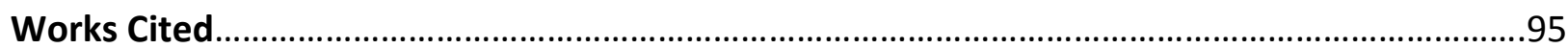




\section{LIST OF FIGURES \& TABLES}

\section{FIGURES}

Figure 1. Gresham city limits with watersheds and the locations of all UIC devices.......................4

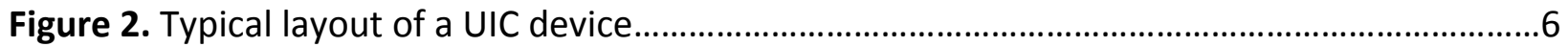

Figure 3. Schematic of crowned street with two catch basins connected to a single UIC device

Figure 4. Histogram of pentachlorophenol concentration in stormwater samples from City of Gresham 2009-2010 wet weather study.....

Figure 5a. Boxplot of pentachlorophenol concentration versus rainfall intensity from City of Gresham 2009-2010 wet weather study

Figure 5b. Boxplot of pentachlorophenol concentration versus stormwater runoff from City of Gresham 2009-2010 wet weather study. 13

Figure 6a. USGS hydrogeologic map of the Portland Basin.......................................................18

Figure 6b. USGS cross-section of hydrogeologic units in the Portland Basin................................18

Figure 7. Map of the depth to groundwater and UIC device sample locations...........................21

Figure 8. Flow chart of contributing area delineation procedure...............................................22

Figure 9. Example of utility pole treatment compound ground staining ......................................26

Figure 10a. Example of utility pole with high amount of treatment compound on base of pole, based on visual estimation.

Figure 10b. Example of utility pole with medium amount of treatment compound on base of pole, based on visual estimation. 27

Figure 10c. Example of utility pole with low amount of treatment compound on base of pole, based on visual estimation. 27

Figure 11a. Example of utility pole characterized as weathered, based on visual estimation.....27

Figure 11b. Example of utility pole characterized as mature, based on visual estimation...........27

Figure 11c. Example of utility pole characterized as juvenile, based on visual estimation...........27

Figure 12a. Example of utility pole with a plastic diffusion plug .................................................28

Figure 12b. Example of a utility pole with a wood diffusion plug...............................................28 
Figure 13. Boxplots of pentachlorophenol concentration for all contributing areas, contributing areas with utility poles, and contributing areas with no utility poles. 36

Figure 14. Map of pentachlorophenol concentration at each UIC device and areas of groundwater well protection zones. 37

Figure 15. Regression tree comparing pentachlorophenol concentration to categorical and continuous data for each utility pole .41

Figure 16. Boxplot of pentachlorophenol concentration versus substrate surrounding the utility pole. .43

Figure 17. Boxplot of pentachlorophenol concentration versus presence of treatment compound ground staining. .44

Figure 18. Boxplot of pentachlorophenol concentration versus age of utility pole .44

Figure 19. Boxplot of pentachlorophenol concentration versus the utility pole manufacturer.

Figure 20. Scatterplot of pentachlorophenol concentration versus the year of utility pole manufacture .48

Figure 21. Boxplot of pentachlorophenol concentration versus a visual estimation of treatment compound present on the base of the utility pole. .49

Figure 22. Boxplot of pentachlorophenol concentration versus vehicle trips per day .52

Figure 23. Boxplot of pentachlorophenol concentration versus street functional class. .53

Figure 24. Boxplot of number of utility poles versus vehicle trips per day .54

Figure 25a. Scatterplot of pentachlorophenol concentration versus total utility pole surface area, based on rainfall intensity during sample collection. .56

Figure 25b. Scatterplot of pentachlorophenol concentration versus total utility pole surface area, based on street functional class .56

Figure 26. Scatterplot of pentachlorophenol concentration versus surface area of utility poles set in concrete .58

Figure 27. Scatterplot of pentachlorophenol concentration versus minimum distance from a utility pole to the catch basin inlet. 
Figure 28a. Results from Anselin Local Moran's I cluster and outlier analysis. 62

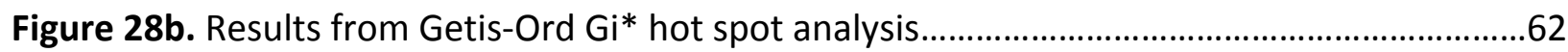

Figure 29. Photo of future utility pole recommendation...........................................................69

\section{TABLES}

Table 1. Variables used in the construction of two regression trees in ' $R$ ' ..................................30

Table 2. Summary data for 60 UIC contributing areas............................................................33-34

Table 3. Characteristics of utility poles located in contributing areas with pentachlorophenol concentration greater than $1 \mu \mathrm{g} / \mathrm{L}$ in stormwater. $39-40$

Table 4. Summary output for node number one of utility pole characteristic regression tree.

Table 5. Summary results from pairwise comparison of the visual estimation of treatment product on base of the utility pole .50

Table 6. Summary output for node number one of UIC contributing area regression tree. .51

Table 7. Summary results from Spearman's $\rho$ rank correlation tests .55 


\section{ABSTRACT}

Urbanization is causing increased amounts of stormwater runoff, while simultaneously decreasing the amount of pervious surface area for infiltration. Multiple priority pollutants have been identified in urban stormwater, including pentachlorophenol (PCP). PCP is often found in stormwater samples exceeding the Safe Drinking Water Act limit of $1 \mu \mathrm{g} / \mathrm{L}$ and can cause human health issues with exposure over time. Treated wood utility poles are the major source of PCP in urban stormwater. With the use of underground injection control (UIC) devices as an alternative method to treat and dispose of stormwater, the potential exists for groundwater contamination of PCP. The City of Gresham currently owns and operates approximately 1,100 UIC devices.

In this study 60 UIC device contributing areas were surveyed for the presence and characteristics of utility poles. A positive correlation was found between utility pole surface area in a UIC contributing area and PCP concentration in stormwater. A stronger correlation exists for surface area of utility poles surrounded by concrete and PCP concentration in stormwater. The year of the last inspection by the electrical company could also be an indicator of PCP concentration in stormwater, as additional treatment compound is often injected into utility poles during these inspections. The intensity of the rainfall event during stormwater sample collection, in combination with these other attributes, may impact how much treatment compound is able to leach from the pole. Recommendations for future work include adding to the sample set of PCP concentrations for multiple UIC sites and using GoogleEarth to identify utility poles surrounded by concrete in other UIC contributing areas. 


\section{INTRODUCTION}

Increasing urbanization has led to increased stormwater runoff and less infiltration of precipitation through pervious surfaces for groundwater recharge (Pitt et al., 1999). Griffin, et al. (1980) found that watershed imperviousness influences pollutant loads in stormwater runoff and reports dating back to the late 1980s to Congress identify urban stormwater runoff as one of the leading causes of water quality impairment of rivers, lakes, and estuaries (USEPA, 1990). Modeling studies have predicted that runoff volumes will continue to increase as cities grow and replace pervious surfaces with impervious areas (Sloto, 1998). Drywells, or underground injection control (UIC) devices, are one type of stormwater infiltration contraptions used in urban areas to reduce stormwater runoff to surface water bodies and direct it to the subsurface (Pitt et al., 1999).

Urban stormwater runoff can vary in both quantity and quality depending on the rainfall volume, intensity, antecedent conditions. Traffic patterns, landuse, regional hydrogeology, and street maintenance can also impact the runoff quality (Tsihrintzis \& Hamid, 1997).

Contaminants commonly found in stormwater runoff include heavy metals, nutrients, pesticides and herbicides, volatile organic compounds, salts, and pathogens (Pitt et al., 1999). Because runoff has the potential to contain many more pollutants than when precipitation was just falling on pervious areas, there is also a greater potential for these pollutants to reach groundwater sources when runoff is directed to a UIC device.

The City of Gresham has approximately 1,100 underground injection control (UIC) devices, primarily located in the Columbia Slough and Fairview Creek watersheds where there are large areas with porous soils (FIGURE 1) (Gresham, 2007). These wells, defined by the US 
Environmental Protection Agency (USEPA) as "a well completed above the water table so that its bottom and sides are typically dry except when receiving fluids," are used to manage stormwater by infiltrating it into the subsurface rather than flowing directly into waterways. Pentachlorophenol (PCP), also known as penta or PCP, is a priority pollutant in urban stormwater and is designated a toxic pollutant in Section 307(a)(1) of the Clean Water Act (33 USC § 1251). It is widely used as an industrial wood preservative and has been known to extend the life of utility poles from seven years to an average of thirty-five (Wilkinson, 1979; Roche, 1965). Historically, PCP was used as a commercial and residential herbicide, defoliant, mossicide, and disinfectant. However due to discovered adverse human health effects and its toxicity to aquatic organisms, the EPA restricted all non-industrial or residential uses of pentachlorophenol in 1987 (USEPA). The USEPA has set a maximum contaminant level of 0.001 $\mathrm{mg} / \mathrm{L}$ for pentachlorophenol in drinking water (USEPA).

In a early EPA investigation of urban stormwater runoff, Cole et al. (1984) found that PCP was detected in stormwater samples from five of nineteen participating cities and $15 \%$ of samples contained PCP ranging from 1-115 $\mu \mathrm{g} / \mathrm{L}$. While broadly used in the timber industry worldwide for the past 50 years (Mills, et al. 2006) on such products as utility poles, railroad ties, and wood crates (Christodoulatos, 1994), most urban areas contain an abundance of PCP treated utility poles. These poles are known to leach PCP and can contaminate surrounding soils and groundwater (Christodoulatos, 1994). Given the continuing development in Gresham, the City is challenged to identify which pollutants are of primary concern and the source or sources of those pollutants. 


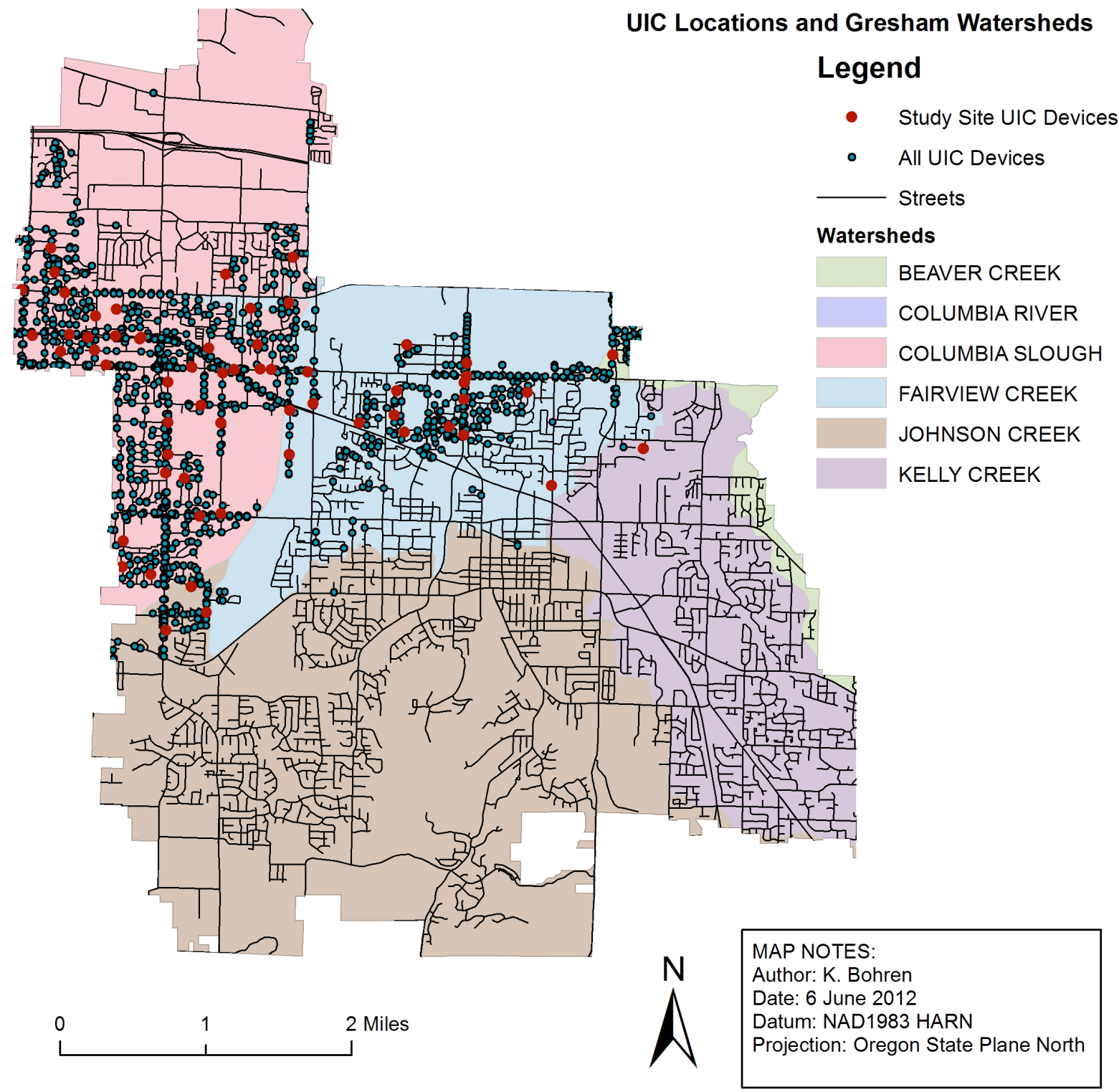

Figure 1. Gresham city limits showing location of the five watersheds. The blue dots represent the approximately 1,100 UIC devices and the red dots represent the 60 random and spatially balanced sample points used in this study and the 2009-2010 Wet Weather Study (Gresham, 2009). The majority of UIC devices are located in the Fairview Creek and Columbia Slough watersheds.

\section{Underground Injection Control (UIC) Device \& WPCF Permit Background}

The USEPA categorizes UIC devices into five classes, with stormwater drainage wells

falling into Class V. These are shallow wells that depend on gravity to inject non-hazardous 
fluids, typically runoff from impervious surfaces, directly underground (40 CFR 144.80). A typical UIC device configuration is shown in FIGURE 2. Stormwater is collected in the catch basin inlet from the impervious surface, possibly diverted to a sedimentation manhole, and infiltrates into the subsurface once it reaches the UIC. Pre-treatment devices include sumped catch basins and sedimentation manholes, which restrict sediment-bound pollutants from reaching the UIC device. They theoretically reduce the amount of maintenance required on UIC devices since less debris is reaching the UIC. These best management practices for UIC devices are most successful with regular maintenance and cleaning (ACWA, 2003).

DEQ recommends a vertical separation distance from the bottom of the UIC device to the seasonal high water table of 7-10 feet in coarse-grained soils (DEQ). In Gresham, the depth of the UICs range from about fifteen to thirty feet, with the majority in the range of 20 feet. There is typically a minimum of 10 feet of vertical separation between the bottom of the UIC and the local groundwater table (T. Lindbo, personal communication). Additionally, under the UIC rule authorization requirements in the Oregon Administrative Rules (OAR) Division 44, DEQ requires that a UIC device is no closer than 500 feet to a domestic drinking water well and a two year travel time or 500 feet to a public drinking water well, which ever is more protective. Additionally, the UIC should be located in soils such that it can fully drain 48 hours after a storm event (ACWA, 2003). There are exemptions for older wells that do not meet these requirements under a municipal UIC WPCF permit, however all newly constructed UIC devices in Gresham must meet the rule authorization requirements (Gresham, 2011a). 


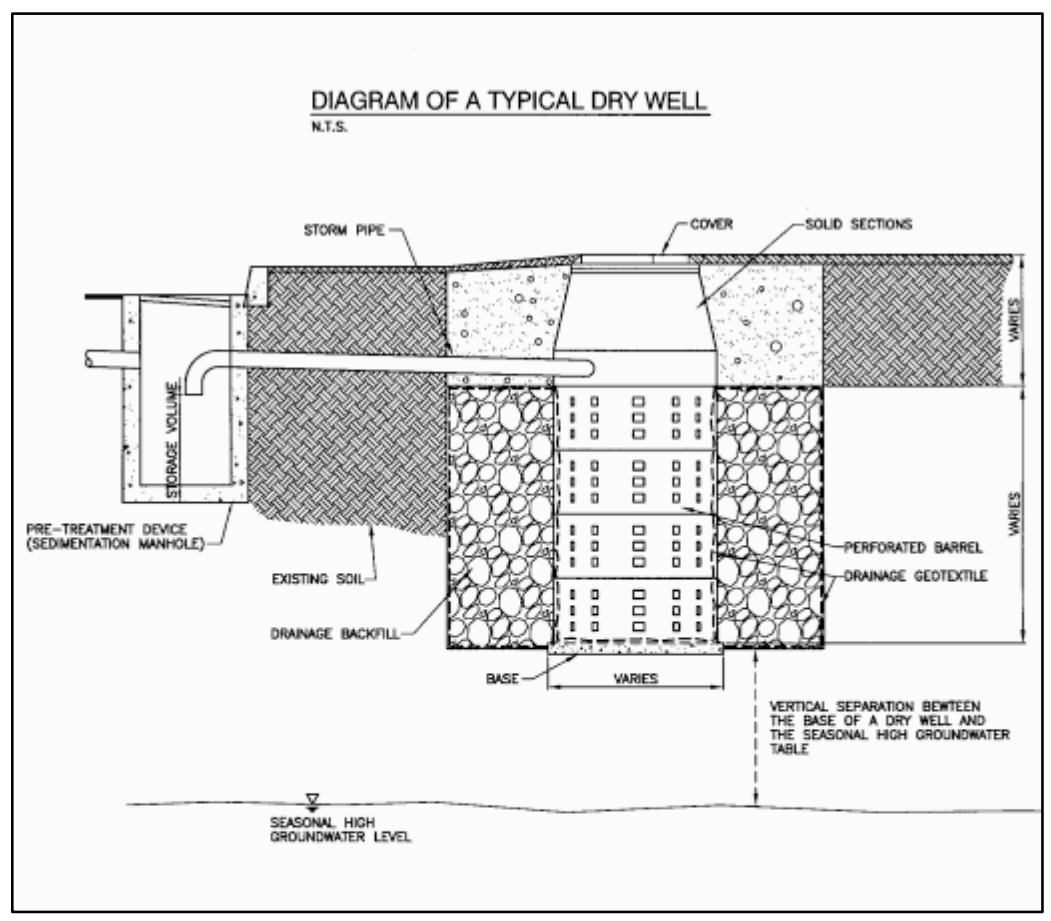

Figure 2. Typical layout of a UIC device. In Gresham, the pretreatment device may be sumped catch basin, sedimentation manhole, or both. From Underground Injection Control Wells Best Management Practices, Oregon Association of Clean Water Agencies, 2003.

Congress passed the Safe Drinking Water Act (SDWA) in the 1970s, granting the USEPA the authority to regulate UIC devices in order to protect freshwater aquifers from contamination. The Underground Injection Control Program was created and regulations were initially passed in the early 1980 s to define the five well classes and set minimum standards. In 1984 the State of Oregon was delegated the authority by the USEPA to administer the UIC permit program under the title 40 of the Code of Federal Regulations (CFR) parts 144-146 (USEPA). The federal regulations were updated in 1999 and DEQ released OAR 340-044 in September 2001. OAR 340-044-0018 includes special reporting and registration requirements for municipalities with greater than 50 UIC devices. 
In 1999, the USEPA estimated that there were approximately 248,000 stormwater drainage wells in the United States, while only approximately 77,000 wells were documented. About $6 \%$ of the documented wells were located in Oregon (USEPA, 1999). In 2005 ODEQ issued its only WPCF/UIC area-wide permit (Permit \#102830) to the City of Portland for their approximately 9,900 UICS (DEQ). The City of Gresham is currently in the process of obtaining a WPCF permit from DEQ.

The State of Oregon has identified groundwater as a critical natural resource that must be protected for future beneficial uses. It has also determined that once polluted, groundwater can be quite difficult and sometimes impossible to clean. As such, the Oregon Administrative Rule (OAR) 340-040 provides minimum groundwater protection standards to assure that groundwater remains at a quality acceptable for human consumption and the WPCF permit requires that UIC systems adhere to these regulations (DEQ).

\section{Pentachlorophenol Background}

Pentachlorophenol, a fungicide used in the wood preservative industry, has a chemical formula of $\mathrm{C}_{6} \mathrm{HCl}_{5} \mathrm{O}$ and a molecular weight of 266.34 . The solubility of pentachlorophenol is dependent on temperature and $\mathrm{pH}$, with solubility increasing with increasing temperature and $\mathrm{pH}$. The pKa is 4.75 (Christodoulatos 1994).

Technical grade PCP, which is most commonly used on wooden utility poles, is typically a grey or brown color and contains $85-90 \%$ PCP, 5-12\% tetrachlorophenol and other polychlorophenols, and traces of other polychlorinated dibenxo-p-dioxins and polychlorinated dibenzofurans (Choudhury et.al, 1986). The poles are generally pressure treated with a mixture 
of PCP in heavy oil, allowing the mixture to coat the cell walls inside the wood matrix and protect the pole from rotting and decay (Wilkinson 1979, Christodoulatos et al 1994).

Utility poles are inspected approximately every ten years by performing a density test. If it is found that the pole has a hollow heart or bug infestation, it will either be treated by injecting additional pentachlorophenol solution into the wood matrix or will be replaced, depending on the damage (PGE, personal communication). During a visual inspection of utility poles, it is easy to determine if additional pentachlorophenol has been injected into the pole by the presence of wood or plastic diffusion plugs.

Studies have demonstrated that aqueous solutions of PCP can be degraded through microbial processes and photolysis (Wong \& Crosby, 1981; Pignatello et.al 1983). The rate at which the PCP degrades from absorbing ultraviolet radiation is dependent on the $\mathrm{pH}$ of the solution as well as the depth of the water. For example, Wong \& Crosby (1981) found that at pH 7.3 the half life of the PCP solution was 3.5 hours while at $\mathrm{pH} 3.3$ the half life was approximately 100 hours. Pignatello et.al (1983) found that degradation decreased with increased stream depth, as less light is able to penetrate from the surface. PCP also adsorbs to soil particles in the subsurface. Sorption is greater at lower temperatures and $\mathrm{pH}$ and when soil contains greater amounts of fines and organic carbon (Christodoulatos et al., 1994)

Exposure to even low levels of PCP over a long period of time can result in liver or kidney damage and other problems with the immune system (USEPA). These effects could be compounded by other chemicals present in technical grade PCP. When there is exposure to high levels of PCP, fever and difficulty breathing can occur (ODHS, 2006). There may be an increased risk of cancer with exposure to high levels of PCP (USEPA). Some animals, when 
exposed to high levels, had increased nasal, endocrine, and liver tumors (ODHS, 2006). Tests also show that it is teratogenic and fetotoxic in rats (Cole et al., 1984).

\section{Previous Investigations}

1) Kennedy/Jenks Report (2009)

In 2009 the Oregon Association of Clean Water Agencies (ACWA) contracted Kennedy/Jenks Consultants to compile and analyze stormwater data from 25,247 samples provided by 15 Oregon public agencies. 45 analytes were analyzed from five major chemical groups: metals, phenols, phthalates, polynuclear aromatic hydrocarbons, and nutrients. Not all samples were analyzed for all of the analytes. The goal of the study was to determine which pollutants were prevalent above ODEQ screening levels for the UIC program and if high levels of pollutants were correlated with the number of vehicle trips per day or adjacent land uses. The City of Gresham was one of the public agencies involved in the contract (Kennedy/Jenks, 2009). Of the 675 samples tested for PCP in the study, Kennedy/Jenks found that $11.7 \%$ exceeded the screening level of $1 \mu \mathrm{g} / \mathrm{L}$ as stated in both the EPA Drinking Water Maximum Contaminant Level and the DEQ Drywell Compliance Maximum Allowable Discharge Level (MADLs from Portland's WPCF permit). The third screening level used in the study, the Oregon Administrative Rule Numerical Groundwater Reference Level (OAR-340-0020) did not have a screening level for PCP. In fact, PCP was one of only three analytes to exceed one or more screening levels in more than $1 \%$ of samples (Kennedy/Jenks, 2009).

Due to the relatively high percentage of non-compliant samples, PCP was one of five analytes used in the study statistical analysis to explore the relationship between stormwater 
pollutants and number of vehicle trips per day or landuse in the area the sample was collected from. The other analytes used in the analysis were lead, nitrate-nitrogen (NO3-N), Bis(2ethylhexyl) phthalate (DEHP), and benzo(a)pyrene (B(a)P). The analysis determined that PCP concentration found in stormwater from streets with greater than 1,000 trips per day was significantly higher $(\alpha=0.05$ ) than stormwater from streets with less than 1,000 trips per day. It also determined that PCP concentrations were significantly higher $(\alpha=0.05)$ in commercial and industrial land uses than in residential land uses, although there were not significant differences between commercial and industrial land uses. In general, the report determined that vehicle trips per day is potentially a better indicator of stormwater quality that surrounding land use (Kennedy/Jenks, 2009).

\section{2) City of Gresham UIC Priority Pollutant Wet Weather Study (2009-2010)}

The City of Gresham conducted an exploratory study of stormwater samples from 60 UIC devices during December 2010 - February 2011 in order to better understand stormwater characteristics in Gresham and to compare those characteristics to stormwater data from the City of Portland. The Generalized Random Tessellation Stratified (GRTS) survey design (Stevens \& Olsen, 2004) was used to select the sites for the study. This methodology is ideal for largescale environmental sampling programs in that it is designed to characterize a system with many sampling locations and produce a sampling population that is spatially balanced. The sampling population can also be selected such that some portions of the system are more intensively sampled than others. Since previous studies have shown that UIC devices located in areas with greater than 1,000 vehicle trips per day have significantly different stormwater 
characteristics than UIC devices located in areas with less than 1,000 trips per day

(Kennedy/Jenks, 2009; Portland SAP, 2006b), the GRTS survey design can be manipulated to select a greater proportion of sites in areas with greater than 1,000 trips per day (Gresham, 2009).

30 sample points were located in areas with less than 1,000 trips per day and 30 sample points were located in areas with greater than 1,000 trips per day. Samples were generally taken from stormwater flowing into a catch basin inlet or sedimentation manhole. In some instances where crowned streets are present and there are two catch basins connected to a single UIC device (FIGURE 3), the sample only represented stormwater from one side of the street.

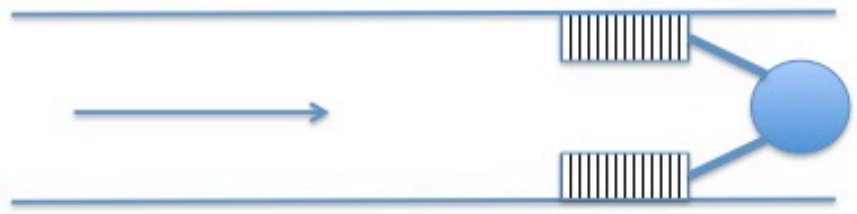

Figure 3. Example of a crowned street with one catch basin inlet (square) on each side of the street draining to a single UIC device (circle). Street flow is represented by the arrow.

Two sites were resampled during the study; one site (UIC-037) was sampled after oil was illegally dumped into the catch basin and so the data was considered to be atypical of usual conditions in that contributing area. A second site (UIC-045), located on SE Stark Street, was resampled to confirm high pollutant loads in the stormwater sample collected during a high intensity rainfall event. The second sample was collected during a lower intensity rainfall event and had lower concentrations of pollutants. 


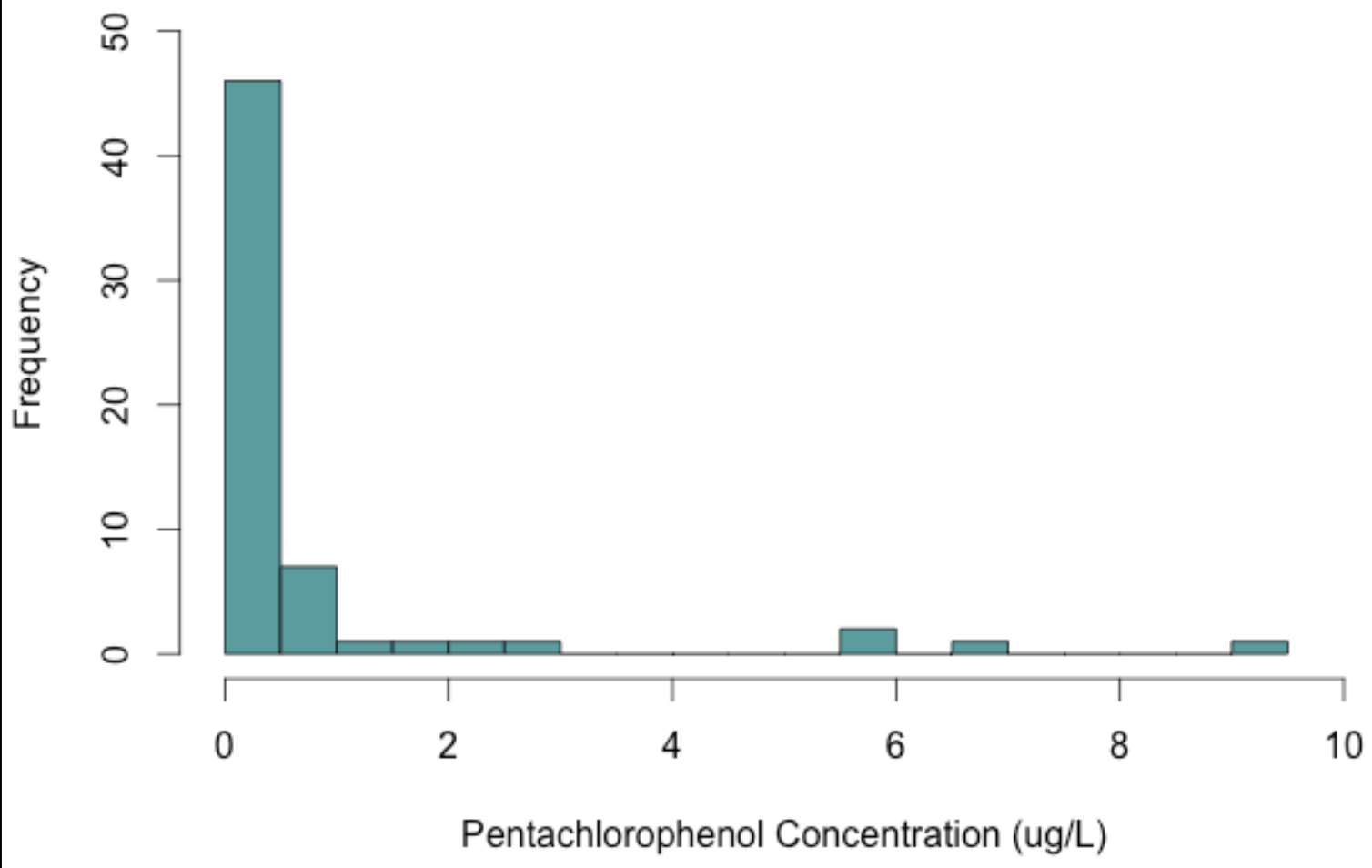

Figure 4. Histogram of pentachlorophenol concentrations $(\mu \mathrm{g} / \mathrm{L})$ in stormwater samples $(n=62)$ from the 20092010 Gresham Wet Weather Study. Eight samples were above the SDWA maximum contaminant level of $1 \mu \mathrm{g} / \mathrm{L}$. The method reporting limit for PCP is $0.04 \mu \mathrm{g} / \mathrm{L}$. Non-detects are reported at this concentration.

The 62 samples were collected on seven days between December 14, 2009 to February 11, 2010. Rainfall during the collection events was classified as "heavy" for 5 samples, "moderate" for 21 samples, "light" for 31 samples, and "not raining" for 5 samples (FIGURE 5a). Runoff rates to the catch basin inlet were classified as "abundant" for 13 samples, "moderate" for 34 samples, and "minimal" for 35 samples (FIGURE 5b). The intensity of rainfall and runoff rates recorded for each sample were subjective, based on the judgment of the stormwater sample collector. PCP concentration in stormwater ranged from $0.04 \mu \mathrm{g} / \mathrm{L}-9.1 \mu \mathrm{g} / \mathrm{L}$ (mean=0.74 $\mu \mathrm{g} / \mathrm{L}$, median=0.12 $\mu \mathrm{g} / \mathrm{L}$ ). As seen in Figure 4, 8 of the 62 samples (13\%) exceeded 
the PCP maximum contaminant level of $1 \mu \mathrm{g} / \mathrm{L} .33 \%$ of the samples had a PCP concentration of $0.04 \mu \mathrm{g} / \mathrm{L}$, the method reporting limit, and all of these UIC devices were located on streets with less than 1,000 vehicles trips per day (equivalent to the "residential" functional class). It is likely that some of these samples at the method reporting limit were actually below the detection limit. The 60 UIC devices selected for this study, as well as the PCP concentrations found in the stormwater samples, were used for the sites in the present study with the exception of the first sample from UIC-037 (total of $n=61$ ).
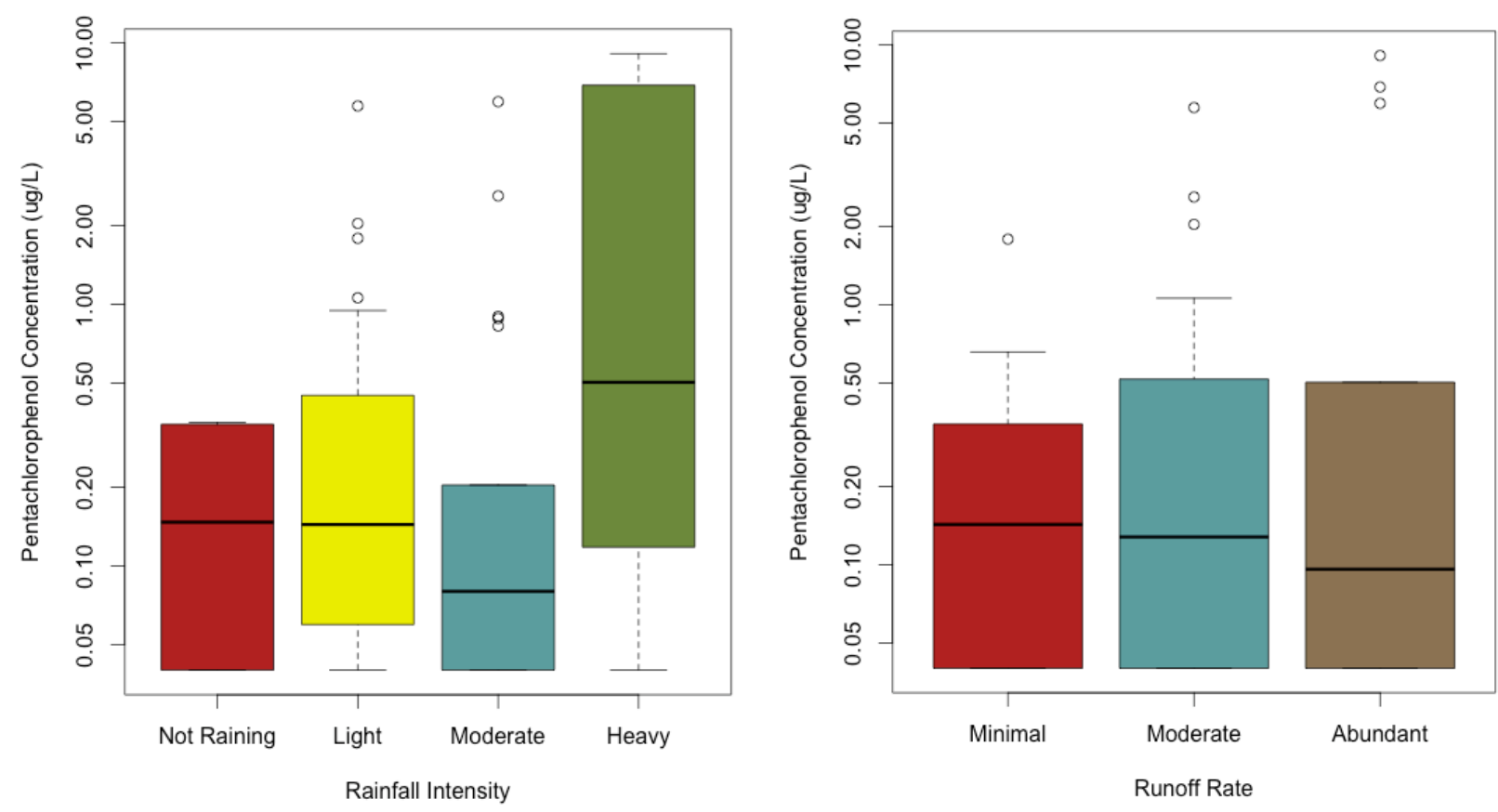

Figure 5a \& 5b. Boxplot of PCP concentration in 61 stormwater samples based on a) rainfall intensity (heavy: $n=5$; moderate: $n=21$; light: $n=31$; not raining: $n=5$ ) and $b$ ) runoff rates (abundant: $n=13$; moderate: $n=34$; minimal: $\mathrm{n}=15$ ) during the time the sample was collected. The method reporting limit for PCP is $0.04 \mu \mathrm{g} / \mathrm{L}$. Non-detects are reported at this concentration. 


\section{3) GSI Water Solutions Report (2011b)}

GSI Water Solutions, Inc. was contracted by the City of Gresham to model the fate and transport of PCP; naphthalene; DEHP; 2,4-D; and toluene in groundwater and to determine whether the SDWA MCL and MADL $(1 \mu \mathrm{g} / \mathrm{L})$ in Portland's WPCF permit could be increased while still protecting groundwater and meeting the requirements of OAR 340-040. They used EPA's BIOSCREEN model and an existing unsaturated zone fate and transport model (Fate and Transport Tool) in their investigation (GSI, 2011b).

The Fate and Transport Tool estimated pollutant attenuation in the unsaturated zone using the Advection Dispersion Equation under average and reasonable maximum scenarios. The model showed that at an EDL of $1 \mu \mathrm{g} / \mathrm{L}, \mathrm{PCP}$ would require 2.4 feet of unsaturated zone under the average scenario and 17.5 feet under the reasonable maximum scenario before it would attenuate to the method reporting limit of $0.04 \mu \mathrm{g} / \mathrm{L}$. Under the reasonable maximum scenario, PCP would require 9.61 feet to attenuate below the EDL. It was noted in the memorandum that the reasonable maximum scenario represents the worst-case scenario and not reasonably likely conditions. It is used more for the purpose of evaluating model sensitivity (GSI, 2011b).

Based on the Fate and Transport Tool, GSI Water Solutions recommended that the EDL for PCP entering UIC devices be increased to $10 \mu \mathrm{g} / \mathrm{L}$ under the assumptions that the recommended EDLs were limited to ten times the existing EDLs and that the separation distance between the bottom of an UIC device and seasonal high water table is ten feet. GSI Water Solutions also assumed that when pollutant concentrations just above the groundwater table are below the method reporting limit, that groundwater is protected (GSI, 2011b). 
The BIOSCREEN model was used to evaluate horizontal movement of a pollutant from the UIC in saturated conditions due to the fact that the reasonable maximum scenario for PCP showed that it would take greater than ten feet of vertical transport though the unsaturated zone to attenuate below the method reporting limit. The model assumed a maximum allowable horizontal travel distance of ten feet to be protective of human health (GSI, 2011b).

The model found that when $10 \mu \mathrm{g} / \mathrm{L}$ of PCP is discharged to a UIC device with five feet of separation from the bottom of the UIC to the top of the water table, the concentration of PCP reaching groundwater will be $4.27 \mu \mathrm{g} / \mathrm{L}$. Once in the saturated zone, PCP will travel approximately two feet under average conditions and 7.5 feet under reasonable maximum conditions before concentrations are less than the method reporting limit (GSI, 2011b). ODEQ is in the process of updating the UIC WPCF Municipal Permit template to reflect some of the findings of this study.

\section{Purpose \& Need}

The City of Gresham has applied for a Water Pollution Control Facility (WPCF) permit from the Oregon Department of Environmental Quality (DEQ) for the approximately 1,100 underground injection control (UIC) devices it owns and operates. Based on data collected by both Gresham and the City of Portland, which was the first municipality in the nation to receive a WPCF permit for Class V Underground Injection Control devices in 2005, pentachlorophenol (PCP) is found in stormwater at levels that exceed limits set by DEQ to protect drinking water in nearly $15 \%$ of UICs sampled. PCP in urban stormwater in the Portland metropolitan area primarily comes from the runoff from utility poles, although could also emanate from TriMet 
MAX tracks (T. Lindbo, personal communication), fence posts, or other treated wood products in UIC contributing areas.

Until recently, the DEQ Municipal UIC WPCF Permit Template listed the maximum daily allowable discharge (MADL) for PCP at $1.0 \mu \mathrm{g} / \mathrm{L}$. This is the current MADL for the City of Portland permit, and is also consistent with the maximum contaminant level (MDL) in the Safe Drinking Water Act. Based on new information, DEQ is revising the effluent discharge limit (EDL) of PCP in the UIC WPCF Permit Template to $10 \mu \mathrm{g} / \mathrm{L}$. (See information presented in Previous Investigations: GSI Water Solutions, Inc. (2011a), above, for additional information).

In order to remain in compliance with the permit once it is issued, the City of Gresham is seeking to identify characteristics of UIC contributing areas that show increased levels of PCP in stormwater. Since the City of Gresham does not have the budget to maintain an extensive monitoring program of all 1,100 UICs, it would prefer to target specific UICs that have a higher probability to be non-compliant.

This study is an attempt to differentiate between utility pole characteristics, such as age or installation in an impervious surface, in UIC device contributing areas that may cause increased levels of PCP in stormwater runoff. Groundwater protection is a primary goal for the City of Gresham stormwater management program, as the City currently owns and operates a municipal drinking water well system that has a delineated wellhead protection area (City of Gresham, 2011a). The goal of this research is to assist the City of Gresham in identifying those UICs within the citywide system with a higher likelihood of having PCP concentrations in excess of what is protective of safe drinking water requirements for groundwater. A secondary goal, since the EDL for PCP has increased from $1.0 \mu \mathrm{g} / \mathrm{L}$ to $10.0 \mu \mathrm{g} / \mathrm{L}$ in the UIC WPCF permit 
template, is to determine priority areas for mitigation efforts to ensure that all WPCF permit conditions are met.

\section{MATERIALS \& METHODS}

\section{Site Description \& Gresham Hydrogeology}

The City of Gresham is located in Multnomah County, Oregon and is the fourth largest city in the state. The City covers approximately twenty-six square miles and includes four watersheds: Fairview Creek, Johnson Creek, Kelley Creek, and the Columbia Slough (Gresham, 2011b) (FIGURE 1). Gresham has a mild climate with cool, moist winters and warm, dry summers. The annual average precipitation is $38-42$ " with the majority of precipitation falling between October and March of each year. The primary supply of water is purchased from the Portland Water Bureau and comes from the Bull Run watershed. During summer months, this supply is augmented by groundwater from the Cascade Wellfield, which draws water from the

Sand and Gravel aquifer (Gresham Water Quality Information).

Gresham is also located in the Portland basin, a 1300 square mile area bounded by the Tualatin Mountains to the west, Lewis River to the north, Cascade foothills to the east, and Clackamas River to the south (McFarland \& Morgan, 1996). The Portland basin is made up of eight major hydrogeologic units, described by Swanson, et al. in 1993 as older rocks, sand and gravel aquifer, confining unit 2, Troutdale sandstone aquifer, confining unit 1, Troutdale gravel aquifer and unconsolidated sedimentary rock aquifer. The primary aquifers in the Gresham region are in the two uppermost units (Snyder, 2008). 

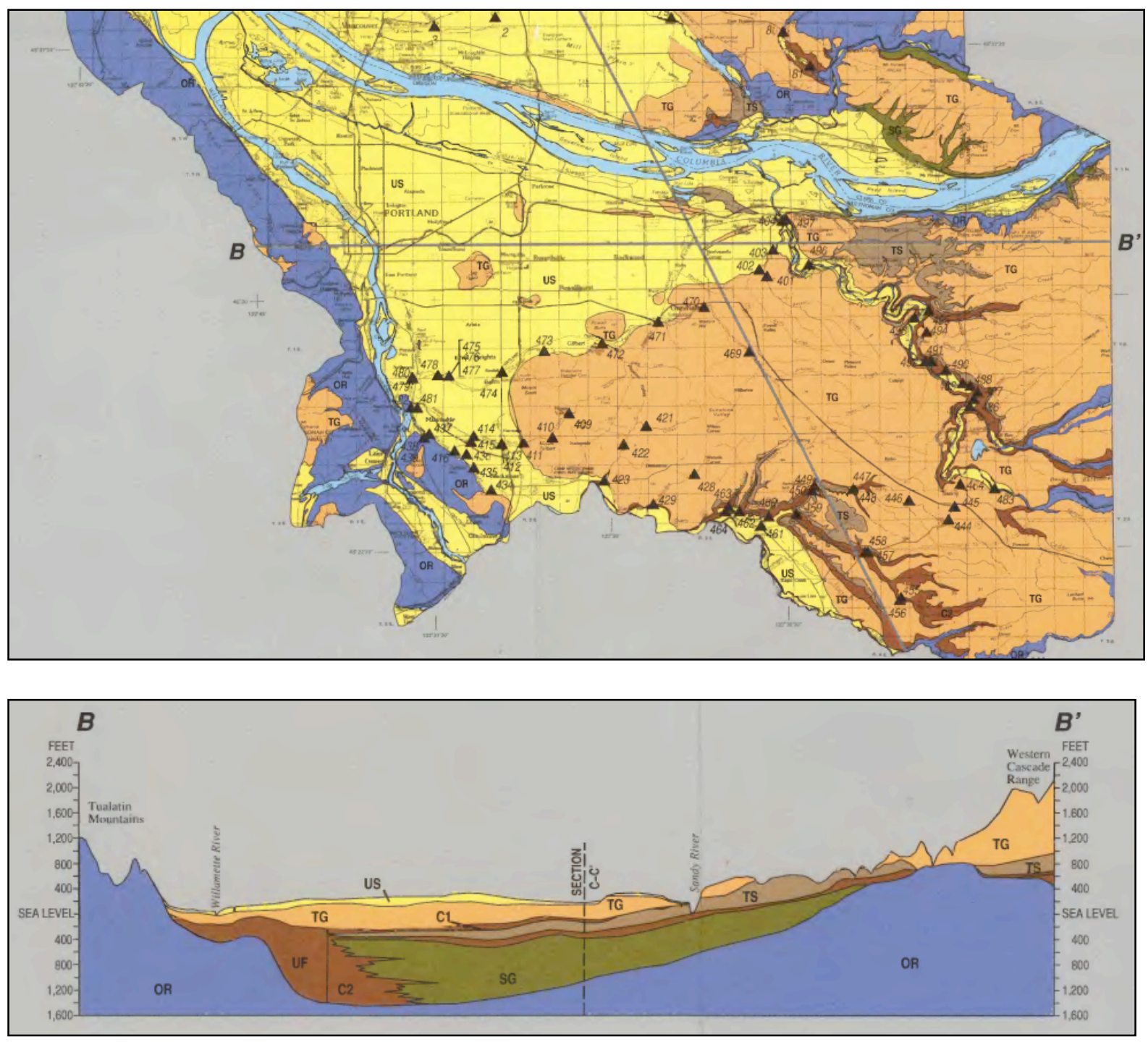

Figure 6a \& 6b. a) USGS hydrogeologic map of the Portland basin and b) cross sectional view of hydrogeologic units. Yellow: unconfined sedimentary aquifer; orange: Troutdale gravel aquifer; dark brown: confining unit 1 or 2; light brown: Troutdale sandstone aquifer; green: sand and gravel aquifer; purple: older rocks.(McCarthy 1996)

The uppermost hydrogeologic unit in southeast Gresham is the Troutdale gravel aquifer (denoted by orange color in FIGURE 6a). This aquifer overlies confining unit 1 and underlies the unconsolidated sedimentary aquifer, as seen in FIGURE 6b. It is made up of poorly to moderately cemented conglomerate and sandy conglomerate. It also includes thick local accumulations of lavas and mantling soil horizon. This unit varies in thickness of $100-400$ feet, 
with a maximum thickness of 800 feet in the locations of Boring Lava or Cascade volcanics. It has a relatively high permeability, making it a productive source of groundwater for the Portland basin (Swanson et al., 1993).

The unconsolidated sedimentary aquifer is the uppermost hydrogeologic unit in northwest Gresham (denoted by yellow color in FIGURE 6a above). It lies above the Troutdale gravel aquifer, as seen in FIGURE 6b, and consists of mostly catastrophic flood deposits from the Missoula floods as well as some water bearing alluvial deposits along smaller streams in the basin. This unit has an average thickness of $50-100 \mathrm{feet}$, with a maximum thickness of about 250 - 300 feet under the Columbia River flood plain at Sauvie Island. It is also considered the most productive aquifer in the Portland basin due to its high permeability and hydraulic conductivity (Swanson et al., 1993).

The Cascade Wellfield, Gresham's secondary water supply, draws water from the sand and gravel aquifer (FIGURE 15 includes the proposed wellhead protection area). This unit is the lowermost hydrogeologic unit, underlain only by the older rocks, and exists along the Columbia River channel. It is best described in the area of the Columbia South Shore wellfield, Portland's backup groundwater supply, where the altitude of the top of the layer ranges from minus 100 to minus 500 feet. The thickness of the layer can exceed 800 feet in the center of the basin, but will be less thick in upland areas where the older rocks are present. Municipal wells that draw water exclusively from the sand and gravel aquifer can yield between 2,000 to 3,000 gallons per minute (Swanson et al., 1993).

Knowing the approximate depth to groundwater is important for monitoring the current network of UIC devices as well as in siting new devices to be protective of groundwater quality. 
In 2008 , it was estimated that there were 11,000 publically owned and $25,000-35,000$ privately owned UIC devices that contributed approximately $38 \%$ of groundwater recharge each year (Snyder, 2008). Snyder (2008) determined that the depth to groundwater is generally less than 300 feet in the Portland basin. These levels are predicted to fluctuate approximately 5.9 feet in the unconsolidated sedimentary aquifer and 6.5 feet in the Troutdale aquifer seasonally. As seen in FIGURE 7, the average depth to groundwater in Gresham's designated UIC device area is 50 feet, with a range of 10 to 100 feet. 


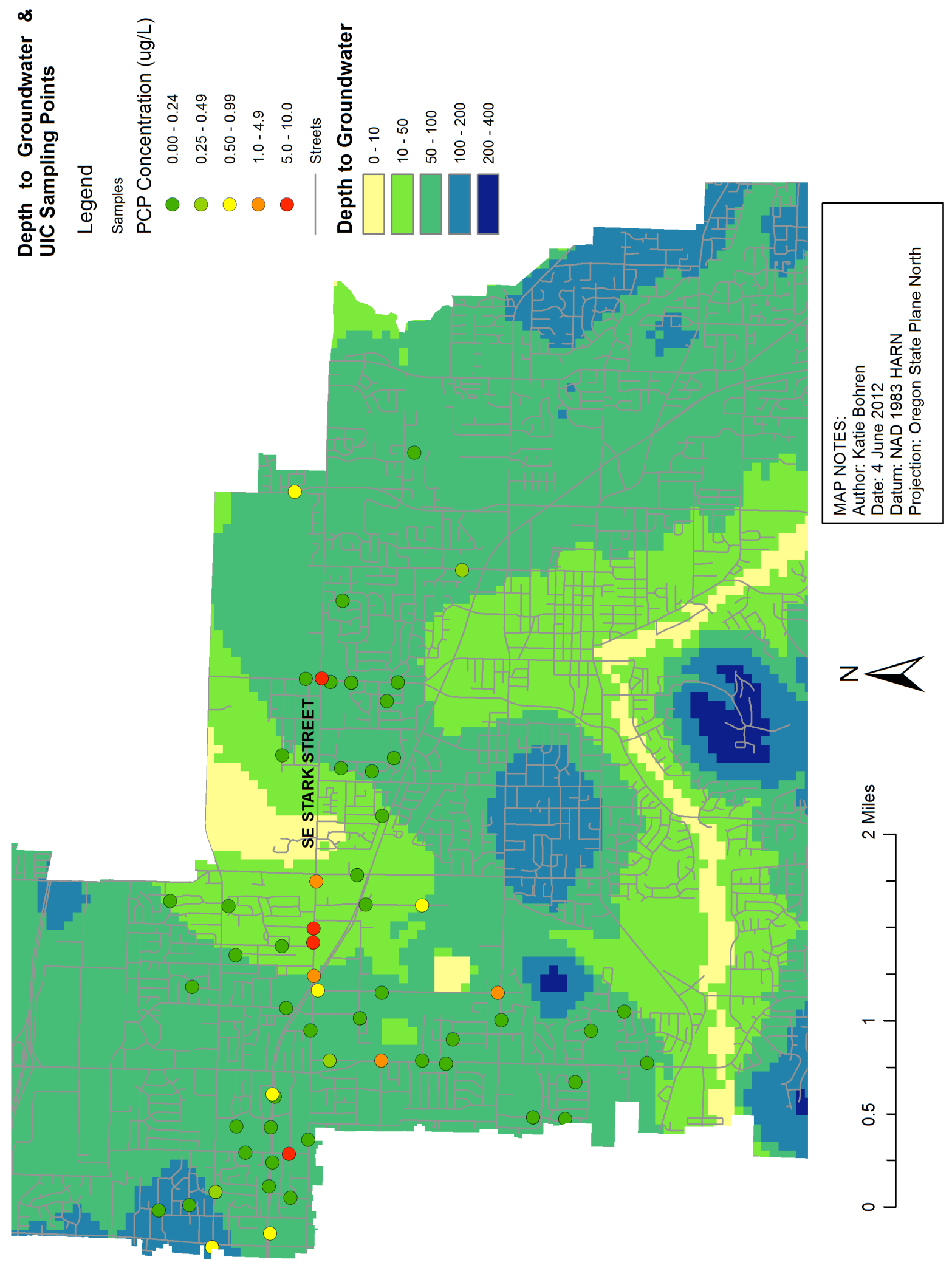

Figure 7. Depth to groundwater for area of Gresham, Oregon containing UIC devices. 


\section{Delineation of UIC Contributing Areas}

The contributing area to each UIC was delineated using tools in the ArcGIS Spatial Analyst "Hydrology" toolbox in ArcGIS (version 10.0) and maps were created in Arclnfo and ArcGIS (ESRI, 2011). This toolbox includes tools to map and evaluate hydrologic and landscape data by incorporating terrain attributes (ESRI, 2006). FIGURE 8 is a flow chart of the steps used to derive hydrologic information from the elevation model and model a contributing area (or watershed).

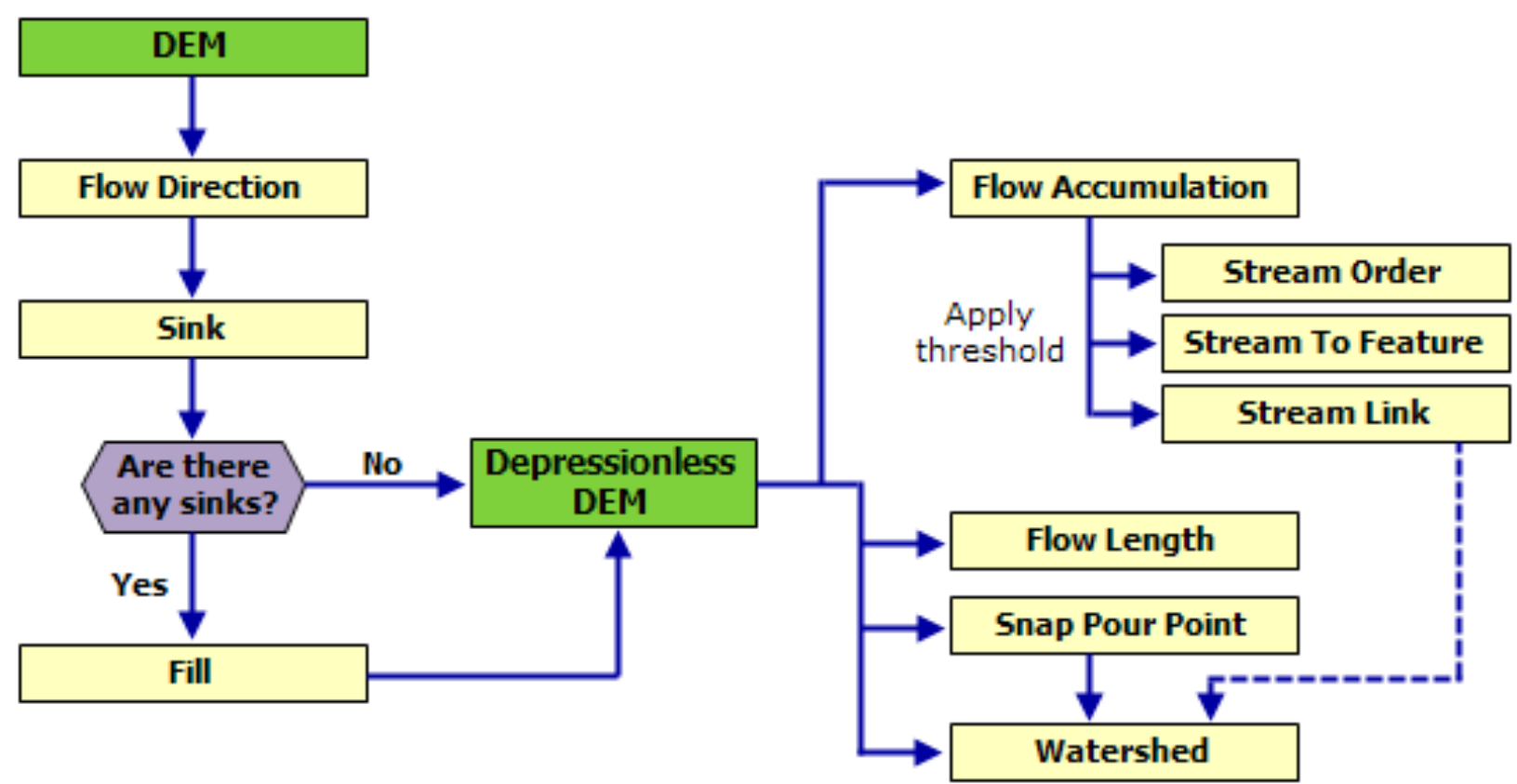

Figure 8. Diagram of process used to create each UIC contributing area in ArcGIS. From ArcGIS Desktop 10 Help Library: Spatial analyst toolbox, hydrology toolset, 2012.

The City of Gresham provided the required input GIS layers, including a 3 foot $(1 \mathrm{~m})$ digital elevation model (DEM), which describes the contours of the land surface, and the location of each catch basin inlet and UIC that was sampled in the 2009-2010 wet weather study described above. The location of each of these devices is typically mapped from the center of the device. 
Using raster data analysis, the Spatial Analyst Hydrology tools systematically determine which areas of land will drain to a specific point: a catch basin connected to a UIC in the case of this study. The model will then locate any artificial depressions, or sinks, that exist in the elevation model that water would incorrectly flow to, fill those sinks to get a smooth surface, and create a flow accumulation grid with flow paths (FIGURE 8) (ESRI, 2012a). The model was run three times with snap distances of 5 feet, 10 feet, and 50 feet for the pour points, or outlets, of the contributing areas. A snap distance is the maximum distance the model will search around the pour point for the cell with the highest flow accumulation in order to more accurately place the pour point (ESRI, 2012a). See Appendix B for the detailed Spatial Analyst procedure used to delineate each contributing area and an example of a map created during this process.

Each of the three modeled contributing areas for a given UIC was visually inspected in ArcMap with regards to the location of nearby catch basins to determine which contributing area was the most accurate. Maps were then produced of each UIC and its contributing, or drainage, area for use in the collection of field data. The impervious surface area of each UIC contributing area was also calculated based on the results of the delineation.

\section{Field Data Collection}

The City of Gresham had previously collected stormwater samples from 60 UIC contributing areas in winter 2009-2010. 30 sites were located on streets with fewer than 1,000 trips per day and 30 sites were located on streets with greater than 1,000 trips per day. Street functional classes can further be described as residential (less than 1,000 trips per day) and 
principle arterial, arterial, boulevard, collector, and community (greater than 1,000 trips per day). The PCP concentration $(\mu \mathrm{g} / \mathrm{L})$ for each site was taken from the water quality data collected during the 2009-2010 Wet Weather Study (Gresham, 2009).

At each of the 60 UIC and contributing area sites, characteristics of the utility poles and collection system were recorded during August - November 2011. It was assumed that the utility poles were in the same condition and of the same quality as they were during the 20092010 Wet Weather Study. This was assumed because it was found that no poles had had an inspection or were treated with additional treatment compound since 2008.

It was first noted if the catch basin was sumped or unsumped. A sumped basin has space in between the bottom of the catch basin and the outlet to the UIC where sediments and other pollutants can settle out of the stormwater. If a catch basin was present, an attempt was made to measure the depth of the sumped area in inches with a yardstick. Due to the depth and configuration of some of the catch basins, this measurement was not always taken. In some cases, there is a sedimentation manhole located in between the catch basin and the UIC. This device provides additional space for sediments and other pollutants to settle out of the stormwater before it enters the UIC. The presence of absence of a sedimentation manhole was noted for each contributing area.

A number of details were recorded for each utility pole located in a given contributing area. The pole was first given a unique identification number based on the GRTS rank of the UIC, for example the first utility pole in the contributing area for UIC-012 was assigned the unique ID of UIC-012-PP1. A GPS coordinate was recorded for each pole using a Garmin Etrex 12 Channel handheld GPS unit. The point was recorded by standing directly in front of the 
utility pole in a perpendicular line to the street. The distance from the utility pole to the catch basin was recorded in feet to the nearest three feet using a 100-foot tape measure. This distance was defined as the distance from the edge of the curb to the closest edge of the catch basin, following gutter flow. If a curb was not present, it was the distance from the edge of the impervious surface to the closest edge of the catch basin following the stormwater flow path.

The circumference of the pole was measured in inches using a 100-foot tape measure. The height of the pole was categorized by one of three estimates provided by Portland General Electric (J. Donovan, personal communication):

- Wooden utility poles used only for street lights = 30-35 feet (33')

- Distribution wooden utility poles with one cross arm $=40-50$ feet $\left(45^{\prime}\right)$

- Subtransmission and transmission wooden utility poles with three conductors at the top in a triangular shape and lower arms for distribution $=55-60$ feet $\left(58^{\prime}\right)$.

The surface area of the pole was calculated by first obtaining the radius of the pole from the measured circumference using the equation:

Radius $(\mathrm{ft})=2 \pi /$ Circumference $(\mathrm{ft})$

and then using the average height of the utility pole based on the above classification to calculate surface area with the equation:

Surface area $\left(\mathrm{ft}^{2}\right)=2 \pi^{*}$ Radius*Height.

The distance in inches from the utility pole to the curb (if present) was measured to the nearest inch using either a yardstick or 100-foot tape measure. This was defined as the perpendicular distance from the front of the pole to the edge of the curb. The substrate surrounding each pole was also recorded as being concrete, asphalt, vegetation, soil, or other. 
The "other" category was used if there were two or more substrates surrounding the utility pole. If the utility pole was installed in a pervious substrate (vegetation or soil), the distance in inches to the nearest impervious surface was recorded. This distance was defined as shortest distance to an impervious surface on the perpendicular line from the utility pole to the street. It was noted if any pole treatment compound staining was visible on the ground surrounding the utility pole (FIGURE 9) and if so, the extent of staining as a measure of the staining radius in inches from the utility pole. Since the staining radius around the pole was generally not uniform, the maximum radius was recorded.

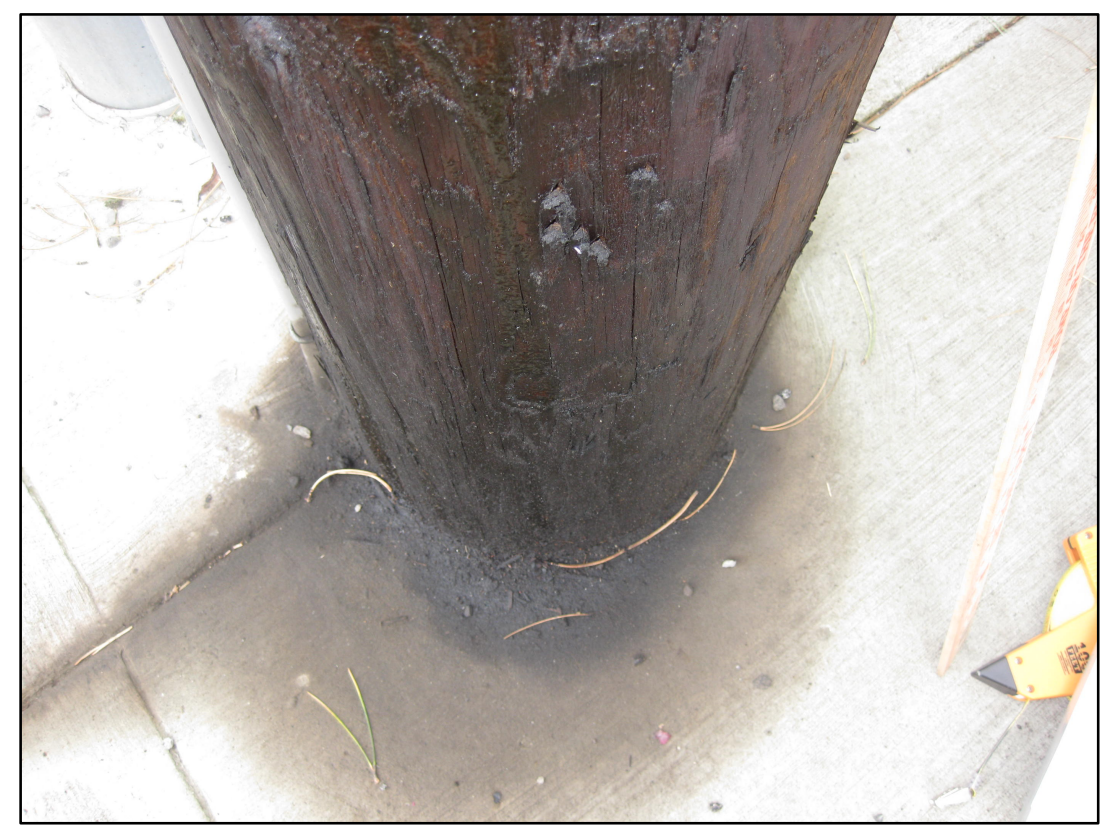

Figure 9. Ground staining from utility pole treatment compound.

A visual inspection of the amount of treatment compound on the utility pole was conducted by classifying the pole as having low, medium, or high amounts of treatment (FIGURES 10a-c). 

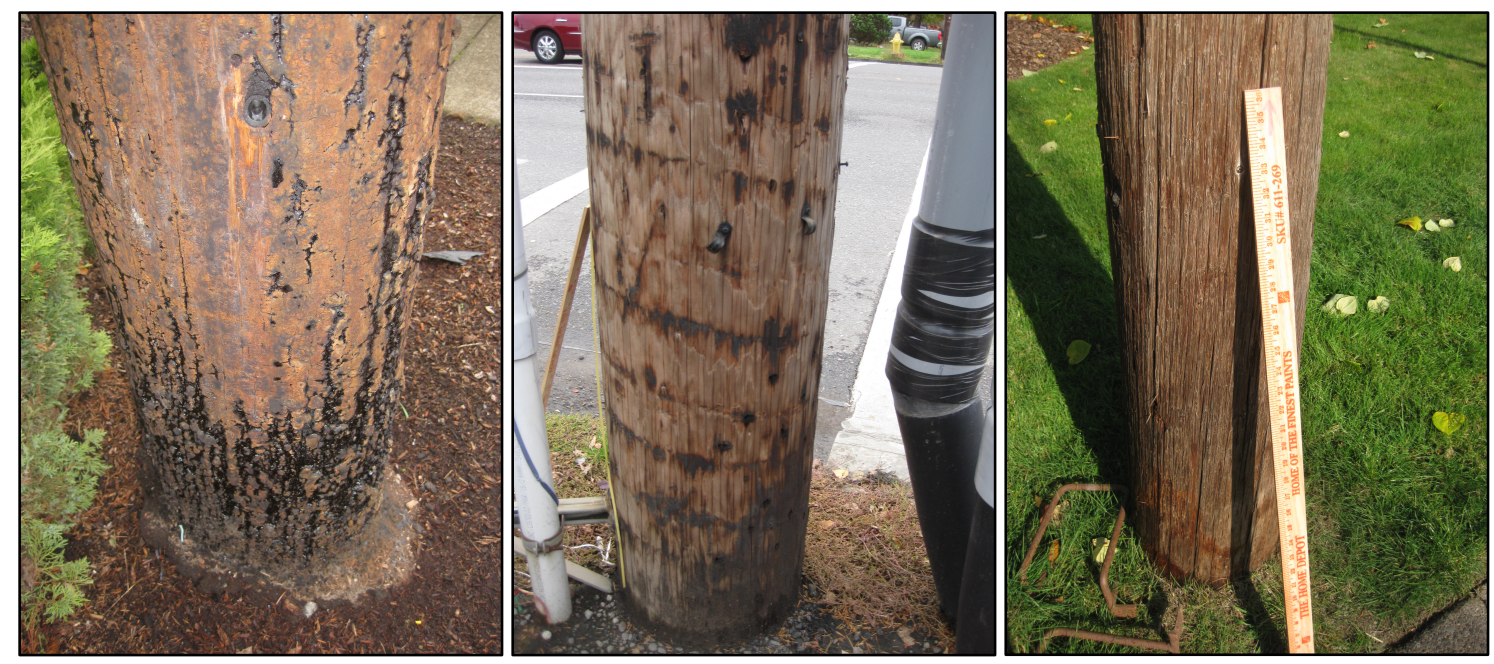

Figure 10a-10c. Example of a utility pole with a) high; b) medium; and c) low treatment compound on lower portion of pole based on a visual estimation during data collection in August-November 2011. See Appendix III for a complete description of these categories.

The age of the utility pole was also visually estimated as juvenile, mature, or weathered

(FIGURES 11a-c).

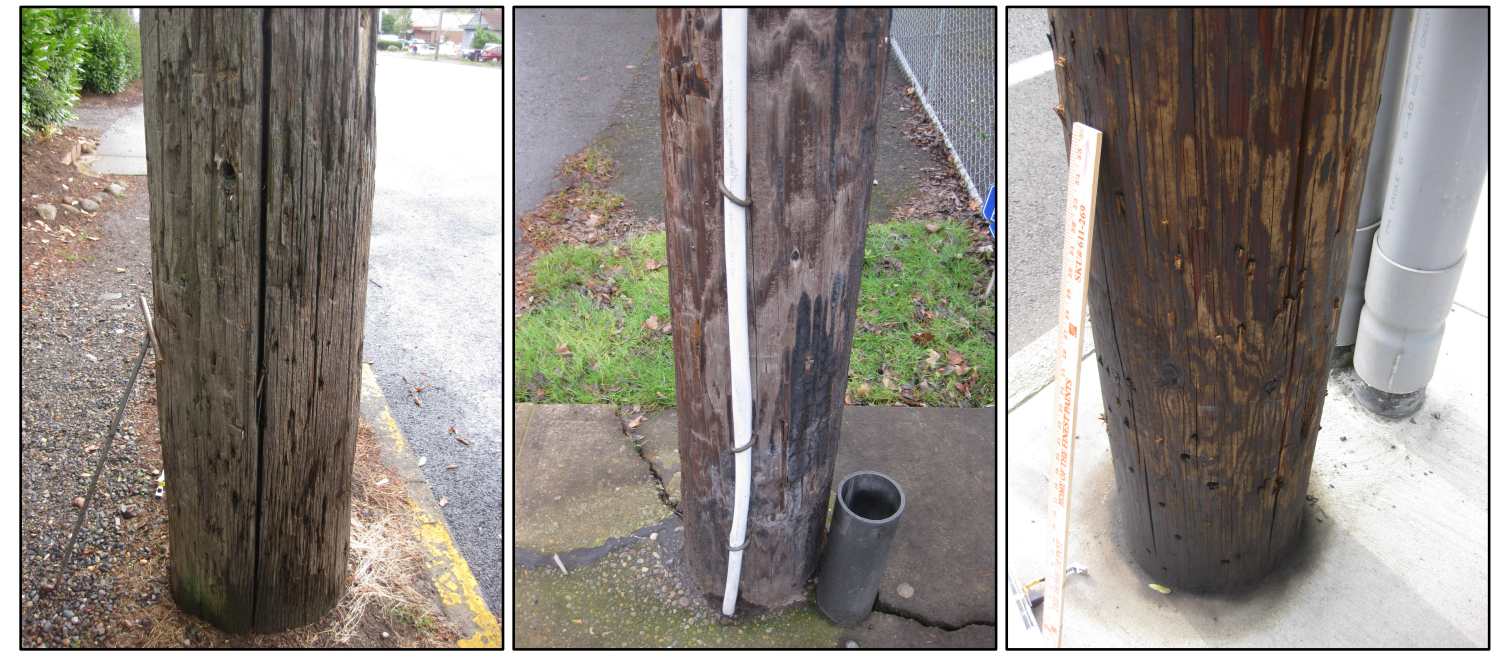

Figure 11a-11c. Example of a utility pole characterized as a) weathered; b) mature; and c) juvenile based on a visual estimation during data collection in August-November 2011. See Appendix III for a complete description of these categories. 
Appendix $\mathrm{C}$ contains the instructions for the field data sheet with complete descriptions of treatment compound on pole and pole age visual estimation categories. The presence, type, and number of diffusion plugs in each pole (FIGURES 12a\&b) was recorded as a proxy for the amount of additional treatment compound added to the utility pole during inspections by the utility company.
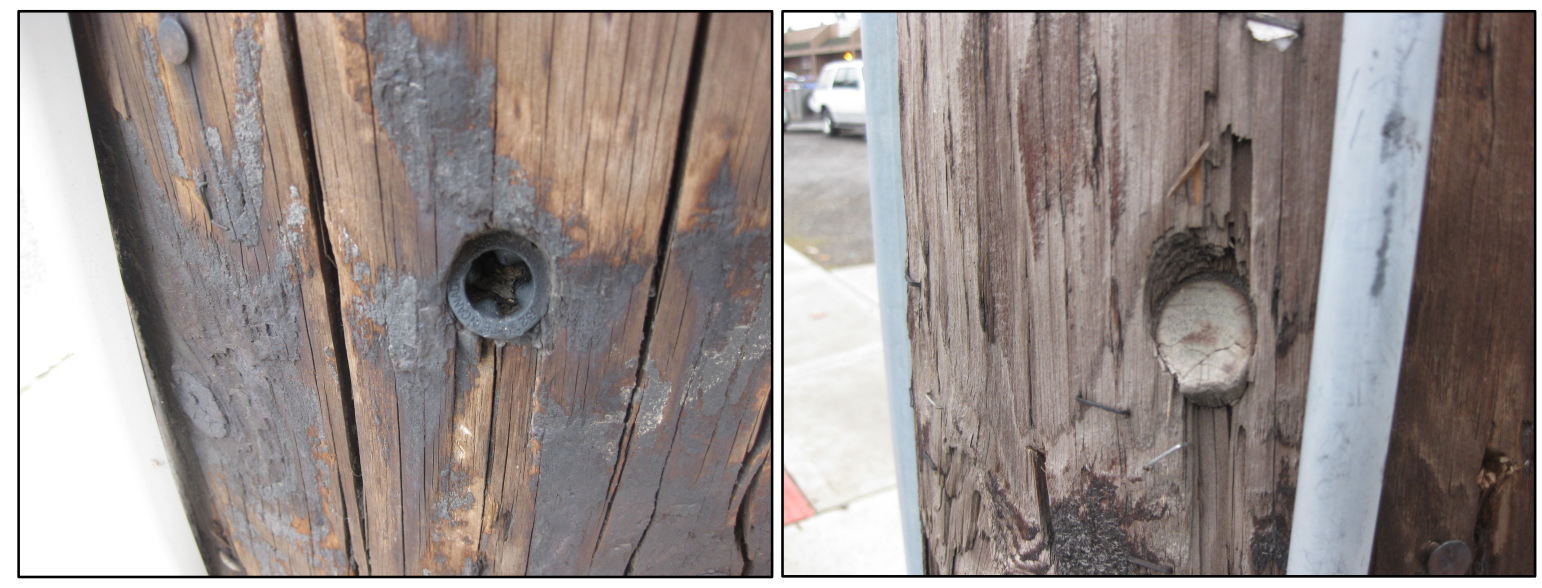

Figure 12a \& 12b. Example of a utility pole with a) plastic diffusion plug and b) wood diffusion plug observed during data collection in August-November 2011.

If present, the Portland General Electric (PGE) power pole map number and power pole number were recorded. The pole manufacturer and manufacture year were also recorded when the tag was present. Additionally, any tags located on the poles denoting inspection years and inspection contractors were recorded.

Finally, the surrounding land use was recorded as residential, commercial, mixed residential and commercial, or industrial. The underlying soil type and soil profile to 80 inches was documented from the United States Department of Agriculture Natural Resources Conservation Service (USDA NRCS) online soil survey. Appendix C also contains the field data sheet used to collect all of the above information. 


\section{Data Analysis}

A large number of variables were collected from each delineated UIC contributing area, but it was unclear which, if any of these variables would describe levels of PCP found in stormwater samples. A regression tree was the first statistical method used to explore the data. When multiple potential predictor variables are present in a data set, this model can be used to predict the strength of each variable as well as which variables have the most significant effect on the response variable. The model uses a regression tree algorithm to determine how to split the data at each node, when to stop splitting, and how to determine the value of the response variable for each predictor (Loh, 2008). Splitting is based on an impurity index for each node, where a node that predicts all replicates in one class has an impurity index equal to zero. The impurity index increases as predictive ability decreases. Additionally, the $\mathrm{R}^{2}$ value can also be calculated at each split by the equation 1 - relative error (Gotelli \& Ellison, 2004).

The Recursive PARTioning ("rpart") package (Therneau \& Atkinson, 2011a) in the statistical software 'R' (R Development Core Team, 2011) was used to create two regression trees: one for categorical and numerical data from each individual utility pole and one using data compiled for each UIC contributing area. TABLE 1 includes the variables used in each regression tree. This model uses a complexity parameter (cp value) to evaluate the deviance within the tree. The $\mathrm{cp}$ value is a proxy for the number of splits in a particular regression tree and will decrease with increasing numbers of splits. The model stops splitting the tree when the $\mathrm{cp}$ value gets too low and the cost of creating more groups is greater than the lack of fit of the model (Maindonald \& Braun, 2006). Additionally, a summary output is available which gives detailed listings of the model, including other primary splits and surrogate splits. Other 
primary splits are those that have a greater impurity index and improve the model less than the actual predictor chosen. Surrogate splits are variables with nearly the same results of the primary split, but account for the possibility of missing variables (Therneau \& Atkinson, 2011b).

Table 1. Variables used in the construction of two regression trees in ' $R$ '.

\begin{tabular}{ll}
$\begin{array}{ll}\text { Regression Tree Based on Individual Pole } \\
\text { Characteristics }\end{array}$ & $\begin{array}{l}\text { Regression Tree Based on Contributing Area } \\
\text { Characteristics }\end{array}$ \\
\hline Surface area of utility pole & Presence of utility poles \\
Utility pole manufacturer & Catch basin type \\
\hline Utility pole manufacture year & Street functional class \\
Year of last inspection & Vehicle trips per day \\
Distance to catch basin inlet & Rainfall intensity during sample collection \\
\hline Distance to the curb & Number of utility poles \\
\hline Substrate utility pole installed in & Total surface area of all utility poles \\
\hline Distance to nearest impervious surface & UIC contributing area \\
\hline Visual estimation of treatment product on utility pole & Ratio of utility pole surface area to UIC contributing area \\
\hline Presence of product staining on ground & Number of utility poles set in concrete \\
\hline Radius of product staining on ground & Surface area of all utility poles set in concrete \\
Visual estimation of pole age & Total distance from all poles to catch basin inlet \\
Presence of diffusion plugs & Average distance from all poles to catch basin inlet \\
Number of diffusion plugs & Maximum distance from utility pole to catch basin inlet \\
\hline & Minimum distance from utility pole to catch basin inlet \\
\hline
\end{tabular}

Based on the results of the regression trees, categorical data containing two groups was further compared with a Wilcoxon-Mann-Whitney rank sum test using the wilcox.test command from the stats package in ' $R$ ' to determine if a significant difference $(\alpha=0.05)$ existed between the groups. For categorical data containing three or more groups, the Kruskal-Wallis rank sum test was used to determine if a significant difference $(\alpha=0.05)$ existed between the groups. This test was completed in ' $R$ ' with the kruskal.test command from the stats package ( $R$ Core Development Team, 2011). If the $p$-value was less than 0.05, a Wilcoxon-Mann-Whitney rank sum test was performed for each pair of groups within the category. To account for 
potential Type I errors, a Bonferri correction $(\alpha / c$ where $c=$ number of tests run) was applied to the confidence level.

Scatter plots of the continuous response variables identified as important in the regression tree and PCP concentrations were constructed. Then Spearman's rank correlation (rho) was calculated to determine if PCP concentrations in a contributing area were significantly associated with any of the response variables $(\alpha=0.05)$. Spearman's rho was calculated in $R$ using the cor.test function (R Core Development Team, 2011). The distribution of the data prohibited the use of parametric statistical anaylsis. Although these non-parametric statistical tests do not have the same power as parametric tests, they can still provide statistically significant trends.

\section{Spatial Analysis}

All spatial statistics were calculated in ArcGIS (version 10.0) and maps were created in Arclnfo and ArcGIS (ESRI, 2011a). Global Moran's I, a measurement of the overall trend of spatial autocorrelation (Anselin, 1995), was calculated in ArcGIS using the Spatial Autocorrelation tool in the Spatial Statistics toolbox. A high positive z-score $(\alpha=0.05)$ indicates that PCP concentrations are generally clustered while a high negative $z$-score indicates that PCP concentrations are generally dispersed. The Cluster and Outlier Analysis (Anselin Local Moran's I) tool was used to map the statistically significant positive and negative spatial autocorrelation on a local scale. Anselin Local Moran's I analyzed the presence of clusters and outliers of concentrations of PCP in stormwater for each of the 60 sites, based on the values of neighboring features. A high positive $z$-score $(\alpha=0.05)$ indicates that a particular location has a 
similar high or low PCP concentration as neighboring sites. A high negative z-score $(\alpha=0.05)$ indicates a spatial outlier (Anselin, 1995), for example a site with high PCP concentration in stormwater surrounded by sites with low PCP concentration in stormwater. For each tool, spatial autocorrelation was calculated using an inverse distance of 5000 feet based on Euclidean distance.

The High/Low Clustering (Getis-Ord General G) tool in the Spatial Statistics toolbox was used to determine if there were high or low clusters of PCP concentration in stormwater in the study area. A high positive $z$-score $(\alpha=0.05)$ indicates clusters of high values of PCP and a high negative z-score indicates clusters of low values of PCP. The Hot Spot Analysis (Getis-Ord Gi*) tool was used to map the statistically significant hot and cold spots on a local scale. A high positive z-score $(\alpha=0.05)$ indicates that a particular UIC site is surrounded by other sites with high PCP concentrations (a "hot spot"). A high negative z-score $(\alpha=0.05)$ indicates that a particular UIC site is surrounded by other sites with low PCP concentrations (a "cold spot") (Getis \& Ord, 1992). For each tool, neighbors were calculated using an inverse distance of 5000 feet based on Euclidean distance.

\section{RESULTS}

60 UIC contributing areas were surveyed for the presence and various characteristics of utility poles, with a total of 86 utility poles identified in 40 UIC contributing areas. TABLE 2 contains summary information from each site. All water quality data and associated rainfall conditions for the 60 UIC sites in the present study were collected during the 2009-2010 Gresham Wet Weather study (Gresham, 2009), as described above in the "Previous 
Investigations" section. All data related to utility poles was collected during August -

November 2011. It is assumed that the conditions and quality of the utility poles are the same

as they were during the $2009-2010$ study.

Table 2. Summary data for the 60 UIC contributing areas used in this study. The System ID is the City of Gresham unique ID for each UIC device. The GRTS Rank is the ID assigned to the UIC device during the selection of spatially balanced sample points using the GRTS survey design. The Street Functional Classes arterial, boulevard, and collector have traffic volumes $>1000$ trips per day. The Street Functional Class residential has traffic volumes $<1000$ trips per day. Water quality data is taken from the 2009-2010 Gresham Wet Weather study. Utility pole data was collected during August-November 2011. See Appendix III for complete utility pole data.

\begin{tabular}{|c|c|c|c|c|c|c|c|c|c|c|}
\hline System ID & $\begin{array}{l}\text { GRTS } \\
\text { Rank }\end{array}$ & Address & $\begin{array}{l}\text { PCP Conc. } \\
\text { (ug/L) }\end{array}$ & $\begin{array}{l}\text { Street } \\
\text { Functional } \\
\text { Class }\end{array}$ & $\begin{array}{l}\text { Rainfall } \\
\text { Intensity }\end{array}$ & $\begin{array}{l}\text { \# of } \\
\text { Poles }\end{array}$ & $\begin{array}{l}\text { Total } \\
\text { Pole } \\
\text { Surface } \\
\text { Area } \\
\text { (ft2) } \\
\end{array}$ & $\begin{array}{l}\text { Surface } \\
\text { Area of } \\
\text { Poles in } \\
\text { Concrete } \\
\text { (ft2) }\end{array}$ & $\begin{array}{l}\text { Min. } \\
\text { Distance } \\
\text { from } \\
\text { Pole to } \\
\text { Inlet (ft) }\end{array}$ & $\begin{array}{l}\text { Avg. } \\
\text { Distance } \\
\text { from } \\
\text { Pole to } \\
\text { Curb (ft) }\end{array}$ \\
\hline 3349-J-088 & UIC-001 & 35 NW PHYLLIS CT & 0.04 & Residential & Moderate & 1 & 43.23 & 0 & 495 & 1.17 \\
\hline 3152-F-032 & UIC-002 & 21333 SE ALDER ST & 0.04 & Residential & Moderate & 2 & 281.25 & 0 & 54 & 2.08 \\
\hline 3047-W-004 & UIC-003 & 16714 NE Glisan St. & 0.348 & Arterial & $\begin{array}{l}\text { Not } \\
\text { Raining }\end{array}$ & 3 & 536.5 & 536.5 & 10 & 1.3 \\
\hline $3348-W-029$ & UIC-004 & 2826 SE 176th PI. & 0.0962 & Residential & Moderate & 0 & 0 & 0 & NA & NA \\
\hline $3047-W-032$ & UIC-007 & 307 SE 167th Ave. & 0.0451 & Residential & Moderate & 0 & 0 & 0 & NA & NA \\
\hline $3249-W-045$ & UIC-008 & 1634 SE 182nd Ave. & 0.0926 & Residential & Light & 0 & 0 & 0 & NA & NA \\
\hline $3050-W-067$ & UIC-009 & 322 NE 193RD AVE & 0.04 & Residential & Moderate & 0 & 0 & 0 & NA & NA \\
\hline 3153-F-051 & UIC-010 & 2863 NE Elliott Ave. & 0.0939 & Residential & Moderate & 2 & 145.18 & 0 & 81 & 1.42 \\
\hline 3048-W-098 & UIC-011 & 17727 E BURNSIDE & 0.827 & Collector & Moderate & 3 & 472.5 & 0 & 24 & 11.86 \\
\hline 3249-W-048 & UIC-012 & 2446 SE 190th Ave. & 1.06 & Collector & Light & 2 & 354.01 & 256.36 & 15 & 1.13 \\
\hline $3050-W-028$ & UIC-013 & 41 NE 194th Ave. & 0.04 & Residential & Light & 0 & 0 & 0 & NA & NA \\
\hline 3153-F-041 & UIC-014 & 1253 NW EASTMAN PKWY & 0.162 & Arterial & Moderate & 1 & 142.65 & 0 & 66 & 7.25 \\
\hline 3149-W-079 & UIC-015 & 19010 E BURNSIDE & 0.884 & Collector & Moderate & 5 & 742.95 & 555.3 & 18 & 1.1 \\
\hline 3449-J-006 & UIC-017 & 310 SW Hartley Ave. & 0.04 & Residential & Moderate & 1 & 82.5 & 0 & 75 & 0.83 \\
\hline 3151-F-054 & UIC-018 & 20909 SE Main Dr. & 0.04 & Residential & Heavy & 0 & 0 & 0 & NA & NA \\
\hline 2947-W-059 & UIC-019 & 16585 NE Oregon St. & 0.04 & Residential & Light & 3 & 214.83 & 71.61 & 60 & 1.08 \\
\hline $3348-W-015$ & UIC-020 & 3223 SE 176th PI. & 0.04 & Residential & Moderate & 0 & 0 & 0 & NA & NA \\
\hline 3055-B-027 & UIC-021 & 3417-3419 NE VIEW AVE & 0.504 & Arterial & Heavy & 3 & 502.2 & 172.35 & 36 & 4.89 \\
\hline 3153-F-021 & UIC-022 & 22200 SE STARK ST. & 0.147 & Arterial & $\begin{array}{l}\text { Not } \\
\text { Raining }\end{array}$ & 2 & 341.1 & 0 & 6 & 8.63 \\
\hline $3047-W-109$ & UIC-023 & 17044 SE BURNSIDE ST & 0.197 & Collector & Light & 1 & 227.36 & 227.36 & 111 & 2.92 \\
\hline $3249-W-026$ & UIC-024 & 18443 SE Lincoln St. & 0.0597 & Residential & Light & 1 & 68.64 & 0 & 30 & 1.5 \\
\hline $3050-W-050$ & UIC-025 & 19716 NE Flanders St. & 0.04 & Residential & Light & 0 & 0 & 0 & NA & NA \\
\hline $3349-W-056$ & UIC-028 & 18630 SE DIVISION ST & 0.123 & Arterial & Light & 2 & 226.35 & 0 & 66 & 9.75 \\
\hline $3150-F-010$ & UIC-029 & 2515 NW Eleven Mile Ave. & 0.133 & Residential & Light & 3 & 484.2 & 0 & 36 & 4.09 \\
\hline 3152-F-082 & UIC-030 & 439 NW 24th St. & 0.04 & Residential & Moderate & 0 & 0 & 0 & NA & NA \\
\hline $3149-W-042$ & UIC-031 & 18655 SE Yamhill Cir. & 0.102 & Residential & Light & 1 & 131.4 & 0 & 15 & 1.08 \\
\hline 2947-W-008 & UIC-032 & 16516 NE Holladay St. & 0.04 & Residential & Light & 0 & 0 & 0 & NA & NA \\
\hline
\end{tabular}




\begin{tabular}{|c|c|c|c|c|c|c|c|c|c|c|}
\hline System ID & $\begin{array}{l}\text { GRTS } \\
\text { Rank }\end{array}$ & Address & $\begin{array}{l}\text { PCP Conc. } \\
\text { (ug/L) }\end{array}$ & $\begin{array}{l}\text { Street } \\
\text { Functional } \\
\text { Class }\end{array}$ & $\begin{array}{l}\text { Rainfall } \\
\text { Intensity }\end{array}$ & $\begin{array}{l}\text { \# of } \\
\text { Poles }\end{array}$ & $\begin{array}{l}\text { Total } \\
\text { Pole } \\
\text { Surface } \\
\text { Area } \\
(\mathrm{ft2})\end{array}$ & $\begin{array}{l}\text { Surface } \\
\text { Area of } \\
\text { Poles in } \\
\text { Concrete } \\
\text { (ft2) }\end{array}$ & $\begin{array}{l}\text { Min. } \\
\text { Distance } \\
\text { from } \\
\text { Pole to } \\
\text { Inlet (ft) }\end{array}$ & $\begin{array}{l}\text { Avg. } \\
\text { Distance } \\
\text { from } \\
\text { Pole to } \\
\text { Curb (ft) }\end{array}$ \\
\hline $3152-F-050$ & UIC-034 & 1047 SE 213th Ave. & 0.04 & Residential & Moderate & 0 & 0 & 0 & NA & NA \\
\hline 2949-W-042 & UIC-035 & 805 NE 190th Ave. & 0.04 & Residential & Light & 3 & 351.06 & 0 & 102 & 1.25 \\
\hline 3149-W-015 & UIC-036 & 1209 SE 190th Ave. & 0.172 & Collector & Light & 1 & 96.36 & 0 & 27 & 16 \\
\hline 3155-K-041 & UIC-037 & 2150 NE Country Club Ct. & 0.04 & Residential & Light & 0 & 0 & 0 & NA & NA \\
\hline 3052-F-020 & UIC-038 & 21414 SE ANKENY ST & 0.04 & Residential & Moderate & 0 & 0 & 0 & NA & NA \\
\hline 3048-W-014 & UIC-039 & 17347 SE STARK ST & 0.223 & Arterial & Light & 1 & 174 & 174 & 150 & 5.92 \\
\hline 3348-W-011 & UIC-040 & 3307 SE 180th Ave. & 0.04 & Residential & Moderate & 0 & 0 & 0 & NA & NA \\
\hline 3149-W-019 & UIC-041 & 19110 SE STARK ST & 2.6 & Boulevard & Moderate & 1 & 251.14 & 251.14 & 96 & 4.83 \\
\hline $3152-F-058$ & UIC-042 & 21430SE Salmon St. & 0.04 & Residential & Light & 0 & 0 & 0 & NA & NA \\
\hline 3049-W-039 & UIC-043 & 241 SE 188th Ave. & 0.1 & Residential & Light & 0 & 0 & 0 & NA & NA \\
\hline 3050-W-019 & $\begin{array}{l}\text { UIC- } \\
\text { 045A }\end{array}$ & 425 SE 196TH AVE & 6.89 & Boulevard & Heavy & 2 & 282.6 & 282.6 & 12 & 3.38 \\
\hline 3050-W-019 & $\begin{array}{l}\text { UIC- } \\
\text { 045B }\end{array}$ & 425 SE 196TH AVE & 0.659 & Boulevard & Light & 2 & 282.6 & 282.6 & 12 & 3.38 \\
\hline 3048-W-021 & UIC-046 & 17440 NE Flanders St. & 0.04 & Residential & $\begin{array}{l}\text { Not } \\
\text { Raining }\end{array}$ & 0 & 0 & 0 & NA & NA \\
\hline 3149-W-059 & UIC-047 & 636 SE 182nd Ave. & 0.354 & Residential & $\begin{array}{l}\text { Not } \\
\text { Raining }\end{array}$ & 4 & 630.54 & 0 & 27 & 5 \\
\hline 2946-W-002 & UIC-048 & 16145 NE GLISAN ST & 0.947 & Arterial & Light & 5 & 1282.86 & 763.86 & 2 & 1.55 \\
\hline 3449-J-073 & UIC-049 & 4020 SE 182nd Ave. & 0.17 & Residential & Light & 2 & 240 & 157.5 & 30 & 1.04 \\
\hline $3250-F-007$ & UIC-050 & 1919 NW Eleven Mile Ave. & 0.9 & Residential & Moderate & 1 & 135 & 135 & 78 & 22 \\
\hline 3047-W-027 & UIC-051 & 276 SE 172nd AVE & 5.74 & Collector & Light & 2 & 388.35 & 388.35 & 12 & 0.92 \\
\hline 3149-W-003 & UIC-052 & 1274-1288 SE 182ND AVE & 1.79 & Arterial & Light & 2 & 386.14 & 386.14 & 15 & 1.09 \\
\hline 2950-W-063 & UIC-053 & 19827 NE Holladay St. & 0.04 & Residential & $\begin{array}{l}\text { Not } \\
\text { Raining }\end{array}$ & 1 & 76.89 & 0 & 105 & 1.25 \\
\hline 3053-F-020 & UIC-054 & 22309 SE STARK ST & 0.08 & Arterial & Moderate & 0 & 0 & 0 & NA & NA \\
\hline 3048-W-097 & UIC-055 & 17730 E BURNSIDE ST & 0.216 & Collector & Light & 2 & 449.5 & 0 & 72 & 11.04 \\
\hline 3050-W-016 & UIC-057 & 19415 SE STARK ST & 9.1 & Boulevard & Heavy & 3 & 612.22 & 612.22 & 24 & 1.64 \\
\hline 3049-W-069 & UIC-059 & 18702 E BURNSIDE ST & 0.0862 & Boulevard & Moderate & 0 & 0 & 0 & NA & NA \\
\hline 3047-W-096 & UIC-060 & 16300 SE BURNSIDE ST & 0.518 & Collector & Light & 4 & 768.5 & 526.64 & 36 & 2.73 \\
\hline 3150-F-043 & UIC-061 & 835 SE 202ND AVE & 0.118 & Collector & Heavy & 1 & 241.86 & 241.86 & 252 & 1.83 \\
\hline 3047-W-047 & UIC-062 & 211 NE 172nd Ave. & 0.163 & Collector & Light & 1 & 112.5 & 0 & 90 & 13 \\
\hline 3153-F-025 & UIC-070 & 815 SE 223RD AVE & 0.149 & Arterial & Light & 1 & 99 & 0 & 225 & 13.5 \\
\hline 3047-W-103 & UIC-071 & 16801 E BURNSIDE & 0.139 & Collector & Light & 1 & 142.65 & 0 & 66 & 10.83 \\
\hline 3153-F-017 & UIC-086 & 22300 SE STARK ST & 5.96 & Arterial & Moderate & 3 & 605 & 605 & 1 & 3.64 \\
\hline 3150-F-047 & UIC-093 & 20132 SE STARK ST & 2.04 & Arterial & Light & 2 & 319.05 & 319.05 & 42 & 1.04 \\
\hline 3254-F-072 & UIC-094 & 1685 NE Cleveland St. & 0.449 & Collector & Light & 5 & 406.56 & 406.56 & 3 & 1.93 \\
\hline $3248-W-020$ & UIC-100 & 1925 SE 182ND AVE & 0.0926 & Arterial & Light & 0 & 0 & 0 & NA & NA \\
\hline 3048-W-091 & UIC-103 & 17376 NE COUCH ST & 0.204 & Collector & Moderate & 2 & 262.35 & 127.35 & 99 & 5.46 \\
\hline
\end{tabular}




\section{Summary Data}

Of the 60 sites, 20 (33\%) do not contain any utility poles (FIGURE 14, sites with no black diamonds). PCP concentrations ranged from $<0.04 \mu \mathrm{g} / \mathrm{L}-0.1 \mu \mathrm{g} / \mathrm{L}$, with $70 \%$ of these sites having a PCP concentration below the method reporting limit of $0.04 \mu \mathrm{g} / \mathrm{L}$ (FIGURE 13). Many sites are located on streets that either have underground utilities or utility poles installed in alleys in between houses. In some cases, utility poles are located on the opposite side of the street from where the sample was collected (See FIGURE 3). $85 \%$ of sites without utility poles are located on streets with less than 1,000 vehicle trips per day (equivalent to the "residential" functional class) where, often times, metal light poles have replaced older wood poles. The remaining $15 \%$ of sites without utility poles are located on arterials and boulevards.

The Mann-Whitney $U$ test $(\alpha=0.05)$ found that PCP concentration in stormwater is significantly different in UIC device contributing areas with and without utility poles present ( $p$ value $=<0.001$ ). See FIGURE 13 boxplots for boxplots of PCP concentration in contributing areas with and without utility poles present. 


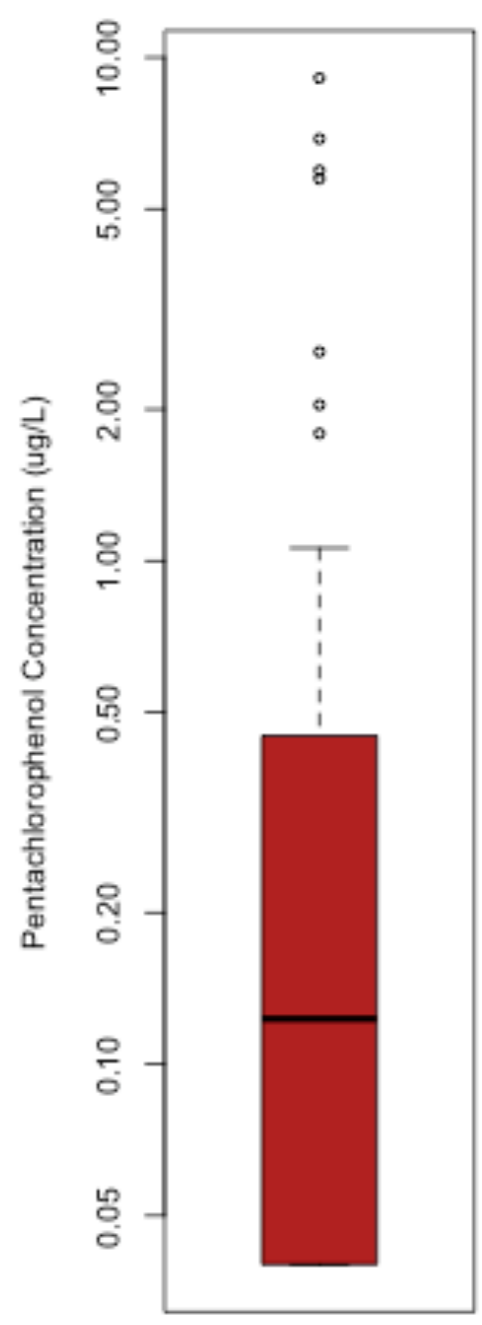

All Sites

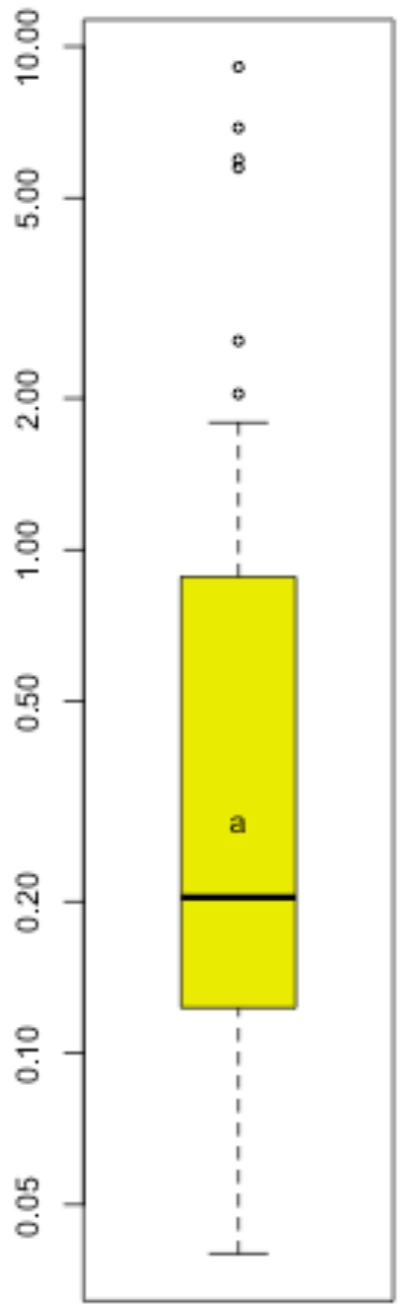

Sites with Utility Poles Present

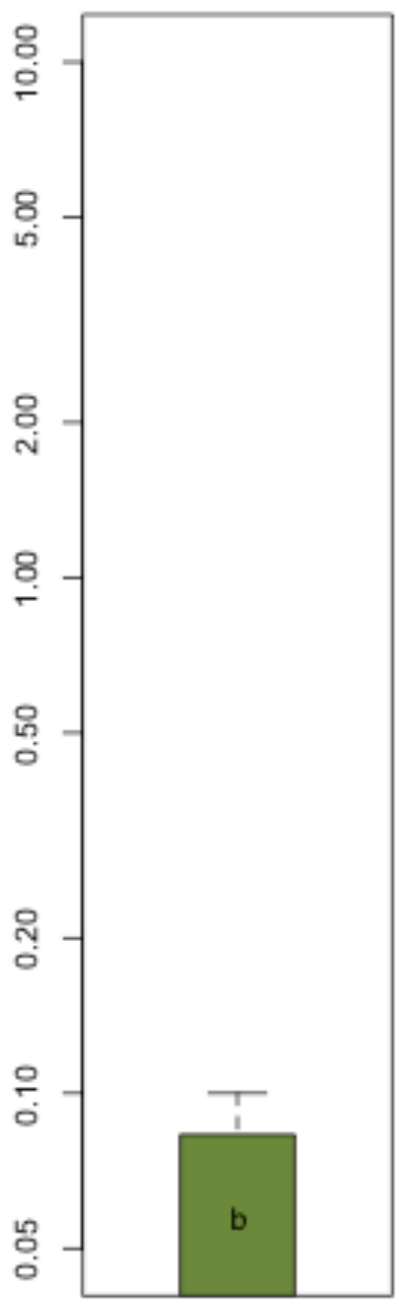

Sites with No Utility Poles

Figure 13. Boxplots of pentachlorophenol concentration ( $\mathrm{gg} / \mathrm{L})$ for all contributing areas $(n=60)$, contributing areas with utility poles present $(n=40)$, and contributing areas with no utility poles present $(n=20)$. Significant differences $(\alpha=0.05)$ in PCP concentration were found between sites with utility poles present and sites without utility poles present. Water quality data is taken from the 2009-2010 Gresham Wet Weather study. Utility pole data was collected during August-November 2011. The method reporting limit for PCP is $0.04 \mu \mathrm{g} / \mathrm{L}$. Non-detects are reported at this concentration. 


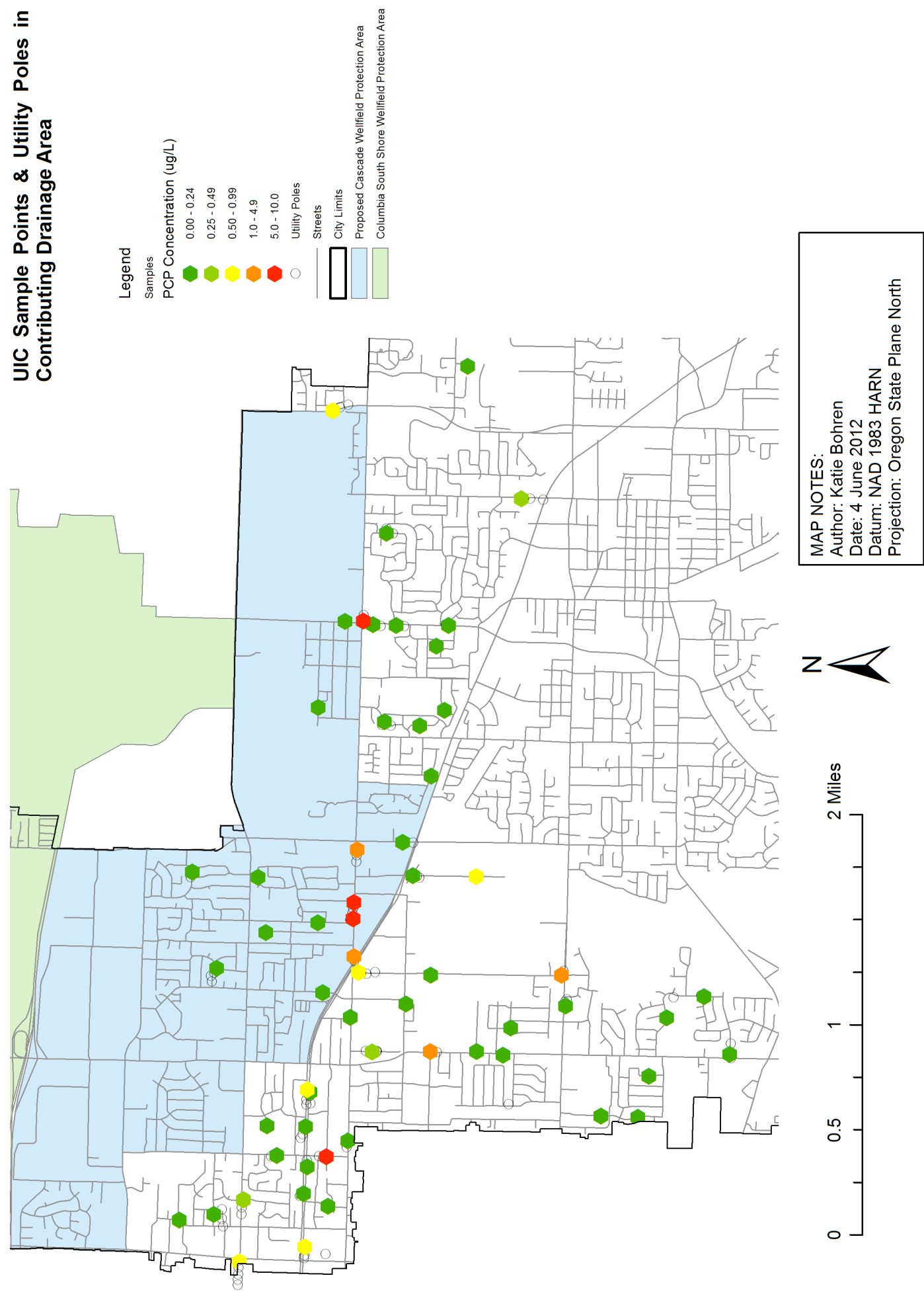

Figure 14. The location of UIC devices included in the 2009-2010 wet weather study and the associated utility poles located in each contributing area. Red points indicate a pentachlorophenol concentration greater than $1 \mu \mathrm{g} / \mathrm{L}$. Wellfield protection areas are located in the northern area of the city. Water quality data is taken from the 20092010 Gresham Wet Weather study. Utility pole data was collected during August-November 2011. 
Eight UIC contributing areas had a PCP concentration greater than $1 \mu \mathrm{g} / \mathrm{L}$, exceeding the current SDWA maximum concentration limit $(\mathrm{MCL})$, with a range of $1.06 \mu \mathrm{g} / \mathrm{L}-9.1 \mu \mathrm{g} / \mathrm{L}$ (red points in FIGURE 15). TABLE 3 contains the data from each utility pole located in one of the eight contributing areas with PCP concentrations greater than $1 \mu \mathrm{g} / \mathrm{L}$. All of these sites are located on streets with greater than 1,000 vehicle trips per day and five of the sites are located on SE Stark Street. Each site has a utility pole less than 100 feet from the catch basin inlet. Seven of the eight sites have a utility pole less than 50 feet from the catch basin inlet and six of the eight sites have a utility pole less than 25 feet from the catch basin inlet.

With the exception of a utility pole in the contributing area at SE $190^{\text {th }}$ and SE Division $(\mathrm{PCP}$ concentration $=1.06 \mu \mathrm{g} / \mathrm{L})$, every utility pole is set in concrete. Each site, with the exception of the site at SE $190^{\text {th }}$ and SE Division, has at least one utility pole with treatment compound staining on the concrete surrounding the pole. Seven of the eight sites (exception at SE Stark \& $202^{\text {nd }}$ ) have had utility pole inspections in the last 10 years and have plastic diffusion plugs in at least one utility pole, if not all. The contributing area at SE Stark \& SE $194^{\text {th }}$ (PCP concentration $=9.1 \mu \mathrm{g} / \mathrm{L}$ ) has two utility poles located less than 75 feet from the catch basin inlet and all utility poles are less than two feet from the curb. It also has the largest cumulative utility pole surface area of the eight sites. 
Table 3. Characteristics of utility poles located in contributing areas with greater than $1 \mu \mathrm{g} / \mathrm{L} \mathrm{PCP}$ in stormwater. For adjacent land use, COM = Commercial and RES = Residential. Water quality data is taken from the 2009-2010 Gresham Wet Weather study. Utility pole data was collected during August-November 2011.

\begin{tabular}{|c|c|c|c|c|c|c|c|c|c|}
\hline $\begin{array}{l}\text { System ID } \\
\text { Power Pole } \\
\text { Unique ID }\end{array}$ & $\begin{array}{l}\text { 3249-W-048 } \\
\text { UIC-012-PP1 }\end{array}$ & UIC-012-PP2 & $\begin{array}{l}3149-W-019 \\
\text { UIC-041-PP1 }\end{array}$ & $\begin{array}{l}\text { 3050-W-019 } \\
\text { UIC-045-PP1 }\end{array}$ & UIC-045-PP2 & $\begin{array}{l}\text { 3047-W-027 } \\
\text { UIC-051-PP1 }\end{array}$ & UIC-051-PP2 & $\begin{array}{l}\text { 3149-W-003 } \\
\text { UIC-052-PP1 }\end{array}$ & UIC-052-PP2 \\
\hline $\begin{array}{l}\text { Penta Conc. } \\
\text { (ug/L) }\end{array}$ & 1.06 & 1.06 & 2.6 & 6.89 & 6.89 & 5.74 & 5.74 & 1.79 & 1.79 \\
\hline Cross Streets & $\begin{array}{l}\text { SE 190TH \& } \\
\text { DIVISION }\end{array}$ & $\begin{array}{l}\text { SE 190TH \& } \\
\text { DIVISION }\end{array}$ & $\begin{array}{l}\text { SE STARK \& } \\
\text { BURNSIDE }\end{array}$ & $\begin{array}{l}\text { SE STARK \& } \\
\text { 196TH }\end{array}$ & $\begin{array}{l}\text { SE STARK \& } \\
196^{\text {TH }}\end{array}$ & $\begin{array}{l}\text { SE 172ND \& } \\
\text { PINE }\end{array}$ & $\begin{array}{l}\text { SE 172ND \& } \\
\text { PINE }\end{array}$ & $\begin{array}{l}\text { SE 182ND \& } \\
\text { MAIN }\end{array}$ & $\begin{array}{l}\text { SE 182ND \& } \\
\text { MAIN }\end{array}$ \\
\hline $\begin{array}{l}\text { Catch Basin } \\
\text { Type }\end{array}$ & SUMPED & SUMPED & SUMPED & SUMPED & SUMPED & SUMPED & SUMPED & SUMPED & SUMPED \\
\hline Sed Manhole & YES & YES & NO & NO & NO & NO & NO & NO & NO \\
\hline $\begin{array}{l}\text { Functional } \\
\text { Class }\end{array}$ & COLLECTOR & COLLECTOR & BOULEVARD & BOULEVARD & BOULEVARD & COLLECTOR & COLLECTOR & ARTERIAL & ARTERIAL \\
\hline $\begin{array}{l}\text { Surface Area } \\
\text { (ft2) }\end{array}$ & 256.36 & 97.65 & 251.14 & 183.6 & 99 & 127.35 & 261 & 251.14 & 135 \\
\hline $\begin{array}{l}\text { Pole } \\
\text { Manufacturer }\end{array}$ & $\begin{array}{l}\text { TAYLOR } \\
\text { TREATING }\end{array}$ & PENTAFIR & PENTAFIR & TAYLOR TREA & & PENTAFIR & DFP & PENTAFIR & PENTAFIR \\
\hline $\begin{array}{l}\text { Manufacture } \\
\text { Year }\end{array}$ & 1999 & 1984 & 1982 & 1995 & 1955 & 1968 & & 1976 & 1968 \\
\hline Last Inspection & 2008 & 2007 & 2002 & 2002 & 1993 & 2008 & 2008 & 2008 & 1989 \\
\hline $\begin{array}{l}\text { Distance UIC } \\
\text { Inlet (ft) }\end{array}$ & 15 & 135 & 96 & 12 & 120 & 171 & 12 & 150 & 15 \\
\hline $\begin{array}{l}\text { Distance Curb } \\
\text { (ft) }\end{array}$ & 0.83 & 1.42 & 4.83 & 1.42 & 5.33 & 0.92 & 0.92 & 1.17 & 1 \\
\hline $\begin{array}{l}\text { Surface } \\
\text { Surrounding } \\
\text { Pole }\end{array}$ & CONCRETE & VEGETATION & CONCRETE & CONCRETE & CONCRETE & CONCRETE & CONCRETE & CONCRETE & CONCRETE \\
\hline $\begin{array}{l}\text { Treatment } \\
\text { Product Visible } \\
\text { Pole }\end{array}$ & MEDIUM & MEDIUM & $\mathrm{HIGH}$ & MEDIUM & MEDIUM & $\mathrm{HIGH}$ & $\mathrm{HIGH}$ & $\mathrm{HIGH}$ & $\mathrm{HIGH}$ \\
\hline $\begin{array}{l}\text { Treatment } \\
\text { Compound } \\
\text { Ground }\end{array}$ & NO & NO & YES & YES & NO & NO & YES & YES & YES \\
\hline $\begin{array}{l}\text { Pole } \\
\text { Appearance }\end{array}$ & JUVENILE & MATURE & MATURE & MATURE & WEATHERED & WEATHERED & MATURE & MATURE & MATURE \\
\hline $\begin{array}{l}\text { Diffusion Plugs } \\
\text { Present }\end{array}$ & PLASTIC & PLASTIC & PLASTIC & PLASTIC & WOOD & PLASTIC & PLASTIC & PLASTIC & WOOD \\
\hline $\begin{array}{l}\text { Number } \\
\text { Diffusion Plugs }\end{array}$ & 4 & 4 & 7 & 5 & 2 & 5 & 4 & 8 & 4 \\
\hline $\begin{array}{l}\text { Adjacent Land } \\
\text { Use }\end{array}$ & RES & RES & COM & COM & COM & RES & RES & RES & COM/RES \\
\hline $\begin{array}{l}\text { Soil Complex } \\
\text { Name }\end{array}$ & $\begin{array}{l}\text { Multnomah } \\
\text { Urban Land } \\
\text { Complex }\end{array}$ & $\begin{array}{l}\text { Multnomah } \\
\text { Urban Land } \\
\text { Complex }\end{array}$ & $\begin{array}{l}\text { Multnomah } \\
\text { Urban Land } \\
\text { Complex }\end{array}$ & $\begin{array}{l}\text { Multnomah } \\
\text { Urban Land } \\
\text { Complex }\end{array}$ & $\begin{array}{l}\text { Multnomah } \\
\text { Urban Land } \\
\text { Complex }\end{array}$ & $\begin{array}{l}\text { Multnomah } \\
\text { Urban Land } \\
\text { Complex }\end{array}$ & $\begin{array}{l}\text { Multnomah } \\
\text { Urban Land } \\
\text { Complex }\end{array}$ & $\begin{array}{l}\text { Multnomah } \\
\text { Silt Loam }\end{array}$ & $\begin{array}{l}\text { Multnomah } \\
\text { Silt Loam }\end{array}$ \\
\hline
\end{tabular}




\begin{tabular}{|c|c|c|c|c|c|c|c|c|}
\hline \multirow{2}{*}{$\begin{array}{l}\text { System ID } \\
\text { Utility Pole } \\
\text { Unique ID }\end{array}$} & \multicolumn{3}{|l|}{$3050-W-016$} & \multicolumn{3}{|l|}{ 3153-F-017 } & \multicolumn{2}{|l|}{ 3150-F-047 } \\
\hline & UIC-057-PP1 & UIC-057-PP2 & UIC-057-PP3 & UIC-086-PP1 & UIC-086-PP2 & UIC-086-PP3 & UIC-093-PP1 & UIC-093-PP2 \\
\hline $\begin{array}{l}\text { Penta Conc. } \\
\text { (ug/L) }\end{array}$ & 9.1 & 9.1 & 9.1 & 5.96 & 5.96 & 5.96 & 2.04 & 2.04 \\
\hline Cross Streets & $\begin{array}{l}\text { SE STARK \& } \\
194 T H\end{array}$ & $\begin{array}{l}\text { SE STARK \& } \\
194 T H\end{array}$ & $\begin{array}{l}\text { SE STARK \& } \\
194 T H\end{array}$ & $\begin{array}{l}\text { SE STARK \& } \\
223 R D\end{array}$ & $\begin{array}{l}\text { SE STARK \& } \\
223 R D\end{array}$ & $\begin{array}{l}\text { SE STARK \& } \\
223 R D\end{array}$ & $\begin{array}{l}\text { SE STARK \& } \\
\text { 202ND }\end{array}$ & $\begin{array}{l}\text { SE STARK \& } \\
202 N D\end{array}$ \\
\hline $\begin{array}{l}\text { Catch Basin } \\
\text { Type }\end{array}$ & SUMPED & SUMPED & SUMPED & UNSUMPED & UNSUMPED & UNSUMPED & SUMPED & SUMPED \\
\hline Sed Manhole & NO & NO & NO & NO & NO & NO & NO & NO \\
\hline $\begin{array}{l}\text { Functional } \\
\text { Class }\end{array}$ & BOULEVARD & BOULEVARD & BOULEVARD & ARTERIAL & ARTERIAL & ARTERIAL & ARTERIAL & ARTERIAL \\
\hline $\begin{array}{l}\text { Surface Area } \\
\text { (ft2) }\end{array}$ & 212.86 & 157.5 & 241.86 & 290 & 172.35 & 142.65 & 153.9 & 165.15 \\
\hline $\begin{array}{l}\text { Pole } \\
\text { Manufacturer }\end{array}$ & PENTAFIR & $\begin{array}{l}\text { MCFARLANE } \\
\text { CASCADE }\end{array}$ & PENTAFIR & $\begin{array}{l}\text { TAYLOR } \\
\text { TREATING }\end{array}$ & $\begin{array}{l}\text { TAYLOR } \\
\text { TREATING }\end{array}$ & PENTAFIR & $\begin{array}{l}\text { TAYLOR } \\
\text { TREATING }\end{array}$ & PENTAFIR \\
\hline $\begin{array}{l}\text { Manufacture } \\
\text { Year }\end{array}$ & 1989 & 2008 & 1989 & 1996 & 1996 & 1968 & 1994 & 1965 \\
\hline Last Inspection & 2002 & & 2002 & 2007 & 2007 & 2007 & & 1989 \\
\hline $\begin{array}{l}\text { Distance UIC } \\
\text { Inlet (ft) }\end{array}$ & 126 & 24 & 69 & 156 & 1 & 123 & 42 & 216 \\
\hline $\begin{array}{l}\text { Distance Curb } \\
\text { (ft) }\end{array}$ & 1.33 & 1.67 & 1.92 & 5.17 & 4.67 & 1.08 & 1.08 & 1 \\
\hline $\begin{array}{l}\text { Surface } \\
\text { Surrounding } \\
\text { Pole }\end{array}$ & CONCRETE & CONCRETE & CONCRETE & CONCRETE & CONCRETE & CONCRETE & CONCRETE & CONCRETE \\
\hline $\begin{array}{l}\text { Treatment } \\
\text { Product Visible } \\
\text { Pole }\end{array}$ & MEDIUM & MEDIUM & MEDIUM & $\mathrm{HIGH}$ & $\mathrm{HIGH}$ & MEDIUM & MEDIUM & LOW \\
\hline $\begin{array}{l}\text { Treatment } \\
\text { Compound } \\
\text { Ground }\end{array}$ & YES & YES & YES & YES & YES & YES & YES & NO \\
\hline $\begin{array}{l}\text { Pole } \\
\text { Appearance }\end{array}$ & MATURE & JUVENILE & MATURE & MATURE & MATURE & MATURE & MATURE & WEATHERED \\
\hline $\begin{array}{l}\text { Diffusion Plugs } \\
\text { Present }\end{array}$ & PLASTIC & NO & PLASTIC & PLASTIC & PLASTIC & PLASTIC & NO & WOOD \\
\hline $\begin{array}{l}\text { Number } \\
\text { Diffusion Plugs }\end{array}$ & 6 & & 8 & 8 & 8 & 4 & & 4 \\
\hline $\begin{array}{l}\text { Adjacent Land } \\
\text { Use }\end{array}$ & COM & COM & COM & COM & COM & COM & COM & COM \\
\hline $\begin{array}{l}\text { Soil Complex } \\
\text { Name }\end{array}$ & $\begin{array}{l}\text { Multnomah } \\
\text { Urban Land } \\
\text { Complex }\end{array}$ & $\begin{array}{l}\text { Multnomah } \\
\text { Urban Land } \\
\text { Complex }\end{array}$ & $\begin{array}{l}\text { Multnomah } \\
\text { Urban Land } \\
\text { Complex }\end{array}$ & $\begin{array}{l}\text { Latourell } \\
\text { Urban Land } \\
\text { Complex }\end{array}$ & $\begin{array}{l}\text { Latourell } \\
\text { Urban Land } \\
\text { Complex }\end{array}$ & $\begin{array}{l}\text { Latourell } \\
\text { Urban Land } \\
\text { Complex }\end{array}$ & $\begin{array}{l}\text { Multnomah } \\
\text { Urban Land } \\
\text { Complex }\end{array}$ & $\begin{array}{l}\text { Multnomah } \\
\text { Urban Land } \\
\text { Complex }\end{array}$ \\
\hline
\end{tabular}

\section{Data Analysis - Utility Poles Characteristics}

\section{Regression Tree Analysis}

The exploratory regression tree analysis of the characteristics of each utility pole (see

list of characteristics assessed for each location in TABLE 1) concluded that the substrate 
surrounding the utility pole is the best predictor of PCP concentration in stormwater

$\left(\mathrm{cp}=0.2096, \mathrm{R}^{2}=.21\right)($ FIGURE 15).

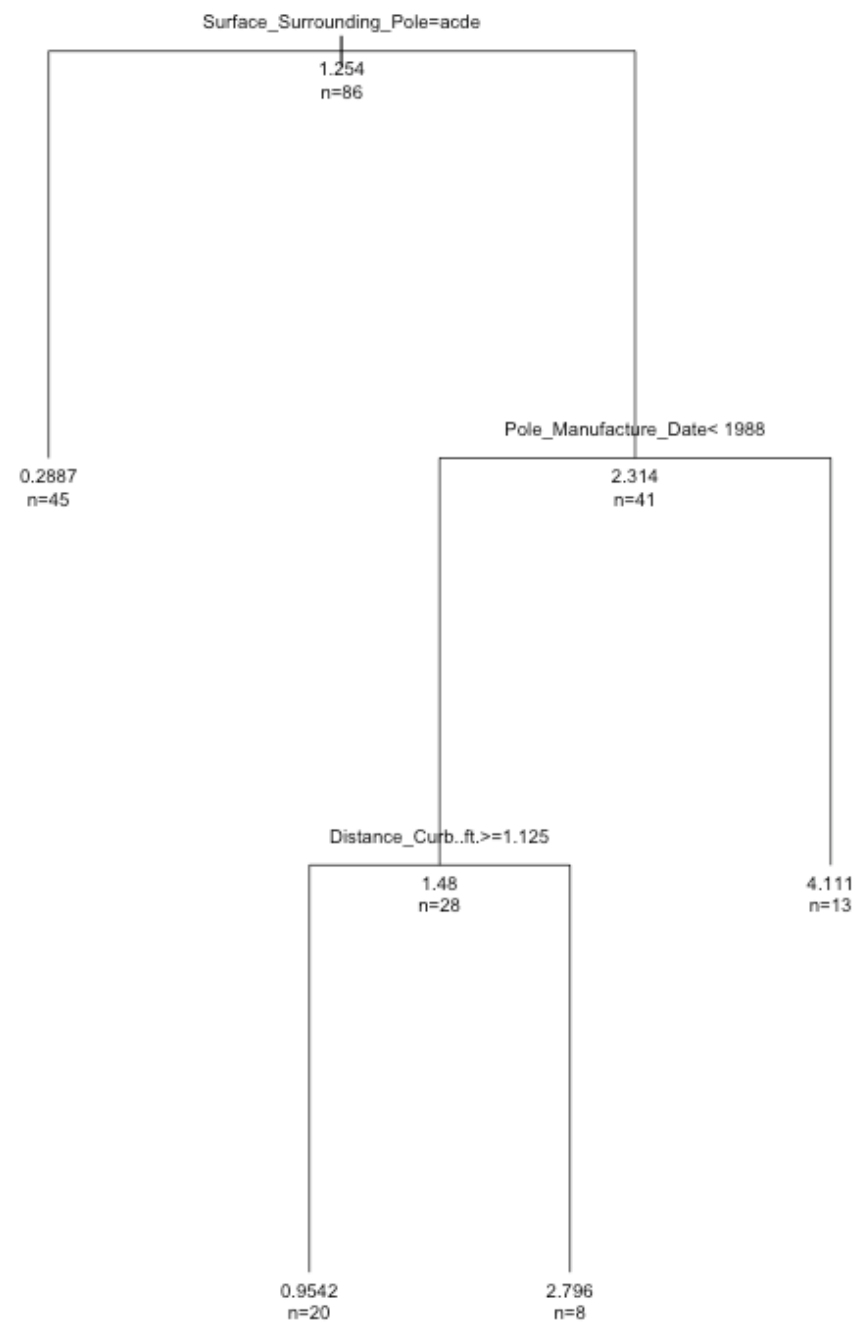

Figure 15. Output from regression tree analysis comparing pentachlorophenol concentration (response variable) to categorical and continuous data (predictor variables) for each individual utility pole. Water quality data is taken from the 2009-2010 Gresham Wet Weather study. Utility pole data was collected during August-November 2011. The tree was created in ' $R$ ' using the "rpart" functions. 
Utility poles installed in concrete (sidewalks) split to the right, while all other substrates (asphalt, dirt, other, and vegetation) split to the left. 41 of the 86 utility poles identified in the study are set in concrete. Other primary splits with lower improvement of the impurity index for the first node were the pole manufacture year, presence of utility pole treatment compound staining on the ground, and the pole manufacturer (TABLE 4). The presence of utility pole treatment compound staining on the ground was also a surrogate split for the first node (68.6\% agreement).

Table 4. Summary output for node number one of utility pole characteristic regression tree from ' $R$ '.

\begin{tabular}{ll}
\hline Primary Splits for Node \#1 & Improvement in Impurity Index \\
\hline Substrate Surrounding the Utility Pole & 0.2097 \\
Utility Pole Manufacture Year & 0.1114 \\
Presence of Utility Pole Treatment Compound Staining on Ground & 0.0983 \\
Utility Pole Manufacturer & 0.0922 \\
\hline
\end{tabular}

The boxplots for each of these utility pole characteristics (FIGURES 16-19) seem to confirm the results of the regression tree analysis. There is a higher concentration of PCP in stormwater when a utility pole is surrounded by concrete, ground staining from utility pole treatment compound is present on the substrate surrounding the pole, or when the utility pole is younger in age. 


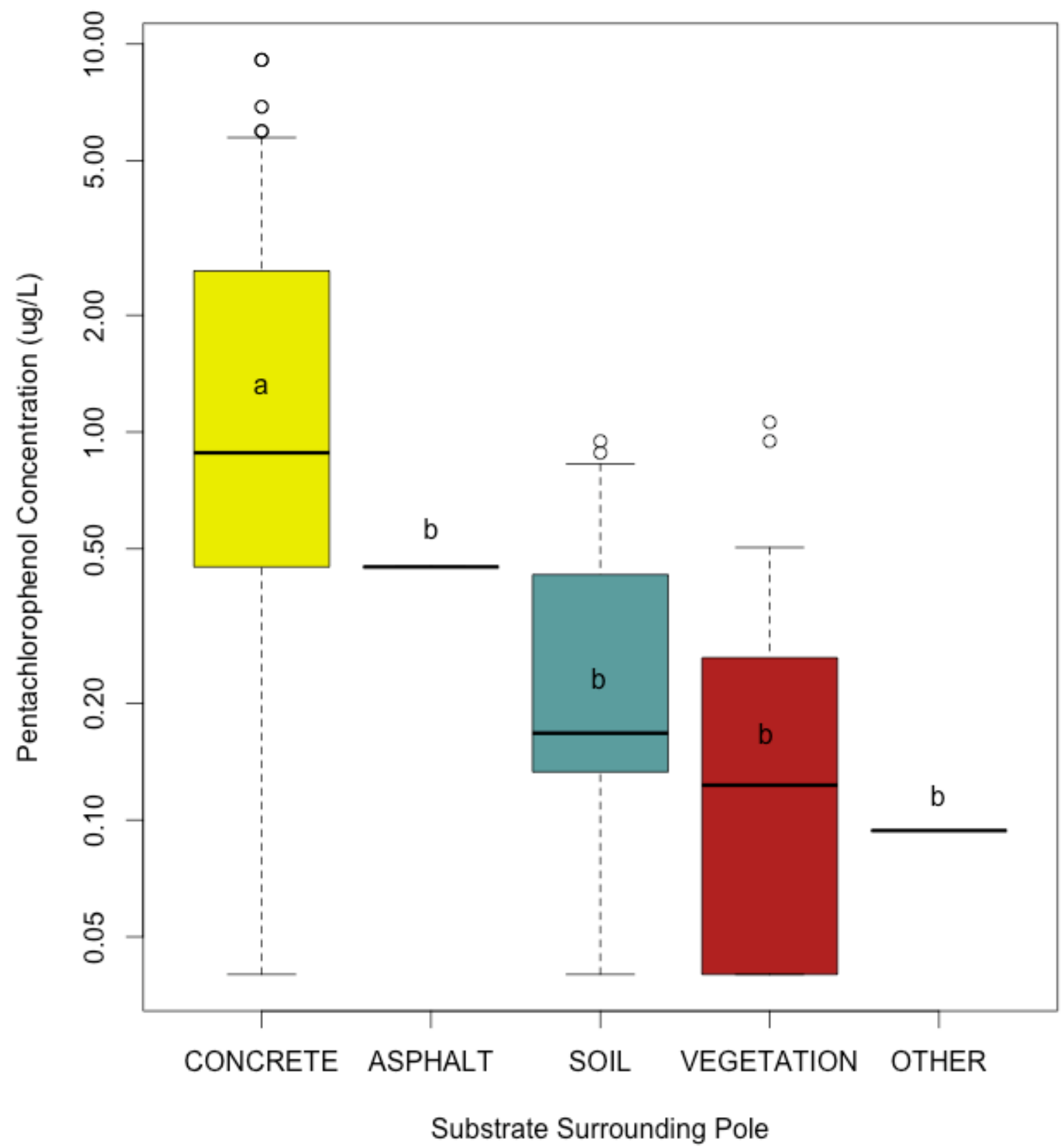

Figure 16. Boxplot of PCP concentrations versus substrate the utility pole is installed in: asphalt $(n=1)$; concrete $(n=41)$; soil $(n=28)$; vegetation $(n=15)$ : other $(n=1)$. Significant differences $(\alpha=0.05)$ in PCP concentration were found between sites with utility poles surrounded by concrete (a) and sites with utility poles surrounded by other substrates (b). Water quality data is taken from the 2009-2010 Gresham Wet Weather study. Utility pole data was collected during August-November 2011. The method reporting limit for PCP is $0.04 \mu \mathrm{g} / \mathrm{L}$. Non-detects are reported at this concentration. 


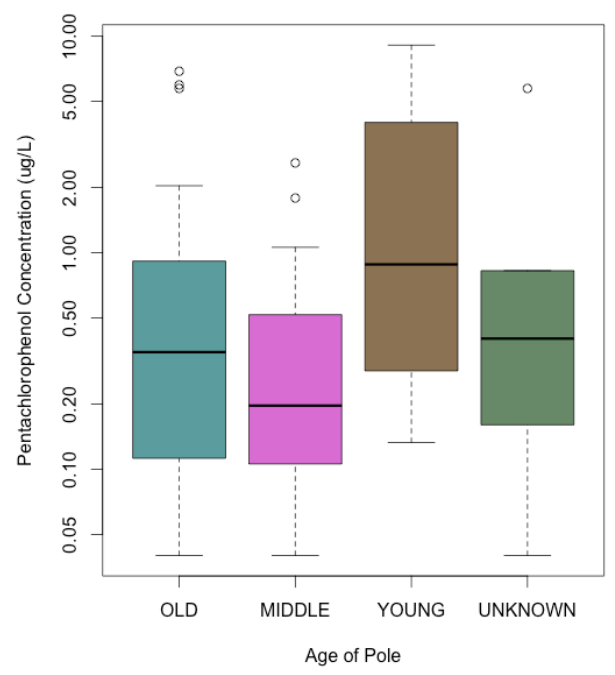

Figure 17. Boxplot of pentachlorophenol concentration in stormwater based on the age of the utility pole. The groups in the "Year" category are as follows, based on the results of the regression tree nodes:

"Old"=manufactured prior to 1970 ( $n=23)$; "Middle"=manufactured between 1970 and 1988 (n=27);

"Young"=manufactured after $1988(n=24)$; "Unknown"=no identification tag present on pole $(n=12)$. Water quality data is taken from the 2009-2010 Gresham Wet Weather study. Utility pole data was collected during AugustNovember 2011. The method reporting limit for PCP is $0.04 \mu \mathrm{g} / \mathrm{L}$. Non-detects are reported at this concentration.

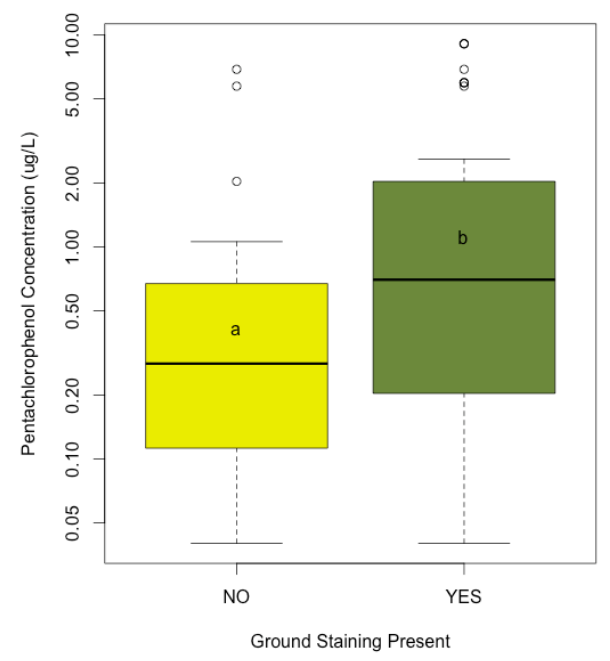

Figure 18. Boxplot of pentachlorophenol concentration in stormwater based on the presence $(n=38)$ or absence $(n=48)$ of treatment compound staining on the ground surrounding the utility pole. Significant differences $(\alpha=0.05)$ in PCP concentration were found between sites with ground staining present $(b)$ and sites without ground staining present (a). Water quality data is taken from the 2009-2010 Gresham Wet Weather study. Utility pole data was collected during August-November 2011. The method reporting limit for PCP is $0.04 \mu \mathrm{g} / \mathrm{L}$. Non-detects are reported at this concentration. 


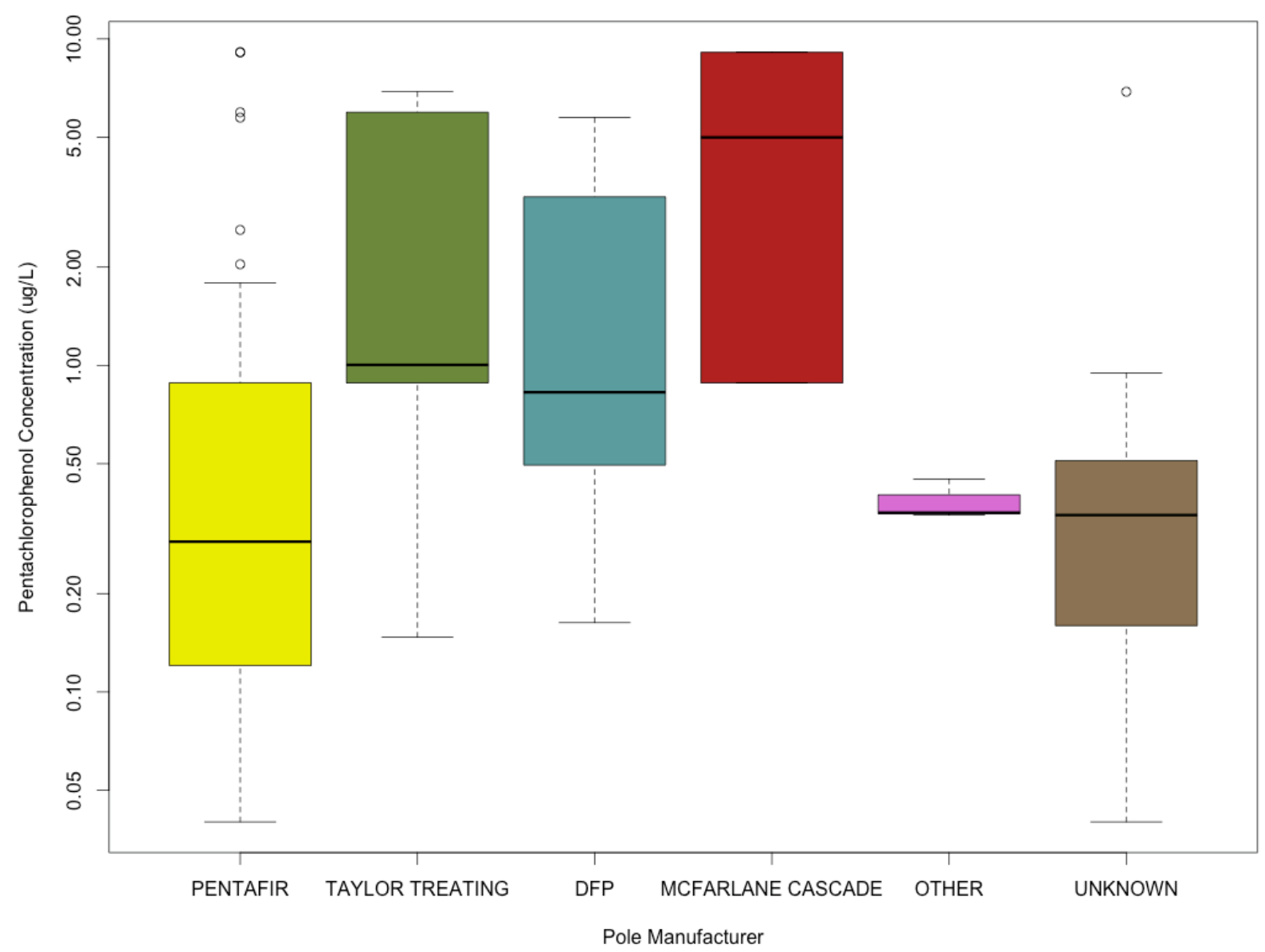

Figure 19. Boxplot of pentachlorophenol concentration in stormwater versus the utility pole manufacturer. Manufacturers are listed from left to right in order of when they were in production: Pentafir $(n=48)$ 1962-1990; Taylor Treating $(n=10)$ 1994-1999; DFP $(n=4)$ 1998; McFarlane Cascade $(n=2)$ 2009; Other $(n=3) ;$ Unknown $(n=18)$. Utility poles listed as "Other" are from manufacturers with only one utility pole identified in the study area with production years of 1960, 2002, and 2010. Utility poles listed as "Unknown" are those poles where the identification tag was either removed or had fallen off. Water quality data is taken from the 2009-2010 Gresham Wet Weather study. Utility pole data was collected during August-November 2011. The method reporting limit for PCP is $0.04 \mu \mathrm{g} / \mathrm{L}$. Non-detects are reported at this concentration.

The second node of the regression tree was split based on the year the utility pole was manufactured; specifically it differentiates between poles manufactured before and after 1988 $\left(\mathrm{cp}=0.1463, \mathrm{R}^{2}=0.15\right)$. This is supported by FIGURE 19, which shows that utility poles manufactured by Taylor Treating, DFP, and McFarlane Cascade result in higher concentrations 
of PCP in stormwater than utility poles manufactured by Pentafir. The third node differentiates between poles located greater than and less than 1.125 feet from the curb $(c p=0.0461$, $\left.\mathrm{R}^{2}=0.04\right)$. Other primary splits in the third node with lower improvement of the impurity index were the distance from the utility pole to the catch basin inlet, the number of diffusion plugs in the utility pole, and the year of the last inspection of the pole (FIGURE 15).

\section{Non-parametric Data Analysis}

$66 \%$ of UIC sites examined in this study had utility poles in the contributing area, and nearly half of those utility poles were set in concrete (41 out of 86). PCP concentration in the stormwater samples from sites with utility poles set in concrete ranged from $<0.04 \mu \mathrm{g} / \mathrm{L}-$ 9.1 $\mathrm{g} / \mathrm{L}$. Based on the boxplot in FIGURE 16, it appears that when utility poles are surrounded by concrete the result is higher concentrations of PCP in the contributing area stormwater. A Mann-Whitney U-test found significant differences $(\alpha=0.05, p$-value $=<0.001)$ in PCP concentration when are utility poles surrounded by concrete (median=0.88 $\mu \mathrm{g} / \mathrm{L}$, mean=2.31 $\mu \mathrm{g} / \mathrm{L}$ ) and when utility poles surrounded by asphalt, soil, or vegetation (median=0.15 $\mu \mathrm{g} / \mathrm{L}$, mean $=0.29 \mu \mathrm{g} / \mathrm{L})$. The majority of sites without utility poles set in concrete are located on residential streets, with the remaining located on community or arterial streets.

The Mann-Whitney U-test also found significant differences $(\alpha=0.05)$ in PCP concentration when there are utility poles with ground staining (median=0.70 $\mu \mathrm{g} / \mathrm{L}$, mean=2.03 $\mu \mathrm{g} / \mathrm{L}$ ) and when there is no ground staining (median=0.28 $\mu \mathrm{g} / \mathrm{L}$, mean=0.64 $\mu \mathrm{g} / \mathrm{L}$ ) around utility poles $(\mathrm{p}=0.002)($ FIGURE 18). 
It appears that there is a correlation between the age of the pole and the concentration of PCP in the contributing area. FIGURES $17 \& 20$ show a slight trend that as utility pole age decreases, PCP concentration in the contributing area increases. Some older utility poles with diffusion plugs present had higher concentrations of PCP in the contributing area, especially if the diffusion plugs were plastic and not wood.

Diffusion plugs are inserted into the pole after additional treatment product has been added during an inspection. Inspection of utility poles usually occur every ten years, so many of the youngest utility poles did not have diffusion plugs. Based on inspection tags, wood diffusion plugs were used until the mid-1990s and plastic diffusion plugs were used exclusively after 2000. FIGURE 21 also shows that while some older poles with wood diffusion plugs are located in a UIC contributing area with a high concentration of $\mathrm{PCP}$, there is also a younger pole with no diffusion plugs or plastic diffusion plugs located in the same contributing area. 


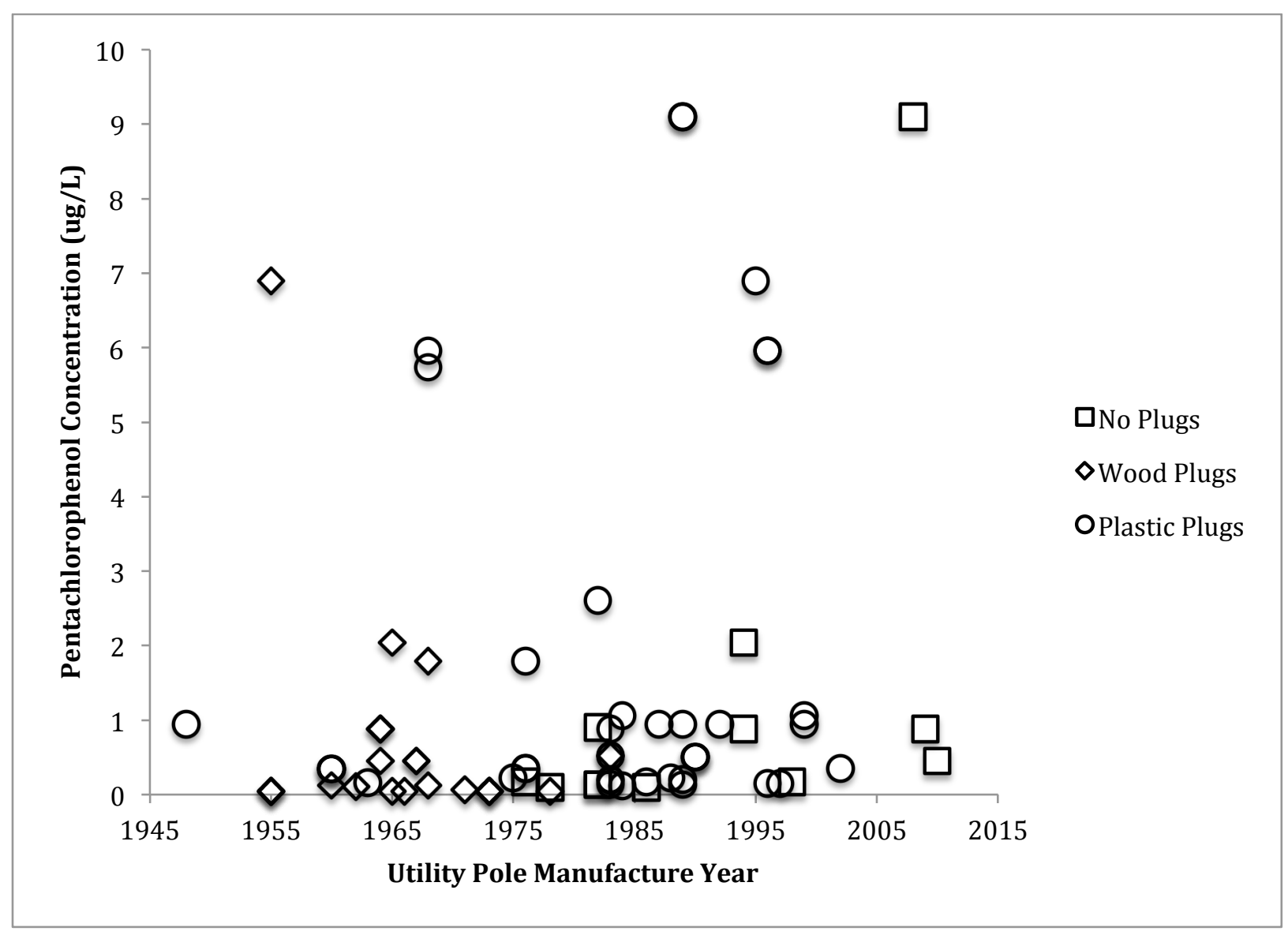

Figure 20. Pentachlorophenol concentration ( $\mu \mathrm{g} / \mathrm{L})$ in a UIC device contributing area as a response to the year a given utility pole in the contributing area was manufactured. Data is based off of 74 utility poles. 12 of the 86 utility poles identified did not have an identification tag with the year manufactured. Symbols represent the presence and type of diffusion plug found at each utility pole. Water quality data is taken from the 2009-2010 Gresham Wet Weather study. Utility pole data was collected during August-November 2011.

Further, the Mann-Whitney U-test found significant differences $(\alpha=0.05)$ in PCP concentrations between utility poles that were inspected after the year 2000 and before the year 2000 (median $_{\text {after } 2000} \mathrm{PCP}=0.52 \mu \mathrm{g} / \mathrm{L}$, mean after $2000 \mathrm{PCP}=1.77 \mu \mathrm{g} / \mathrm{L}$; median before 2000

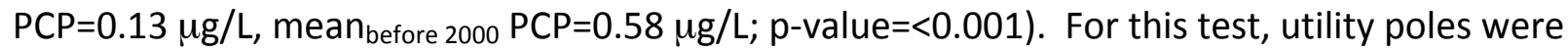
considered to have had an inspection after the year 2000 if an inspection tag was present indicating so, if plastic diffusion plugs were present, or if the pole was installed after 2000. Utility poles were considered not to have had an inspection after the year 2000 if an inspection 
tag indicated an earlier inspection year, wood diffusion plugs were present, or the pole was

installed prior to 2000 and had no diffusion plugs.

The Kruskal-Wallis test confirmed significant differences $(\alpha=0.05)$ in PCP concentrations based on the visual estimation of the amount of treatment product on the utility pole (median $_{\text {high }}$ PCP=0.40 $\mu \mathrm{g} / \mathrm{L} ;$ median $_{\text {medium }} \mathrm{PCP}=0.50 \mu \mathrm{g} / \mathrm{L}$; median $_{\text {low }} \mathrm{PCP}=0.15 \mu \mathrm{g} / \mathrm{L} ; \mathrm{p}-$ value $=0.013$, FIGURE 21). Based on the regression tree analysis, this characteristic is less important in determining PCP concentration in stormwater than those utility pole characteristics discussed above.

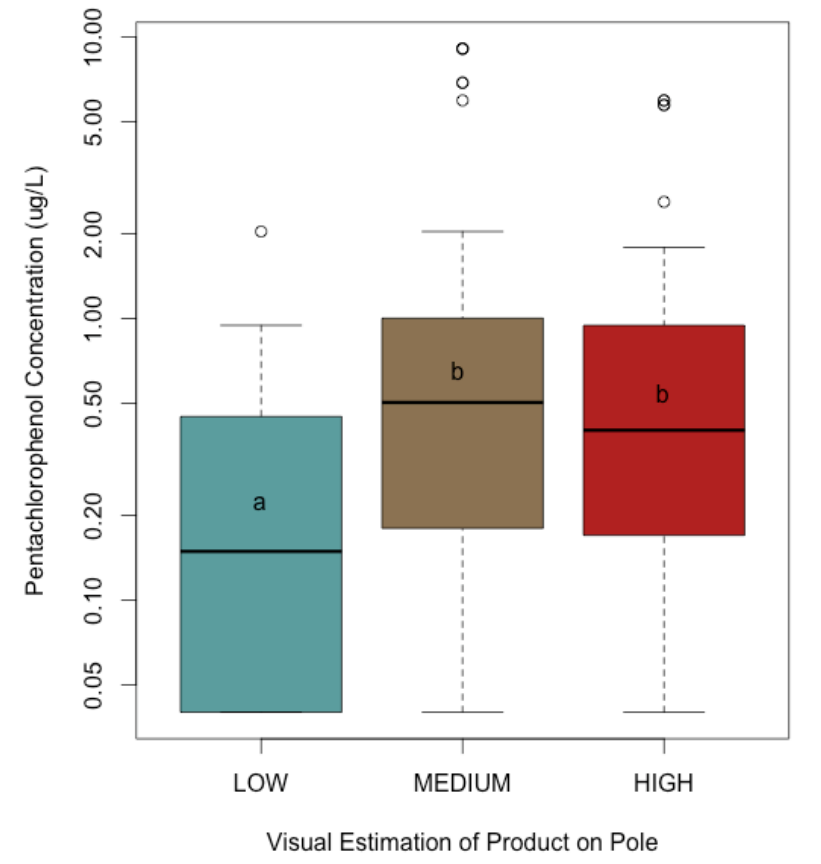

Figure 21. Boxplot of pentachlorophenol concentration in stormwater based on a visual estimation of treatment compound staining on the lower 6 feet of the utility pole. Low: $n=21$; Medium: $n=35$; High: $n=30$. Significant differences $(\alpha=0.05)$ in PCP concentration were found between utility poles with a low estimation of treatment compound staining (b) utility and utility poles with a medium or high estimation of treatment compound staining (a). Water quality data is taken from the 2009-2010 Gresham Wet Weather study. Utility pole data was collected during August-November 2011. The method reporting limit for PCP is $0.04 \mu \mathrm{g} / \mathrm{L}$. Non-detects are reported at this concentration. 
A pairwise comparison with the Mann-Whitney $U$ test $(\alpha=0.016$ after Bonferri

correction) found that PCP concentration from contributing areas containing utility poles with a low amount of treatment product visible on the pole were significantly different from both contributing areas containing utility poles with medium and high amounts of treatment product visible on the pole. There were no differences in PCP concentration from contributing areas with high or medium amounts of treatment product visible on the pole. TABLE 5 is a summary of the Mann Whitney $U$ test results.

Table 5. Summary of results from Mann-Whitney $U$ test $(\alpha=0.016)$ to compare the concentration of pentachlorophenol in stormwater to the three different categories of the visual estimation of treatment compound on a utility pole. A Bonferri correction was used to account for an increase in Type I error with multiple comparisons.

\begin{tabular}{lll}
\hline $\begin{array}{l}\text { Visual Estimation of Treatment Product on } \\
\text { Utility Pole }\end{array}$ & W & p-value \\
\hline High vs. Medium & 514.5 & 0.6137 \\
High vs. Low & 446.5 & 0.012 \\
Medium vs. Low & 222.5 & 0.007228 \\
\hline
\end{tabular}

\section{Data Analysis - Contributing Area Characteristics}

\section{Regression Tree Analysis}

The regression tree used to explore the characteristics of each UIC device contributing area found that the most important criteria affecting the concentration of PCP is the total surface area of utility poles set in concrete in a particular contributing area $(c p=0.4079$, $\mathrm{R}^{2}=0.41$ ). The split occurs when the surface area of utility poles set in concrete is greater or less than 246.5 square feet. 14 of 60 sites in the study have a total surface area of utility poles set it concrete greater than 246.5 square feet (14 of 40 sites with utility poles present). Other primary splits with a lower improvement of the impurity index were the number of poles set in concrete, the minimum distance to the catch basin inlet, the total surface of all utility poles, 
and the ratio of utility pole surface area to UIC contributing area (TABLE 6). Scatterplots for these data sets are presented in FIGURES 22-24 below in the discussion of Spearman's $\rho$ rank correlation. A surrogate split for node number one is the functional class of the street the UIC device is located on (agreement=82\%).

Table 6. Summary output for node number one of UIC contributing area characteristic regression tree from ' $R$ '.

\begin{tabular}{ll}
\hline Primary Splits for Node \#1 & Improvement in Impurity Index \\
\hline Surface area of utility poles surrounded by concrete & 0.4079 \\
Number of utility poles surrounded by concrete & 0.3898 \\
Minimum distance from a utility pole to the catch basin inlet & 0.2285 \\
Total surface area of all utility poles in contributing area & 0.2255 \\
Ratio of utility pole surface area to UIC contributing area & 0.1618 \\
\hline
\end{tabular}

\section{Nonparametric Data Analysis}

The Mann-Whitney $U$ test $(\alpha=0.05)$ confirmed the results of Kennedy/Jenks (2009) that PCP concentration in stormwater from UIC devices located on streets with greater than 1,000 vehicles per day (median=0.35 $\mu \mathrm{g} / \mathrm{L}$, mean=1.37 $\mu \mathrm{g} / \mathrm{L}$ ) is significantly different ( $\mathrm{p}$-value $=<0.001$ ) than stormwater from UIC devices located on streets with less than 1,000 vehicles per day (median=0.04 $\mu \mathrm{g} / \mathrm{L}$, mean=0.09 $\mu \mathrm{g} / \mathrm{L}$ ). FIGURE 23 shows the distribution of PCP concentration in stormwater samples from streets with less than 1,000 trips per day and streets with greater than 1,000 trips per day. 


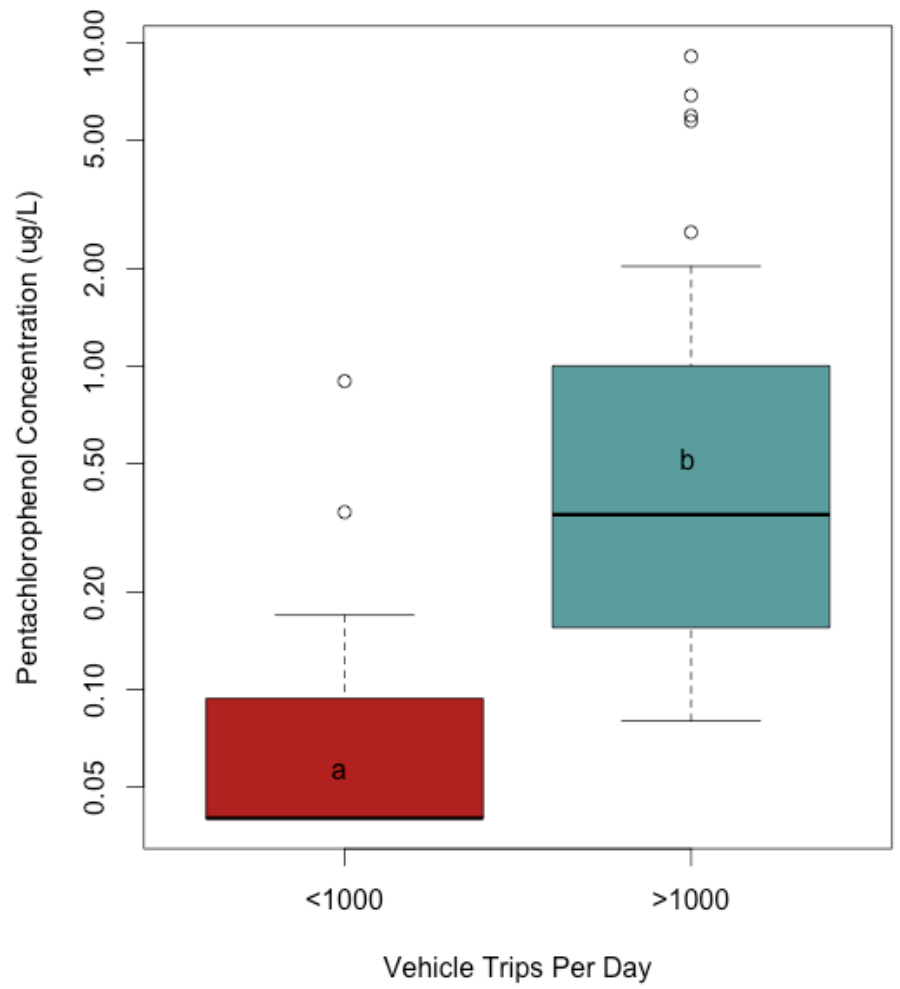

Figure 22. Boxplot of pentachlorophenol concentration $(\mu \mathrm{g} / \mathrm{L})$ for streets with less than 1,000 vehicle trips per day and greater than 1,000 trips per day. $\mathrm{N}=30$ for streets with less than 1,000 vehicle trips per day and $n=31$ for streets with greater than 1,000 vehicle trips per day (one site sampled twice). Significant differences $(\alpha=0.05)$ in PCP concentration were found between sites located on streets with $>1000$ trips (b) per day and $<1000$ trips per day (a). Water quality data is taken from the 2009-2010 Gresham Wet Weather study. Utility pole data was collected during August-November 2011. The method reporting limit for PCP is $0.04 \mu \mathrm{g} / \mathrm{L}$. Non-detects are reported at this concentration.

However, a Kruskal-Wallis rank sum test $(\alpha=0.05)$ found no significant differences ( $p$ -

value $=0.29$ ) in PCP concentrations between the three functional classes with greater than 1,000 vehicle trips per day (FIGURE 23). 


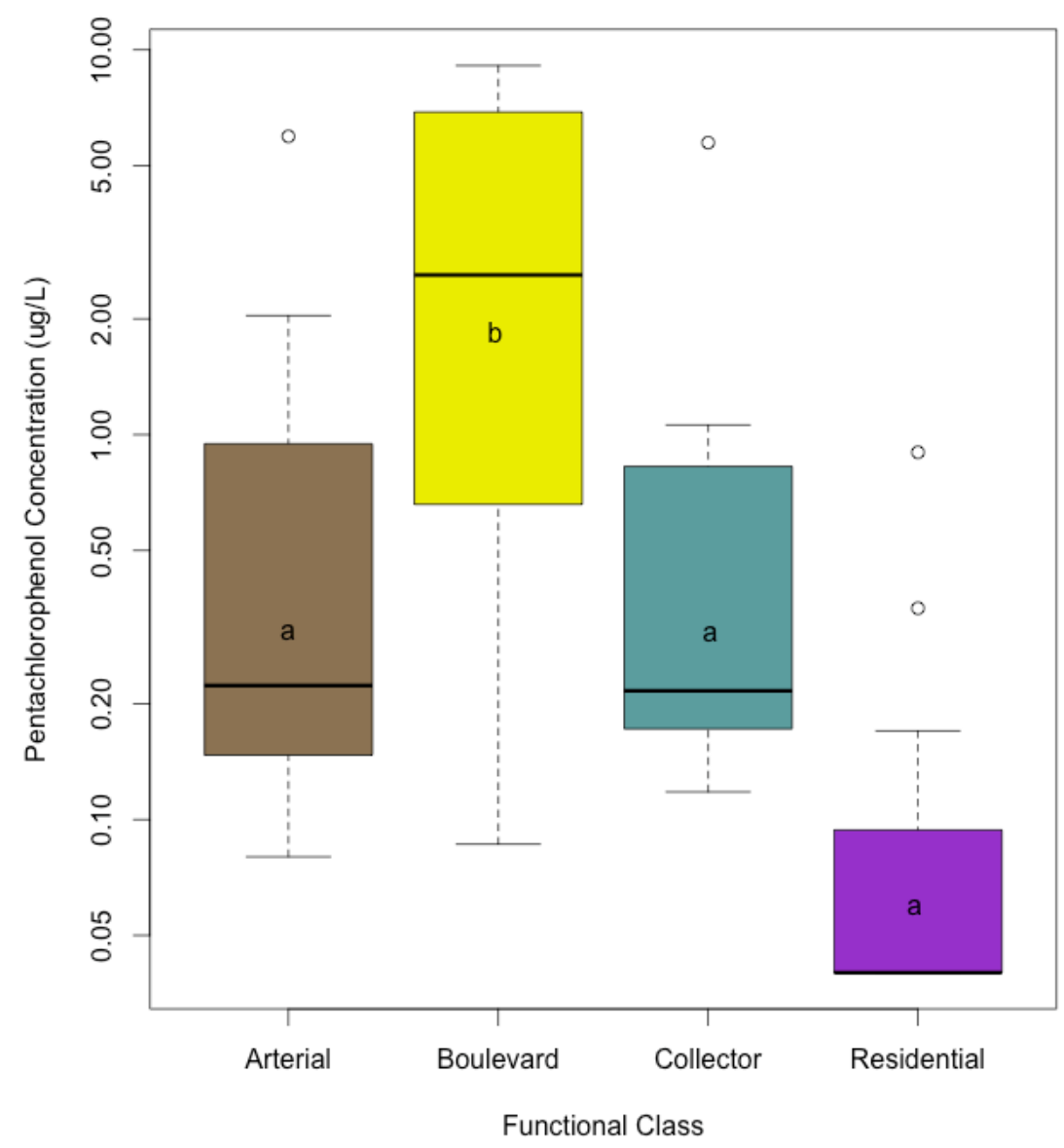

Figure 23. Boxplot of PCP concentration by street functional class. All streets in the residential functional class $(n=30)$ have less than 1,000 vehicle trips per day. The arterial $(n=13)$, boulevard $(n=5)$, and collector $(n=13)$ functional classes (sum of $n=31$ ) have greater than 1,000 vehicle trips per day. Water quality data is taken from the 2009-2010 Gresham Wet Weather study. Utility pole data was collected during August-November 2011. The method reporting limit for PCP is $0.04 \mu \mathrm{g} / \mathrm{L}$. Non-detects are reported at this concentration.

While this study concurs with Kennedy/Jenks (2009) that streets with higher numbers of vehicle traffic per day have greater concentrations of pollutants in stormwater, utility poles are the primary source of PCP in urban runoff. FIGURE 24 demonstrates that there is a relationship between the number of utility poles in a given UIC contributing area and the traffic volume on that street. 


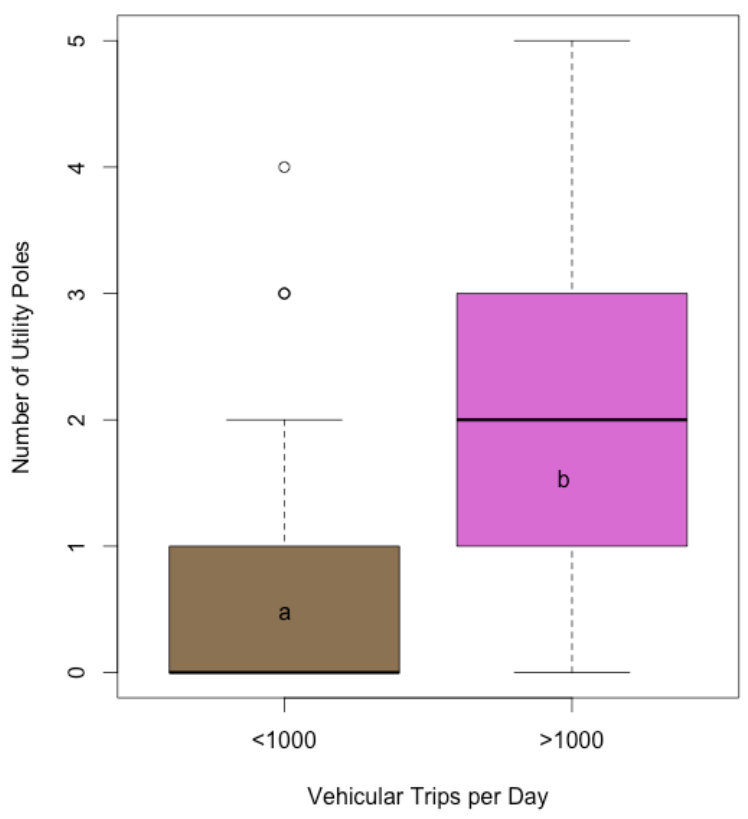

Figure 24. Number of utility poles versus vehicle trips per day for 60 UIC contributing areas. Significant differences $(\alpha=0.05)$ in the number of utility poles located on streets with $>1000$ trips per day (b) and $<1000$ trips per day (a) were found.

A Mann-Whitney U-test found a significant difference $(\alpha=0.05, p$-value $=<0.001)$ in the number of utility poles between streets with greater than 1,000 trips per day (median=2.00 utility poles, mean=2.03 utility poles) and streets with less than 1,000 trips per day (median=0.00, mean=0.83).

19 UIC contributing areas had a PCP concentration below the detection limit of $<0.04 \mu \mathrm{g} / \mathrm{L}$ and all are located on streets with less than 1,000 vehicle trips per day, or the residential functional class (FIGURE 15, UIC points denoted by a yellow point). Six contributing areas have utility poles present, but only one contributing area has a utility pole surrounded by concrete. The utility poles located in the other five contributing areas are surrounded by either a soil or vegetative substrate. Additionally, three of the six sites have a minimum distance from utility pole to catch basin inlet of greater than 100 feet. 


\section{Spearman's $\rho$ Rank Correlation}

Spearman's $\rho$ (rho) rank correlation coefficient was calculated using only those

contributing areas with utility poles, for a total of $n=41$ sites. Based on the results of the

regression tree analysis for UIC contributing areas (See TABLE 6), Spearman's $\rho$ was calculated

for eight UIC contributing area characteristics. The results are presented in TABLE 7 below.

Table 7. Spearman's $\rho$ rank correlation coefficient (bolded values are significant at $\alpha=0.05$ ) for various UIC device contributing area characteristics to determine correlations with pentachlorophenol concentration in stormwater. Only those contributing areas with utility poles present were used in the calcuations $(n=41)$. Water quality data is taken from the 2009-2010 Gresham Wet Weather study. Utility pole data was collected during August-November 2011.

\begin{tabular}{|c|c|c|}
\hline & $\rho$ & p-Value \\
\hline Average distance from utility poles to the street curb (ft) & 0.07613 & 0.636 \\
\hline Total surface area for all utility poles $\left(\mathrm{ft}^{2}\right)$ & 0.61553 & $<0.001$ \\
\hline Total surface area for utility poles set in concrete $\left(\mathrm{ft}^{2}\right)$ & 0.76108 & $<0.001$ \\
\hline $\begin{array}{l}\text { Minimum distance from a utility pole to the catch basin inlet } \\
\text { (ft) }\end{array}$ & -0.5258 & $<0.001$ \\
\hline $\begin{array}{l}\text { Maximum distance from a utility pole to the catch basin } \\
\text { inlet (ft) }\end{array}$ & 0.10587 & 0.510 \\
\hline $\begin{array}{l}\text { Average distance from utility poles to the catch basin inlet } \\
\text { (ft) }\end{array}$ & -0.05567 & 0.729 \\
\hline $\begin{array}{l}\text { Total distance from all utility poles to the catch basin inlet } \\
(\mathrm{ft})\end{array}$ & 0.14623 & 0.362 \\
\hline Ratio of utility pole surface area to UIC contributing area & 0.4564 & 0.003 \\
\hline
\end{tabular}

The scatter plots of total utility pole surface area $\left(\mathrm{ft}^{2}\right)$ for a UIC device contributing area versus PCP concentration ( $\mu \mathrm{g} / \mathrm{L})$ (FIGURES 26a \& $b$ ), shows a positive relationship between utility pole surface area and PCP concentration in stormwater. 

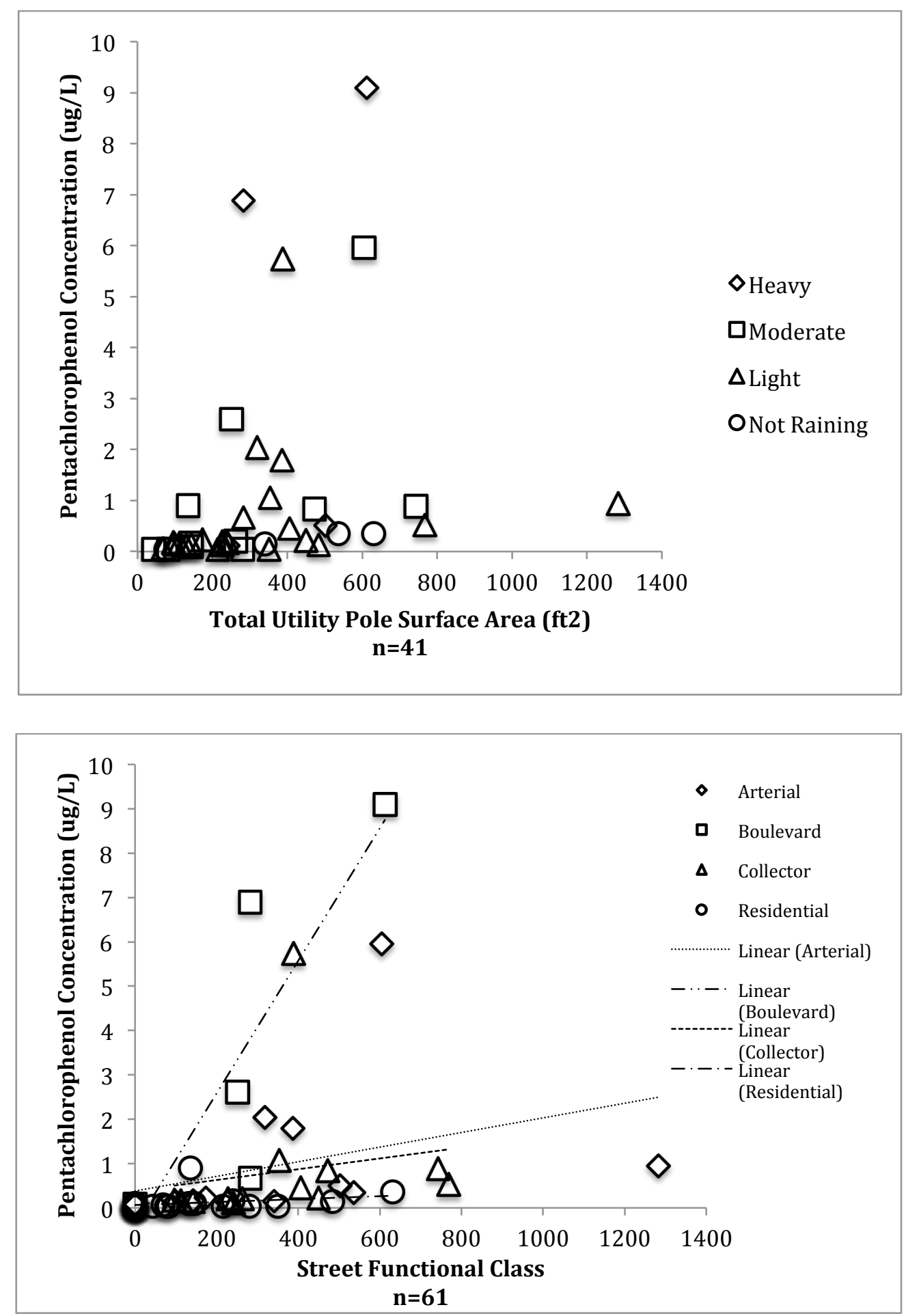

Figure 25a \& 25b. Scatter plot of surface area (ft2) for all poles in a UIC device contributing area versus pentachlorophenol concentration $(\mu \mathrm{g} / \mathrm{L})$. Water quality data is taken from the 2009-2010 Gresham Wet Weather study. Utility pole data was collected during August-November 2011. a) Symbols are representative of rainfall during the stormwater sample collection event. Only contributing areas with utility poles present are included in the scatter plot $(n=41)$. b) Symbols are representative of street functional class. Contributing areas with and without utility poles are included in this scatter plot only $(n=61)$. 
This is confirmed by Spearman's $\rho$ rank correlation coefficient ( $p$-value $=<0.001, \rho=0.62$ ) at the 95\% confidence level (TABLE 7). Additionally, FIGURE 25a shows that rainfall intensity during sample collection can be a factor in determining PCP concentration in stormwater. Three UIC contributing areas have approximately $600 \mathrm{ft}^{2}$ of utility poles. The site sampled during a heavy rainfall event (denoted by a diamond symbol) has the highest PCP concentration, followed by the site sampled during a moderate rainfall event (square symbol). The site sampled when it was not raining (circle symbol) has the lowest PCP concentration of the three. FIGURE 25b, which includes all 61 sites in the study, not just those with utility poles present, further demonstrates that street classes with higher volumes of traffic also have a greater total surface area of utility poles, and in some cases, higher concentrations of PCP in stormwater.

FIGURE 26 depicts a scatterplot of the total surface area $\left(\mathrm{ft}^{2}\right)$ for all utility poles surrounded by concrete for a given contributing area against PCP concentrations in stormwater. 


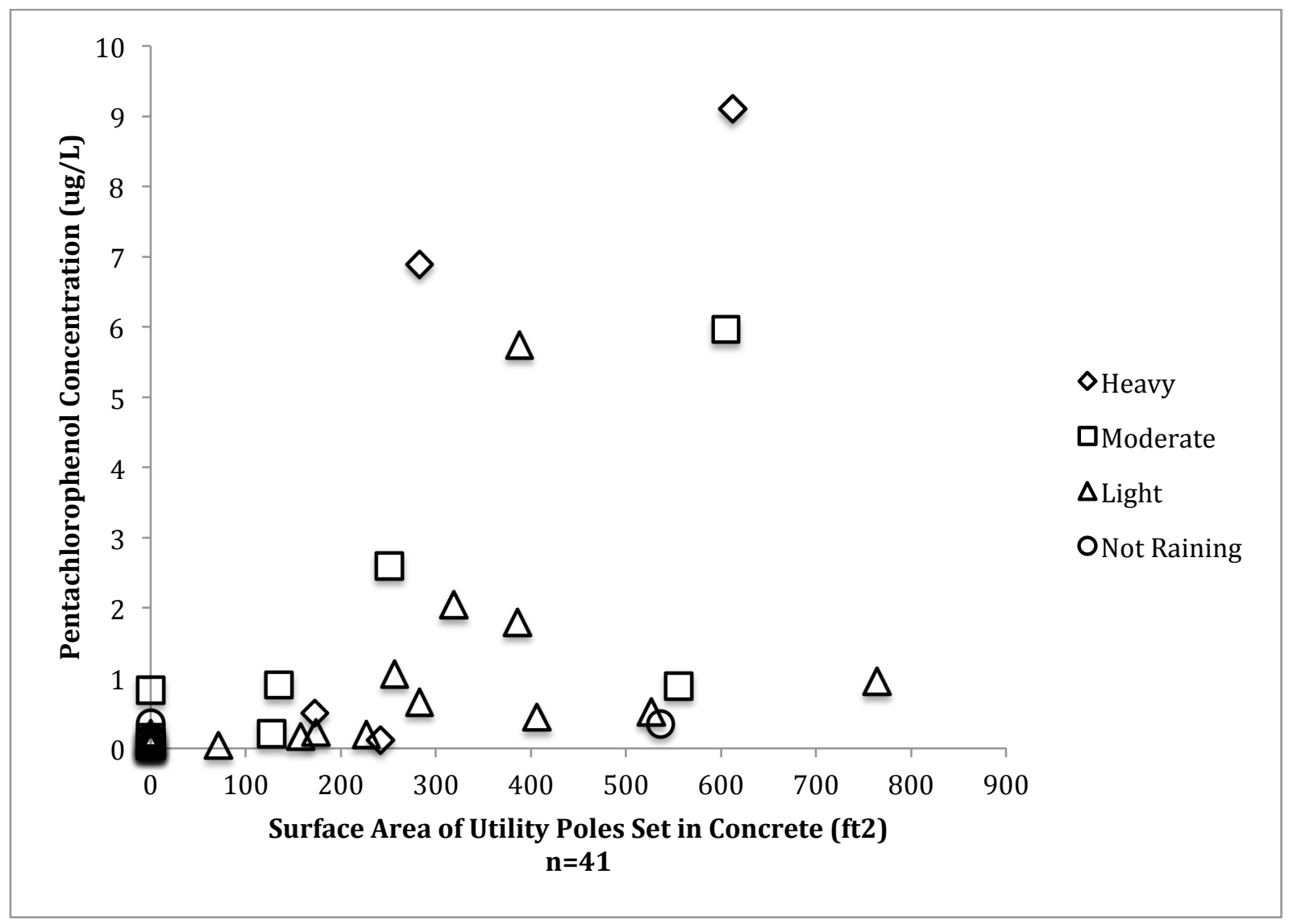

Figure 26. Scatter plot of surface area ( $\mathrm{ft} 2$ ) of utility poles set in concrete in a UIC device contributing area versus pentachlorophenol concentration $(\mu \mathrm{g} / \mathrm{L})$. Symbols are representative of rainfall during the stormwater sample collection event. Water quality data is taken from the 2009-2010 Gresham Wet Weather study. Utility pole data was collected during August-November 2011. Only contributing areas with utility poles present were included in the scatter plot $(n=41)$.

As with total utility pole surface area, the PCP concentration in stormwater appears to increase as the surface area for utility poles surrounded by concrete increases. This is also confirmed by Spearman's $\rho$ rank correlation coefficient ( $p$-value $=<0.001, \rho=0.76$ ) at a $95 \%$ confidence interval (TABLE 7). FIGURE 26 again shows that rainfall intensity during sample collection could be an influential factor in PCP concentration in stormwater. There are three sites with low PCP concentrations in stormwater that were sampled during light intensity and no rain conditions with utility pole surface area greater than $500 \mathrm{ft}^{2}$ surrounded by concrete. However, other sites 
with greater than $500 \mathrm{ft} 2$ of utility pole surface area surrounded by concrete sampled during higher intensity storm events have a concentration of PCP in stormwater exceeding $5 \mu \mathrm{g} / \mathrm{L}$.

A third scatter plot was created to determine if there is a relationship between the minimum distance from a utility pole in a UIC contributing area to the catch basin inlet and PCP concentration in stormwater (FIGURE 27).

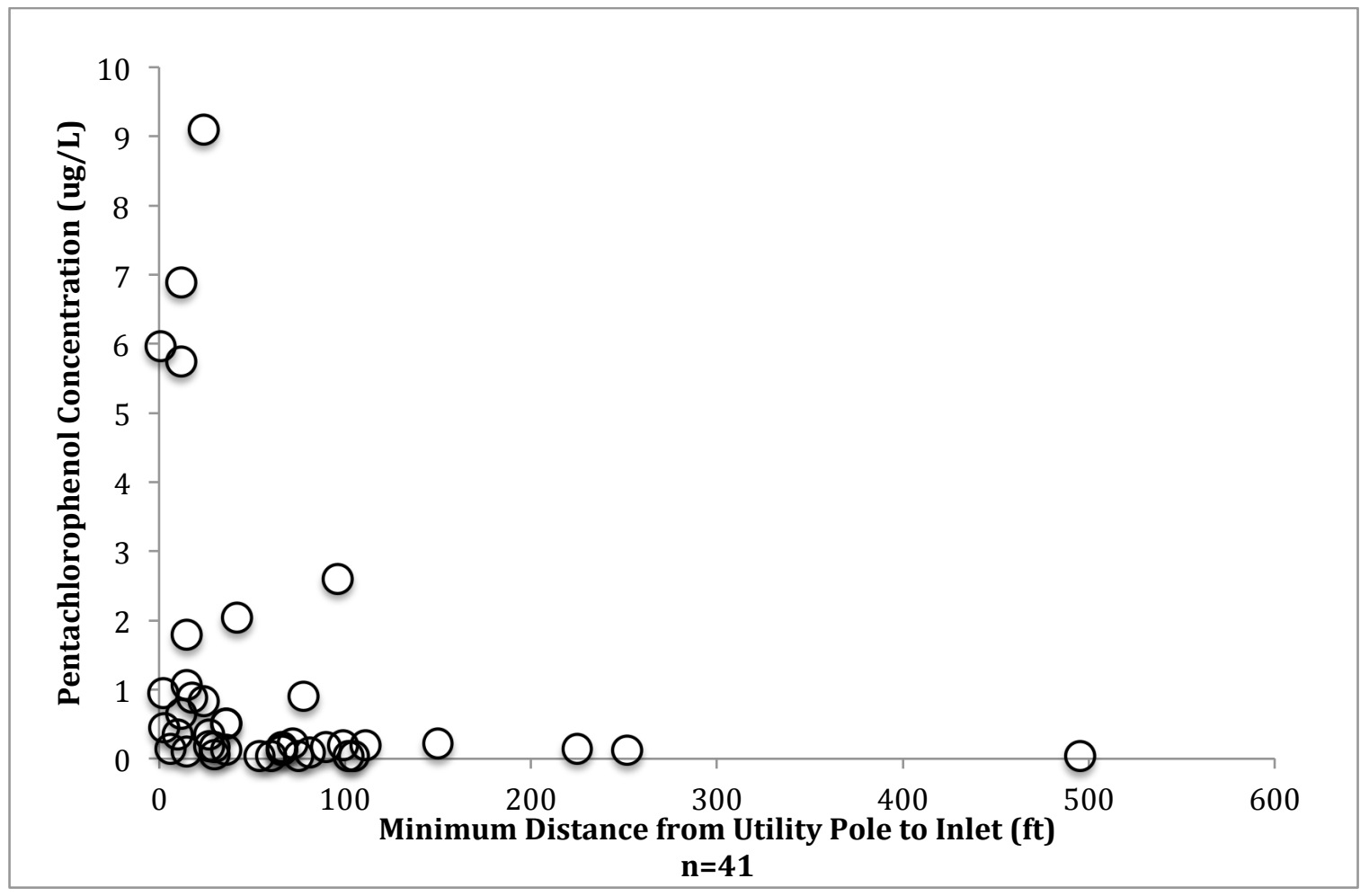

Figure 27. Scatter plot of minimum distance from a utility pole to the catch basin inlet versus pentachlorophenol concentration $(\mu \mathrm{g} / \mathrm{L})$ in a UIC device contributing area. Water quality data is taken from the 2009-2010 Gresham Wet Weather study. Utility pole data was collected during August-November 2011. Only contributing areas with utility poles present were included in the scatter plot $(n=41)$.

As the minimum distance from a utility pole to the catch basin inlet decreases, the PCP concentration in stormwater tends to increase. This negative correlation is confirmed by the Spearman's $\rho$ rank correlation coefficient ( $p$-value $=<0.001, \rho=-0.53$ ) at the $95 \%$ confidence interval (TABLE 7). 
Spearman's $\rho$ rank correlation coefficient was also calculated for the average distance from utility poles to the street curb, total distance from all utility poles to the catch basin inlet, average distance from the utility poles to the catch basin inlet, and maximum distance from a utility pole to the catch basin inlet to determine if there were any correlations with PCP concentration in stormwater. At the $95 \%$ confidence level, there were no significant correlations between any of these characteristics and PCP concentration in stormwater for UIC device contributing areas (TABLE 7).

\section{Spatial Data Analysis}

Site UIC-045 was the only site sampled two times during the 2009-2010 wet weather study, once during a heavy rain event $(\mathrm{PCP}$ concentration $=6.89 \mu \mathrm{g} / \mathrm{L})$ and once during a light rain event $(\mathrm{PCP}$ concentration $=0.66 \mu \mathrm{g} / \mathrm{L})$. The Global Moran's I was calculated twice in ArcGIS, once with each PCP concentration for site UIC-045 to maintain spatial balance. With the high concentration of PCP at site UIC-045, there was statistically significant $(\alpha=0.05)$ positive spatial autocorrelation ( $p$-value $=0.035, z$-score $=2.11$ ), or clustered concentrations of PCP. There was no significant positive or negative spatial autocorrelation ( $p$-value $=0.437, z$-score $=-0.78)$ when the lower PCP concentration from site UIC-045 was used.

The graphic output from the Anselin Local Moran's I using the higher PCP concentration for site UIC-045 is presented in FIGURE 28a. Red points denote clusters of high or low PCP concentrations while blue points denote PCP concentrations that are dispersed, or unlike neighboring sample sites. Clustered PCP concentrations are present on SE Stark Street, where there are multiple sites with higher concentrations of PCP. Dispersed PCP concentrations seem 
to be present on streets with lower traffic volumes, where a sample with a high concentration of PCP is surrounded by samples with lower concentrations or vice versa.

The Getis-Ord General G tool was also calculated twice under the same conditions listed above. There was significant clustering $(\alpha=0.05)$ of high concentrations of PCP in stormwater contributing areas when the higher value for UIC-045 was used ( $p$-value=0.001, z-score=3.20). There was no significant clustering of high or low values when the lower PCP concentration from site UIC-045 was used ( $p$-value=0.394, $z$-score=0.852).

The graphic output from the Getis-Ord Gi* using the higher PCP concentration for site UIC-045 is presented in FIGURE 28b. The red points represent hot spots, or statistically significant clustering of high values of PCP concentration in stormwater. The majority of hot spots are located on SE Stark Street. There were no cold spots, or statistically significant clusters of sample points with low PCP concentrations, found in the analysis. 


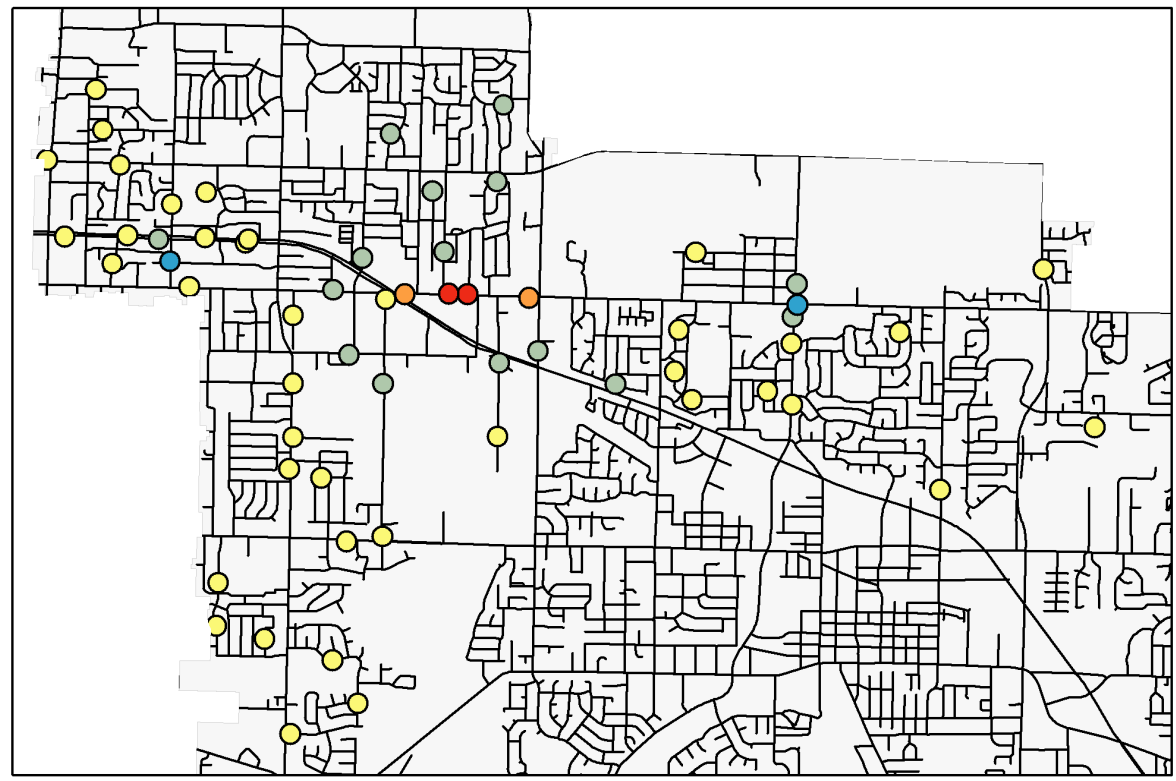

Local Moran's I Cluster Analysis

Legend

Local Morans I

LMiZScore IDW 23048

O $-3.41--2.62$

O $-2.62--0.26$

O $-0.26-0.51$

O $\quad 0.51-2.19$

O $2.19-14.05$

- Streets

Gresham City Limits

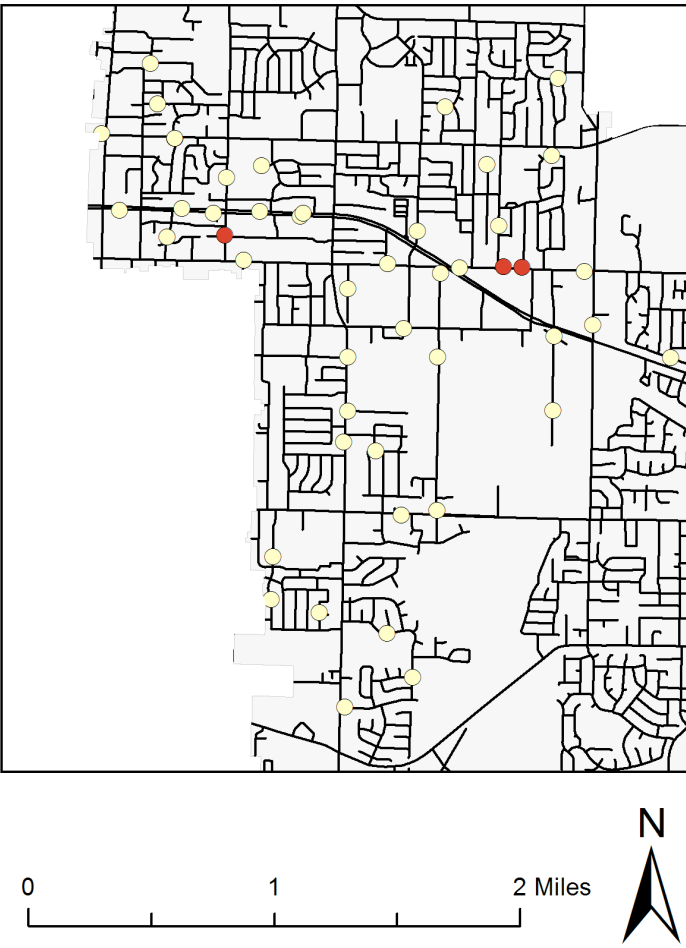

Getis-Ord Gi ${ }^{*}$ Hot Spot Analysis

Legend

Hot Spot Analysis

GiZScore

$<-2.58$ Std. Dev.

- $\quad-2.58--1.96$ Std. Dev.

$-1.96-1.65$ Std. Dev.

$-1.65-1.65$ Std. Dev

(1.65-1.96 Std. Dev.

$1.96-2.58$ Std. Dev.

$>2.58$ Std. Dev.

- Streets

Gresham City Limits

Figure 28a \& 28b. Results from a) the Anselin Local Moran's I cluster and outlier analysis (top) and b) Getis-Ord Gi* hot spot analysis (bottom). Water quality data is taken from the 2009-2010 Gresham Wet Weather study. Utility pole data was collected during August-November 2011. Maps created in ArcGIS Version 10.0. 


\section{DISUCSSION}

The goal of this study is to identify significant characteristics of UIC contributing areas, specifically characteristics of utility poles, that could be used as predictors of high PCP concentration in stormwater. Although there is a considerable amount of variation between the 60 UIC contributing areas and 86 utility poles included in the study, there are some patterns that can be distinguished to aid in future management decisions.

Kennedy/Jenks (2009) demonstrated that streets with greater than 1,000 vehicle trips per day have higher pollutant loads, including PCP, than streets with less than 1,000 trips per day. This study also found statistically significant differences $(\alpha=0.05)$ between the traffic classes. Beyond that, it is less certain if certain street functional classes that fall in the "greater than 1,000 vehicle trips per day" category should be monitored to a greater extent. FIGURE $25 b$ indicates that boulevards and arterials may have higher PCP concentrations in runoff than collectors, and sampling emphasis could be placed on these functional classes. For example, only four sample points were taken from the functional class "boulevard" (all locations on SE Stark Street), however three of the four samples exceeded the current SDWA MCL for PCP.

The spatial analysis also supports the fact that higher traffic streets have greater concentrations of PCP in stormwater. The Local Moran's I indicates that high concentrations of PCP in stormwater are clustered on SE Stark Street near the intersection with E Burnside Street. The spatially dispersed points are also located on or near SE Stark Street, where a high concentration of PCP in stormwater is located closer to lower concentrations of PCP in stormwater samples collected on smaller streets (FIGURE 28a). The hot spot analysis (FIGURE 
28b) further confirms that the highest concentrations of PCP in stormwater are located on or near SE Stark Street.

Utility poles on SE Stark Street tend to have a surface area greater than $150 \mathrm{ft}^{2}$ and be surrounded by a concrete substrate. Most of the utility poles have also been inspected in the last 10 years and have had additional treatment compound infused (assumed by the presence of plastic diffusion plugs). Spearman's $\rho$ rank correlation (TABLE 7) determined that there is a significant positive correlation $(\alpha=0.05)$ between utility pole surface area and PCP concentration in stormwater. Nonparametric comparisons also determined that poles surrounded by concrete lead to a significantly $(\alpha=0.05)$ higher concentration of PCP in stormwater. This is also true for poles with plastic diffusion plugs present. These three factors could explain why high PCP concentrations are clustered on SE Stark Street.

Fundamentally, the source of PCP in stormwater runoff is PCP treatment compound that has leached from wood utility poles. It doesn't have much to do with the amount of traffic on a particular street. FIGURE 24 shows a statistically significant difference $(\alpha=0.05)$ between the number of utility poles located in UIC contributing areas for sites with greater and less than 1,000 vehicle trips per day. Street class can be used as a proxy for the quantity or total surface area of utility poles, but focus should be placed on documenting the characteristics of the utility poles to gain a full understanding of the potential for high PCP concentrations in stormwater.

General characteristics of residential street classes also explain this seeming correlation between street class and number of utility poles in a UIC contributing area. A residential neighborhood is more likely to have tree courts or grassy strips where utility poles could be installed. They are also more likely to have a shorter height and smaller total surface area 
(mean height $_{<1000 \mathrm{TPD}}=39.56 \mathrm{ft}$, mean surface area $_{<1000 \mathrm{TPD}}=115.39 \mathrm{ft}^{2} ;$ mean height $\mathrm{m}_{>1000 \mathrm{TPD}}=$ $48.34 \mathrm{ft}$, mean surface area $>1000 \mathrm{TPD}=163.32 \mathrm{ft}^{2}$ ).

The results of the regression tree analysis for utility pole characteristics indicate that the substrate surrounding the utility pole is the most important indicator of PCP in runoff. This corroborates the findings of the regression tree analysis for contributing area characteristics that total surface area of utility poles surrounded by concrete is the most important indicator of PCP in runoff. For future analysis of contributing area characteristics, it may be easiest to identify the presence or absence of utility poles surrounded by concrete, or the number of poles per basin set in concrete rather than measure the total surface area of each pole.

Other results from the regression tree analysis for utility pole characteristics conclude that the presence of ground staining, age of pole, and visual estimation of treatment compound on the pole could be indicators of high concentration of PCP in runoff. Multi-collinearity likely exists between these variables, especially if the presence and type of diffusion plugs in the pole is taken into account. When plastic diffusion plugs are present, it indicates that additional treatment compound has been injected into the pole in the past 12 years. Likely, this would lead to an increased amount of product leaching from the pole and staining the ground around it.

Additional significant factors identified in this study are minimum distance from the utility pole to the catch basin inlet, total surface area of all utility poles set in concrete in the contributing area, and amount of treatment product visible on the pole. These findings are similar to findings by GSI Water Solutions, Inc. (2011a) of important utility pole characteristics to use as indicators of PCP concentration in stormwater for 70 contributing areas in Portland. 
They derived an empirical equation to relate the PCP concentration of stormwater to the total surface area of poles set in concrete, distance from a catch basin, and surface staining. The most weight was given to the total surface area of poles set in concrete, so that if there were no poles in concrete the equation was equal to zero (GSI, 2011a). This supports the outcome of the two exploratory regression trees, which both determined that utility poles surrounded by concrete were the most significant variable contributing to PCP concentration in stormwater.

A final factor that can affect the amount of PCP treatment compound leaching from utility poles, and thus the concentration of PCP in stormwater is the intensity of the rainfall event and the volume of runoff entering the catch basin inlet. FIGURES $25 a$ and 26 graphically show that the two highest concentrations of PCP in stormwater samples from the 2009-2010 Wet Weather Study were collected during a storm with heavy rainfall intensity.

\section{Limitations of the Study}

Although this study included 60 UIC device contributing areas, the biggest limitation was the relatively small set of water quality data and the time lapse from when the water quality data was collected and when the utility pole data was collected. A major assumption of the study was that the utility poles located in the 60 sites were in the same condition that they were during the $2009-2010$ sample collection. This is probably true for the most part. The last known inspection, when additional treatment compound could be injected into poles, was conducted in 2008 (based on the presence of inspection tags on the poles). However, there was one pole manufactured in 2009 (located in contributing area of UIC-094, PCP concentration $=0.884 \mu \mathrm{g} / \mathrm{L}$ ) and one in 2010 (located in contributing area of UIC-015, PCP concentration = 
$0.449 \mu \mathrm{g} / \mathrm{L})$. It is hard to say when these poles were installed, or what affect they may be having on the PCP concentration in stormwater for those contributing areas.

All comparisons between utility pole or contributing area characteristics were made with only one sample point of PCP concentration. These samples were collected over three months during varying rain intensities, which proved to be a potentially significant factor in the concentration of PCP. UIC-037 was sampled twice because illegally dumped oil was found in the catch basin during the first sample collection. Both concentrations were close to the detection limit, so a PCP concentration of $0.04 \mu \mathrm{g} / \mathrm{L}$ was used in this study. This site, however, did not contain any utility poles.

Site UIC-045, located on SE Stark Street, was the other site sampled twice during the 2009-2010 wet weather study. This was done to verify the high concentrations of PCP found along SE Stark Street. The sample collected during heavy rainfall had a PCP concentration of $6.89 \mu \mathrm{g} / \mathrm{L}$ while the sample collected during light rainfall had a PCP concentration of $0.659 \mu \mathrm{g} / \mathrm{L}$, an order of magnitude difference. The samples also exceed the SWDA MDL in once circumstance and not in the other. Because this was the only site used in the present study with two PCP concentration points, the samples were considered as two distinct data points and a mean was not calculated. The exception was in the spatial analysis, where all tests were run twice. It would have been useful to have multiple samples from each site so that a geometric mean of the PCP concentration could be calculated and used to make comparisons. Due to the nature of the data, non-parametric statistical analysis had to be used. These tests are not very powerful compared to their parametric counterparts. It is also difficult to determine which variable is the best predictor for PCP concentration in runoff because multiple 
regression was not used. Additionally, many of the categorical data sets did not have sufficient numbers in each group to make statistical comparisons between groups. For example, the study found 48 poles manufacturered by Pentafir but only 10 poles manufactured by Taylor Treating, 4 manufactured by DFP, and 2 manufactured by McFarlane Cascade.

\section{RECOMMENDATIONS}

DEQ is in the process of updating the UIC WPCF Municipal Permit Template to reflect the findings of the GSI, Inc. (2011a) report and the maximum discharge limit for PCP will likely change to an effluent discharge limit equal to $10 \mu \mathrm{g} / \mathrm{L}$, it is still important to monitor the concentration of this pollutant in stormwater due to its variability and potential to impact groundwater resources.

The findings of this study suggest that contributing areas with utility poles surrounded by concrete on streets with greater than 1,000 vehicle trips per day have the potential to have greater concentrations of PCP in runoff. Again this apparent correlation between street class and utility pole characteristic should be questioned and future data collection should focus on utility pole characteristics. The streetview function in GoogleEarth could be a useful tool to estimate the extent of utility poles set in concrete in other UIC contributing areas, beginning with high traffic streets. GoogleEarth could also be used to visually estimate the height of the pole (based on the categories in the Methods Section above), which could give an idea of the total surface area.

Given the significantly higher concentrations of PCP in stormwater when utility poles are surrounded by concrete, when new sidewalks are constructed or existing sidewalks are 
repaired on high traffic streets maintain a buffer of soil or vegetation around the pole. This may already be occurring, based on the findings in the contributing area for UIC-011 (3048-W098, E. Burnside and $177^{\text {th }}$, PCP concentration from 2009-2010 study $=0.827 \mu \mathrm{g} / \mathrm{L}$; FIGURE 29). This practice could also occur when new utility poles are installed to replace unsafe poles or to retrofit older pole sites in known high PCP concentration contributing areas.

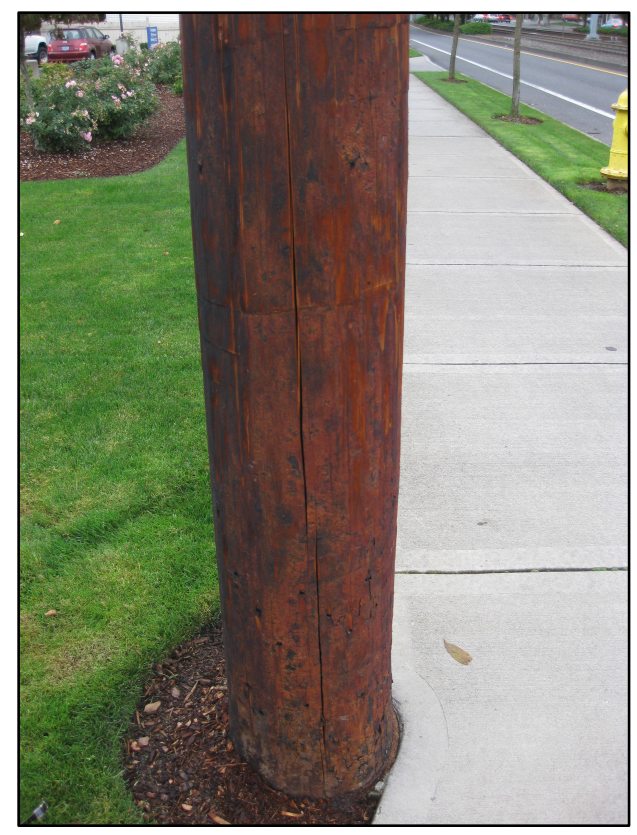

Figure 29. Utility pole located around E. Burnside and NE $177^{\text {th }}$ Ave. outside of Providence Elder Care building. Sidewalk appears to be new with pervious surface left around the majority of the pole.

The local water table should be ten feet below the bottom of a UIC, if the runoff from utility poles is allowed to infiltrate around the pole there should be enough vertical separation for any PCP to attenuate before it would reach groundwater. It should also reduce the total amount of PCP in stormwater entering the UIC, as contributing areas with no poles set in concrete have significantly less PCP in runoff than contributing areas with utility poles set in concrete. This recommendation will likely require collaboration between multiple departments, 
jurisdictions, and agencies, but the outcome will be safe, clean groundwater for future beneficial use.

Additionally, UIC devices located on SE Stark Street, particularly in the area east of the intersection with E Burnside Street, should to be monitored more frequently. High concentrations of PCP in stormwater are clustered in this area, and the groundwater table varies from 10-50 (FIGURE 7). This could be a potential area of concern for groundwater contamination if the parameters of the Fate and Transport tool or BIOSCREEN model are exceeded (See Previous Studies: GSI Water Solutions Report (2011b) for additional information).

Multiple samples should be collected from UIC devices during varying rain intensities to get an accurate representation of the variation in PCP concentration. FIGURE 26 depicts that multiple sites with the surface area of utility poles surrounding concrete exceeding $400 \mathrm{ft}^{2}$ had lower concentrations of PCP in stormwater. These same sites were sampled during light intensity rain events or when it was not raining at all, and may have the potential to leach more PCP during higher rain intensity events. It may also be prudent to sample during summer storm events to see if higher concentrations of PCP are present after it is allowed to "build up" on the utility pole.

Spearman's $\rho$ detected a statistically significant correlation $(\alpha=0.05)$ between pole surface area in a UIC contributing area and PCP concentration in stormwater samples (TABLE 7), and it may be prudent to verify that utility poles located in other UIC contributing areas located on residential streets follow these trends. Again, GoogleEarth could be used to get an idea of pole characteristics instead of performing site visits. 
Finally, given the findings and limitations of the current study, it seems crucial to collect more data both in terms of stormwater samples from the same and different UIC devices as well as the characteristics of utility poles in newly sampled contributing areas. The new sample points and concentrations can be incorporated into the existing GIS layer to see if spatial patterns change with more data points. Also geometric means can be calculated for each sample point, giving a better estimate of the average concentration of PCP entering a specific UIC device. This is similar to the current methods employed by the City of Portland to meet their WPCF permit requirements (Appendix A). 


\section{ACKNOWLEDGEMENTS}

I would like to thank my advisor, Dr. Joe Maser, and the rest of my committee, Torrey Lindbo (City of Gresham) and Dr. Bill Fish (PSU), for all of their help and insight throughout the project development and report writing process. I would especially like to thank Torrey for his assistance and ideas in the data collection and analysis portion of the project. Thank you also to Lynne Kennedy (City of Gresham) for the initial encouragement and enthusiasm for this project and Deanna Foster (City of Gresham) for all of her GIS expertise and assistance with creating the watershed delineation maps for each of the sixty UIC sites. Thanks to the City of Portland, Bureau of Environmental Services for helping with the creation of my field data sheet and sharing the results and lessons learned from their PCP/Utility Pole study. Thanks to Dr. Yangdong Pan (PSU) and PSU Graduate students Jalene Littlejohn, Alieen Miller, and Brian Turner for ideas for appropriate statistical analysis of the data and to the faithful members of the PSU ESM Grad Student Association for helping me prepare for the presentation. Great thanks to Felicia Chapman for making the editing process a bit more enjoyable.

I would also not have been able to complete this project without the support of my great, loving family; especially Jeremy, Norman, and Leeroy. 


\section{APPENDIX A}

City of Portland Exploratory Study \& Current Compliance Monitoring 
The City of Portland received the first and only WPCF permit from ODEQ in June 2005 for its approximately 9,900 UIC devices. The majority of the Portland's UICs are located in east Portland where soils are more porous and have higher infiltration rates (Portland UICMP, 2006a). Prior to receiving the permit, the City of Portland conducted two pilot studies between 2003 and 2005 to characterize stormwater entering UIC devices and to estimate the number of samples that might exceed regulatory limits for a particular analyte. The estimations were then used to calculate the number of UICs that would need to be sampled annually in order to obtain statistically representative water quality data for the entire UIC network (Portland SAP, 2006b).

PCP exceeded the maximum allowable discharge limit (MADL) in the pilot studies $8.1 \%$ of the time. Because PCP is designated as a primary pollutant of concern by the EPA, Portland used this figure in the calculation of a representative sample size under the assumption that it will provide an adequate number of samples to evaluate analytes of less concern. The GRTS survey design was used to identify six panels of 15 sampling locations based on daily traffic volumes (greater than 1,000 trips per day and less than 1,000 trips per day). One panel is stationary and is sampled each year of the permit and the other five panels rotate and are sampled approximately every five years. Five stormwater samples are collected at each location during October to May and the geometric mean concentration is calculated for each analyte (Portland SAP, 2006b).

During fiscal year 2008-2009, five of the 30 sampling locations exceeded the MADL for PCP $(1 \mu \mathrm{g} / \mathrm{L})$ based on the geometric mean concentration. 26 individual samples from 11 UIC locations exceeded the MADL for PCP. The WPCF permit allows the unsaturated zone of the 
subsurface to act as a part of the water quality system as long as adequate vertical separation is present. Using the Groundwater Protection Demo (GWPD) tool to evaluate the reduction of a pollutant in the unsaturated zone, Portland has determined that a vertical separation distance of greater than 5 feet is protective of groundwater resources. Since the UIC devices that exceeded the MADL for PCP had adequate vertical separation, the groundwater was still protected in those areas. These results were similar to the previous three years of wet weather monitoring (Portland UICMP Annual Report, 2009). 


\section{APPENDIX B}

Contributing Area Delineation Procedure \& Example of Contributing Area Delineation Map 


\section{City of Gresham Maps \& Data Services - Procedure \\ Watershed Delineation}

Author: drf

Date: $8 / 25 / 10$

Revised (date

and author):
Reviewer:

Date:

Revised (date

and reviewer):

Purpose/Summary: create a watershed from a single point or points.

Process:

- Start mxd with general area you think will be included in watershed, add LiDAR

- Make graphic polygon of area to keep and convert to shapefile

- For all tool procedures accept the defaults unless otherwise noted.

- Clip DEM- L:\LIDAR\dem_be\dem_navd88. Clip it conservatively [toolbox\Data Management tools \Raster Processing \RasterProccessing\Clip] using above created shapefile (You can always clip more later, you can't put it back) (example of naming conventions that may be given during the delineation process follow) The clipped LiDAR DEM = "clip_dem"

- Create Flow Direction from clipped LiDAR. [toolbox \Spatial Analyst Tools \Hydrology $\backslash F l o w$ Direction] FlowDirection: "clip_dem"="dem_flow"

- Make Sink area from Flow Direction [\Hydrology \Sink] using Flow Direction Sink: "dem_flow" = "sink_flow"

- Create Fill [\Hydrology\Fill] using clipped LiDAR as Input surface raster Fill: "clip_dem"="fill_sink"

- Create second corrected Flow Direction using Fill as Input surface raster Second flow Direction: "fill_sink" = "fill_flow2"

- Input second Flow Direction into Flow Accumulation [\Hydrology\Flow Accumulation] Flow accumulation: "fill_flow2" = "flow_accum" 
- Create Flow Length with second Flow Direction as the Input flow direction raster [Spatial Analyst Tools\Hydrology \Flow Length] Use:downstream

Flow Length : "fill_flow2" = "flow_length"

- Use Snap Pour Point [\Hydrology\Snap Pour Point] to set watershed basin starting points. Input a single or multiple points as a shapefile and Flow Accumulation. I used $50 \mathrm{ft}$ for a snap distance. Snap Pour Point: "flow_accum" = "pour_point"

- Create Watershed using second Flow Direction and Snap Pour Point shapefile. [Spatial Analyst Tools \Hydrology\Watershed]

Watershed: "fill_flow2" + "pour_point" = "new watershed"

- This is your Watershed. Convert raster watershed to polygon, [Toolbox\Conversion Tools \From Raster\Raster to Polygon]

- Now check that there are no other things happening to change the shape of the basin. Are there pipes and inlet/outlets running from outside or inside the basin to the other side of the boundary? If yes, then you are going to need to account for that by either adding to the Snap Pour Points for inlets or cutting out areas for outlets that drain outside the basin, possibly with aerials and contours. Talk this portion over with the requestor of the watershed project.

- If you have to add more Snap Pour Points because of additional inlets outside of basin that are piped inside the basin, you will have to start at the Snap Pour Point and continue on through making an additional watershed polygon and Union the two polygons.

- Do you need to clip to City Limits? Or some other political boundary.

- Make sure you Recalculate Geometry if you need acreage or other total area figure. 


\section{APPENDIX C}

Field Data Collection Sheet \& Instructions 
City of Gresham UIC - Power Pole Data Collection Sheet DATE

\begin{tabular}{|l|l|}
\hline UIC DATA: \\
\hline UIC Unique ID\# & \\
\hline Catch Basin Type & \\
\hline Depth of Sumped Area (inches) & \\
\hline $\begin{array}{l}\text { Sedimentation Manhole } \\
\text { Present }\end{array}$ & \\
\hline
\end{tabular}

\section{FIELD TEAM}

CROSS STREETS:

\begin{tabular}{|c|c|c|c|c|c|}
\hline \multicolumn{6}{|l|}{ POWER POLE DATA: } \\
\hline \multicolumn{6}{|l|}{ Power Pole Unique ID\# } \\
\hline \multicolumn{6}{|l|}{ Inlet to Pole Direction } \\
\hline $\begin{array}{l}\text { GPS Coordinates: } \\
\text { latitude }\end{array}$ & $\mathrm{N} 45^{\circ}$ & $N 45^{\circ}$ & $\mathrm{N} 45^{\circ}$ & $\mathrm{N} 45^{\circ}$ & $\mathrm{N} 45^{\circ}$ \\
\hline longitude & W122 ${ }^{\circ}$ & W122 ${ }^{\circ}$ & W122 ${ }^{\circ}$ & W122 ${ }^{\circ}$ & W122 ${ }^{\circ}$ \\
\hline \multicolumn{6}{|l|}{ Pole Circumference (inches) } \\
\hline \multicolumn{6}{|l|}{ Pole Diameter (inches) } \\
\hline \multicolumn{6}{|l|}{ Pole Height } \\
\hline \multirow{2}{*}{\multicolumn{6}{|c|}{$\begin{array}{l}\text { PGE Power Pole Map \# } \\
\text { PGE Power Pole \# }\end{array}$}} \\
\hline & & & & & \\
\hline \multicolumn{6}{|l|}{ Pole Material (Manufacturer) } \\
\hline \multicolumn{6}{|l|}{ Installation/Manufacture Date } \\
\hline \multicolumn{6}{|l|}{ Inspection Tag Years } \\
\hline \multicolumn{6}{|l|}{ Distance to UIC inlet (feet) } \\
\hline \multicolumn{6}{|l|}{ Distance to Curb, if present } \\
\hline \multicolumn{6}{|l|}{$\begin{array}{l}\text { Surface Immediately } \\
\text { Surrounding Pole }\end{array}$} \\
\hline \multicolumn{6}{|l|}{$\begin{array}{l}\text { Distance to Nearest Impervious } \\
\text { Surface }\end{array}$} \\
\hline \multicolumn{6}{|l|}{$\begin{array}{l}\text { Treatment Product Visible on } \\
\text { Pole }\end{array}$} \\
\hline \multicolumn{6}{|l|}{$\begin{array}{l}\text { Treatment Compound on } \\
\text { Ground }\end{array}$} \\
\hline \multicolumn{6}{|l|}{ Pole Appearance } \\
\hline \multicolumn{6}{|l|}{ Diffusion Plugs Present } \\
\hline \# of plugs present & & & & & \\
\hline
\end{tabular}

\begin{tabular}{|l|l|l|l|l|l|}
\hline SURROUNDING AREA DATA: & & & & \\
\hline Adjacent Land Use & & & & & \\
\hline Soil Type & & & & & \\
\hline
\end{tabular}

\section{OTHER NOTES:}




\section{DATA SHEET INSTRUCTIONS}

\begin{tabular}{|c|c|}
\hline UIC DATA & \\
\hline UIC Unique ID\# & City of Gresham System ID \\
\hline Catch Basin Type & $\begin{array}{l}S=\text { Sumped } \\
U=\text { Unsumped }\end{array}$ \\
\hline Depth of Sumped Area & Measure depth in inches using a yard stick \\
\hline $\begin{array}{l}\text { Sedimentation Manhole } \\
\text { Present }\end{array}$ & $\begin{array}{l}Y=Y e s \\
N=\text { No }\end{array}$ \\
\hline
\end{tabular}

\begin{tabular}{|c|c|}
\hline \multicolumn{2}{|l|}{ POWER POLE DATA } \\
\hline Power Pole Unique ID & $\begin{array}{l}\text { Number each power pole in the drainage basin sequentially using the GRTS rank umber in the } \\
\text { following format: UIC-\#\#\#-PP1, etc. }\end{array}$ \\
\hline GPS Coordinate & Latitude and longitude in WGS 84 units \\
\hline Pole Circumference & Measure circumference at breast height using tape measure to the nearest 1" \\
\hline Pole Diameter & Calculate pole diameter using the measured circumference \\
\hline Pole Height & $\begin{array}{l}S=\text { utility pole used for light only. } 20-30^{\prime} \\
M=\text { utility pole used for simple utility connections. May have one cross bar. } 40-50^{\prime} \\
T=\text { utility pole has } 3^{+} \text {transducers at top of pole. My have additional cross bar at a lower height. } 50+\end{array}$ \\
\hline PGE Power Pole Map \# & Record PGE map number listed on PGE ID tag, if present. Tag located on street face of pole. \\
\hline PGE Power Pole \# & Record PGE pole number listed on PGE ID tag, if present. Tag located on street face of pole. \\
\hline $\begin{array}{l}\text { Pole Manufacturer } \\
\text { Information }\end{array}$ & Record pole material or manufacturer, if present. Tag located on either side of pole. \\
\hline $\begin{array}{l}\text { Pole Manufacture / } \\
\text { Installation Year }\end{array}$ & Year manufactured will be on manufacturer tag. If not present, use year installed on PGE tag. \\
\hline Inspection Tag Years & Record each year pole inspected. \\
\hline Distance to UIC Inlet & $\begin{array}{l}\text { Measure from pole to nearest catch basin to } \pm 3 \text { feet. Measure along stormwater flow path parallel } \\
\text { to curb or street. }\end{array}$ \\
\hline Distance to Curb (if present) & Measure perpendicular from pole to edge of curb to \pm 1 inch. \\
\hline $\begin{array}{l}\text { Surface Immediately } \\
\text { Surrounding Pole }\end{array}$ & $\begin{array}{l}C=\text { Wood to concrete } \\
V=\text { Wood to vegetated surface (grass or weeds) } \\
D=\text { Wood to dirt, gravel, bark chips } \\
A=\text { Wood to asphalt } \\
O=\text { Wood to other }\end{array}$ \\
\hline $\begin{array}{l}\text { Distance to Nearest } \\
\text { Impervious Surface }\end{array}$ & Measure perpendicular from pole to nearest impervious surface \pm 1 inch \\
\hline $\begin{array}{l}\text { Treatment Product Visible on } \\
\text { Pole }\end{array}$ & $\begin{array}{l}H=\text { Heavily treated: pole surface has runs, drips, seeps of wood treatment } \\
M=\text { Medium: treatment apparent from staining, oily appearance } \\
L=\text { No recent treatment apparent: gray and weathered appearance } \\
O=\text { Other...describe in comments }\end{array}$ \\
\hline $\begin{array}{l}\text { Treatment Compound on } \\
\text { Ground }\end{array}$ & $\begin{array}{l}Y=\text { Yes } \\
N=\text { No } \\
\text { If yes, indicate radius of compound to } \pm 1 \text { inch. }\end{array}$ \\
\hline Pole Appearance & $\begin{array}{l}J=\text { Juvenile: pole surface appears fairly smooth with uniform color. From appearance pole appears } \\
\text { relatively young. } \\
M=\text { Mature: age of pole can't be estimated. Pole surface appears slightly weathered, some cracking } \\
\text { and color variation possible. Doesn't fit in one of the other categories } \\
W=\text { Weathered: pole surface appears aged from color and cracked, splintered, and/or dry }\end{array}$ \\
\hline Diffusion Plugs Present & $\begin{array}{l}\text { Note whether diffusion plugs are present in the pole to indicate field treatement, material of the } \\
\text { plugs if not plastic, and number of plugs }\end{array}$ \\
\hline
\end{tabular}


APPENDIX D

Comprehensive Utility Pole Data for 60 UIC Contributing Areas \& Soil Complexes 


\begin{tabular}{|c|c|c|c|c|c|c|c|c|c|c|}
\hline GRTS Rank & $\begin{array}{l}\text { Power Pole } \\
\text { Unique ID }\end{array}$ & System ID & Penta (ug/L) & $\begin{array}{l}\text { Catch Basin } \\
\text { Type }\end{array}$ & Sed Manhole & Functional Class & GPS Latitude & GPS Longitude & \begin{tabular}{|l|} 
Pole \\
Circumference \\
(ft)
\end{tabular} & $\begin{array}{l}\text { Pole Height } \\
(\mathrm{ft})\end{array}$ \\
\hline UIC-001 & UIC-001-PP1 & 3349-J-088 & 0.04 & SUMPED & NO & RESIDENTIAL & N45 $29.817^{\prime}$ & W122²8.183' & 1.31 & 33 \\
\hline \multirow[t]{2}{*}{ UIC-002 } & UIC-002-PP1 & 3152-F-032 & 0.04 & SUMPED & YES & RESIDENTIAL & N45웅.014' & W122 $26.625^{\prime}$ & 3.08 & 45 \\
\hline & UIC-002-PP2 & & & & & & $\mathrm{N} 45^{\circ} 31.051^{\prime}$ & W122 $26.621^{\prime}$ & 3.17 & 45 \\
\hline \multirow[t]{3}{*}{ UIC-003 } & UIC-003-PP1 & 3047-W-004 & 0.348 & SUMPED & NO & ARTERIAL & $\mathrm{N} 45^{\circ} 31.580^{\prime}$ & W122ํํ․ $2942^{\prime}$ & 3.17 & 58 \\
\hline & UIC-003-PP2 & & & & & & N45ํ31.583' & W122 $29.482^{\prime}$ & 3.08 & 58 \\
\hline & UIC-003-PP3 & & & & & & N45ํ31.583' & W122을 $29.521^{\prime}$ & 3 & 58 \\
\hline UIC-004 & UIC-004-PPO & 3748-W-029 & 0.0962 & SUMPED & NO & RESIDENTIAL & & & & \\
\hline UIC-007 & UIC-007-PPO & 3047-W-032 & 0.0451 & SUMPED & NO & RESIDENTIAL & & & & \\
\hline UIC-008 & UIC-008-PPO & 3249-W-045 & 0.0926 & SUMPED & NO & RESIDENTIAL & & & & \\
\hline UIC-009 & UIC-009-PPO & 3050-W-057 & 0.04 & SUMPED & NO & RESIDENTIAL & & & & \\
\hline \multirow[t]{2}{*}{ UIC-010 } & UIC-010-PP1 & 3153-F-051 & 0.0939 & SUMPED & NO & RESIDENTIAL & $\mathrm{N} 45^{\circ} 31.053$ & W122 $25.467^{\prime}$ & & 33 \\
\hline & UIC-010-PP2 & & & & & & $\mathrm{N} 45^{\circ} 31.025^{\prime}$ & W122 $25.495^{\prime}$ & 3.08 & 33 \\
\hline \multirow[t]{3}{*}{ UIC-011 } & UIC-011-PP1 & 3048-W-098 & 0.827 & SUMPED & NO & COLLECTOR & $\mathrm{N} 45^{\circ} 31.328^{\prime}$ & W122 $28.776^{\prime}$ & 3.5 & 45 \\
\hline & UIC-011-PP2 & & & & & & $\mathrm{N} 45^{\circ} 31.327^{\prime}$ & W122 $28.838^{\prime}$ & 3.5 & 45 \\
\hline & UIC-011-PP3 & & & & & & $\mathrm{N} 45^{\circ} 31.325^{\prime}$ & W122ํ․ $28.868^{\prime}$ & & 45 \\
\hline \multirow[t]{2}{*}{ UIC-012 } & UIC-012-PP1 & 3249-W-048 & 1.06 & SUMPED & YES & COLLECTOR & N45 $30.274^{\prime}$ & W122 $28.069^{\prime}$ & 4.42 & 58 \\
\hline & UIC-012-PP2 & & & & & & $\mathrm{N} 45^{\circ} 30.276^{\prime}$ & W1222․․043' & 2.17 & 45 \\
\hline UIC-013 & UIC-013-PPO & 3050-W-028 & 0.04 & SUMPED & NO & RESIDENTIAL & & & & \\
\hline UIC-014 & UIC-014-PP1 & 3153-F-041 & 0.162 & SUMPED & $\mathrm{NO}$ & ARTERIAL & ${\mathrm{N} 45^{\circ} 30.798^{\prime}}$ & W122ํํ‥022' & 3.17 & 45 \\
\hline \multirow[t]{5}{*}{ UIC-015 } & UIC-015-PP1 & 3149-W-079 & 0.884 & UNSUMPED & YES & COLLECTOR & $\mathrm{N} 45^{\circ} 31.132^{\prime}$ & W122ํ․․․․ & 3.17 & 45 \\
\hline & UIC-015-PP2 & & & & & & N45ํ31.115' & W122 $28.090^{\prime}$ & 3.67 & 45 \\
\hline & UIC-015-PP3 & & & & & & N45운.112' & W122 $28.087^{\prime}$ & 3 & 45 \\
\hline & UIC-015-PP4 & & & & & & ${\mathrm{N} 45^{\circ} 31.090^{\prime}}$ & 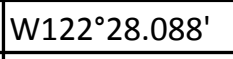 & 3 & 45 \\
\hline & UIC-015-PP5 & & & & & & ${\mathrm{N} 45^{\circ} 31.056^{\prime}}$ & W122ํ28.078' & 3.67 & 45 \\
\hline UIC-017 & UIC-017-PP1 & 3449-J-006 & 0.04 & SUMPED & NO & RESIDENTIAL & $\mathrm{N} 45^{\circ} 29.704^{\prime}$ & W122 $28.168^{\prime}$ & 2.5 & 33 \\
\hline UIC-018 & UIC-018-PP0 & 3151-F-054 & 0.04 & SUMPED & NO & RESIDENTIAL & & & & \\
\hline \multirow[t]{3}{*}{ UIC-019 } & UIC-019-PP1 & 2947-W-059 & 0.04 & SUMPED & NO & RESIDENTIAL & N45ํ31.664' & W122 $29.497^{\prime}$ & 2.17 & 33 \\
\hline & UIC-019-PP2 & & & & & & $\mathrm{N} 45^{\circ} 31.663$ & W122 $29.551^{\prime}$ & 2.17 & 33 \\
\hline & UIC-019-PP3 & & & & & & $\mathrm{N} 45^{\circ} 31.657$ & W122 29.596 & 2.17 & 33 \\
\hline UIC-020 & UIC-020-PPO & 3348-W-015 & 0.04 & SUMPED & NO & RESIDENTIAL & & & & \\
\hline
\end{tabular}




\begin{tabular}{|c|c|c|c|c|c|c|c|c|c|c|}
\hline GRTS Rank & $\begin{array}{l}\text { Power Pole } \\
\text { Unique ID }\end{array}$ & $\begin{array}{l}\text { Surface } \\
\text { Area (ft2) }\end{array}$ & $\begin{array}{l}\text { PGE Power } \\
\text { Pole Map }\end{array}$ & $\begin{array}{l}\text { PGE Power } \\
\text { Pole Number }\end{array}$ & Pole Manufacturer & $\begin{array}{l}\text { Pole } \\
\text { Manufacture } \\
\text { Date }\end{array}$ & $\begin{array}{l}\text { Last } \\
\text { Inspection }\end{array}$ & $\begin{array}{l}\text { Distance to } \\
\text { UIC Inlet (ft) }\end{array}$ & $\begin{array}{l}\text { Distance to } \\
\text { Curb (ft) }\end{array}$ & $\begin{array}{l}\text { Substrate } \\
\text { Surrounding } \\
\text { Pole }\end{array}$ \\
\hline UIC-001 & UIC-001-PP1 & 43.23 & A1308B & 1276 & & & & 495 & 1.17 & DIRT \\
\hline \multirow[t]{2}{*}{ UIC-002 } & UIC-002-PP1 & 138.6 & & & PENTAFIR & 1966 & 1989 & 225 & 2.08 & DIRT \\
\hline & UIC-002-PP2 & 142.65 & D134A & 7062 & PENTAFIR & 1965 & 1989 & 54 & 2.08 & VEGETATION \\
\hline \multirow[t]{3}{*}{ UIC-003 } & UIC-003-PP1 & 183.86 & A1331C & 2990 & & 1960 & 2008 & 10 & 1.33 & CONCRETE \\
\hline & UIC-003-PP2 & 178.64 & A1331 & 2989 & CREOFIR & 1960 & 2008 & 157 & 1.25 & CONCRETE \\
\hline & UIC-003-PP3 & 174 & A1331C & 2988 & & 1960 & 2008 & 310 & 1.33 & CONCRETE \\
\hline UIC-004 & UIC-004-PPO & & & & & & & & & \\
\hline UIC-007 & UIC-007-PPO & & & & & & & & & \\
\hline UIC-008 & UIC-008-PPO & & & & & & & & & \\
\hline UIC-009 & UIC-009-PPO & & & & & & & & & \\
\hline \multirow[t]{2}{*}{ UIC-010 } & UIC-010-PP1 & 43.542474 & D133A & 12183 & & 1978 & & 81 & 1.25 & OTHER \\
\hline & UIC-010-PP2 & 101.64 & D133B & 14100 & & 1986 & & 171 & 1.58 & DIRT \\
\hline \multirow[t]{3}{*}{ UIC-011 } & UIC-011-PP1 & 157.5 & A1331D & 502 & DFP & & 2008 & 24 & 10 & DIRT \\
\hline & UIC-011-PP2 & 157.5 & A1331 & 504 & DFP & & 2008 & 189 & 14.58 & DIRT \\
\hline & UIC-011-PP3 & 0 & & & & & & 321 & 11 & DIRT \\
\hline \multirow[t]{2}{*}{ UIC-012 } & UIC-012-PP1 & 256.36 & D1305C & 1660 & TAYLOR TREATING & 1999 & 2008 & 15 & 0.83 & CONCRETE \\
\hline & UIC-012-PP2 & 97.65 & D135C & 4249 & PENTAFIR & 1984 & 2007 & 135 & 1.42 & VEGETATION \\
\hline UIC-013 & UIC-013-PPO & & & & & & & & & \\
\hline UIC-014 & UIC-014-PP1 & 142.65 & D137D & 6342 & PENTAFIR & 1963 & 2007 & 66 & 7.25 & DIRT \\
\hline \multirow[t]{5}{*}{ UIC-015 } & UIC-015-PP1 & 142.65 & D135B & 13598 & PENTAFIR & 1983 & 2007 & 18 & 1.17 & CONCRETE \\
\hline & UIC-015-PP2 & 165.15 & D1305B & 455 & MCFARLANE CASCADE & 2009 & & 63 & 1.33 & CONCRETE \\
\hline & UIC-015-PP3 & 135 & D135B & 2001 & PENTAFIR & 1964 & 1989 & 114 & 1.33 & CONCRETE \\
\hline & UIC-015-PP4 & 135 & D135B & 236 & PENTAFIR & 1964 & 1989 & 255 & 1.08 & CONCRETE \\
\hline & UIC-015-PP5 & 165.15 & D135B & 3020 & TAYLOR TREATING & 1994 & & 420 & 0.58 & DIRT \\
\hline UIC-017 & UIC-017-PP1 & 82.5 & & & & & 1993 & 75 & 0.83 & DIRT \\
\hline UIC-018 & UIC-018-PPO & & & & & & & & & \\
\hline \multirow[t]{3}{*}{ UIC-019 } & UIC-019-PP1 & 71.61 & A1331B & 5102 & PENTAFIR & 1973 & 1993 & 144 & 0.83 & VEGETATION \\
\hline & UIC-019-PP2 & 71.61 & A1331B & 5101 & PENTAFIR & 1973 & 1993 & 60 & 0.92 & CONCRETE \\
\hline & UIC-019-PP3 & 71.61 & A1331B & 5100 & PENTAFIR & 1973 & 1993 & 246 & 1.5 & VEGETATION \\
\hline UIC-020 & UIC-020-PPO & & & & & & & & & \\
\hline
\end{tabular}




\begin{tabular}{|c|c|c|c|c|c|c|c|c|c|c|}
\hline GRTS Rank & $\begin{array}{l}\text { Power Pole } \\
\text { Unique ID }\end{array}$ & $\begin{array}{l}\text { Distance to } \\
\text { Impervious } \\
\text { Surface (ft) }\end{array}$ & $\begin{array}{l}\text { Visual Est. of } \\
\text { Product on } \\
\text { Pole }\end{array}$ & $\begin{array}{l}\text { Treatment } \\
\text { Compound on } \\
\text { Ground }\end{array}$ & \begin{tabular}{|l} 
Radius \\
Treatment \\
Compound \\
Ground (in)
\end{tabular} & $\begin{array}{l}\text { Pole } \\
\text { Appearance }\end{array}$ & $\begin{array}{l}\text { Diffusion } \\
\text { Plugs } \\
\text { Present }\end{array}$ & $\begin{array}{l}\text { Number } \\
\text { Diffusion } \\
\text { Plugs }\end{array}$ & Adjacent Land Use & $\begin{array}{l}\text { Soil } \\
\text { Complex }\end{array}$ \\
\hline UIC-001 & UIC-001-PP1 & 0.58 & LOW & NO & & WEATHERED & NO & & RESIDENTIAL & $29 \mathrm{~A}$ \\
\hline \multirow[t]{2}{*}{ UIC-002 } & UIC-002-PP1 & 1.58 & MEDIUM & YES & 2 & MATURE & WOOD & 3 & RESIDENTIAL & $26 B$ \\
\hline & UIC-002-PP2 & 1.67 & MEDIUM & NO & & WEATHERED & WOOD & 2 & RESIDENTIAL & $26 B$ \\
\hline \multirow[t]{3}{*}{ UIC-003 } & UIC-003-PP1 & NA & $\mathrm{HIGH}$ & NO & & MATURE & PLASTIC & 5 & RESIDENTIAL & $30 \mathrm{~A}$ \\
\hline & UIC-003-PP2 & NA & LOW & NO & & WEATHERED & PLASTIC & 4 & RESIDENTIAL & $30 \mathrm{~A}$ \\
\hline & UIC-003-PP3 & NA & MEDIUM & YES & 1.5 & MATURE & PLASTIC & 5 & RESIDENTIAL & $30 \mathrm{~A}$ \\
\hline UIC-004 & UIC-004-PPO & & & & & & & & & $30 \mathrm{~A}$ \\
\hline UIC-007 & UIC-007-PPO & & & & & & & & & $30 \mathrm{~A}$ \\
\hline UIC-008 & UIC-008-PPO & & & & & & & & & $30 \mathrm{~A}$ \\
\hline UIC-009 & UIC-009-PPO & & & & & & & & & $30 \mathrm{~A}$ \\
\hline \multirow[t]{2}{*}{ UIC-010 } & UIC-010-PP1 & 0.71 & LOW & NO & & WEATHERED & NO & & RESIDENTIAL & $25 B$ \\
\hline & UIC-010-PP2 & 1.08 & LOW & NO & & WEATHERED & NO & & RESIDENTIAL & $25 \mathrm{~B}$ \\
\hline \multirow[t]{3}{*}{ UIC-011 } & UIC-011-PP1 & 6 & HIGH & NO & & MATURE & PLASTIC & 5 & COMMERCIAL & $30 \mathrm{~A}$ \\
\hline & UIC-011-PP2 & 6.25 & MEDIUM & NO & & MATURE & PLASTIC & 5 & COMMERCIAL & $30 \mathrm{~A}$ \\
\hline & UIC-011-PP3 & 5 & MEDIUM & NO & & MATURE & PLASTIC & & RESIDENTIAL & $30 \mathrm{~A}$ \\
\hline \multirow[t]{2}{*}{ UIC-012 } & UIC-012-PP1 & NA & MEDIUM & NO & & JUVENILE & PLASTIC & 4 & RESIDENTIAL & $30 \mathrm{~A}$ \\
\hline & UIC-012-PP2 & 0.92 & MEDIUM & NO & & MATURE & PLASTIC & 4 & RESIDENTIAL & $30 \mathrm{~A}$ \\
\hline UIC-013 & UIC-013-PP0 & & & & & & & & & $30 \mathrm{~A}$ \\
\hline UIC-014 & UIC-014-PP1 & 1.25 & MEDIUM & NO & & WEATHERED & PLASTIC & 4 & RESIDENTIAL & $26 \mathrm{~B}$ \\
\hline \multirow[t]{5}{*}{ UIC-015 } & UIC-015-PP1 & NA & MEDIUM & YES & 4 & WEATHERED & PLASTIC & 3 & COMMERCIAL & $30 \mathrm{~A}$ \\
\hline & UIC-015-PP2 & NA & $\mathrm{HIGH}$ & YES & 10 & JUVENILE & NO & & RESIDENTIAL & $30 \mathrm{~A}$ \\
\hline & UIC-015-PP3 & NA & LOW & NO & & WEATHERED & WOOD & 4 & RESIDENTIAL & $30 \mathrm{~A}$ \\
\hline & UIC-015-PP4 & NA & MEDIUM & NO & & WEATHERED & WOOD & 4 & RESIDENTIAL & $30 \mathrm{~A}$ \\
\hline & UIC-015-PP5 & 0.08 & MEDIUM & YES & 1 & MATURE & NO & & RESIDENTIAL & $30 \mathrm{~A}$ \\
\hline UIC-017 & UIC-017-PP1 & 0.25 & LOW & NO & & WEATHERED & NO & & RESIDENTIAL & $29 \mathrm{~A}$ \\
\hline UIC-018 & UIC-018-PP0 & & & & & & & & & $26 B$ \\
\hline \multirow[t]{3}{*}{ UIC-019 } & UIC-019-PP1 & 2.17 & MEDIUM & YES & 9 & WEATHERED & WOOD & 3 & RESIDENTIAL & $30 \mathrm{~A}$ \\
\hline & UIC-019-PP2 & NA & LOW & NO & & MATURE & WOOD & 3 & RESIDENTIAL & $30 \mathrm{~A}$ \\
\hline & UIC-019-PP3 & 1.08 & LOW & NO & & MATURE & WOOD & 3 & RESIDENTIAL & $30 \mathrm{~A}$ \\
\hline UIC-020 & UIC-020-PPO & & & & & & & & & $30 \mathrm{~A}$ \\
\hline
\end{tabular}




\begin{tabular}{|c|c|c|c|c|c|c|c|c|c|c|}
\hline GRTS Rank & $\begin{array}{l}\text { Power Pole } \\
\text { Unique ID }\end{array}$ & System ID & Penta (ug/L) & $\begin{array}{l}\text { Catch Basin } \\
\text { Type }\end{array}$ & Sed Manhole & Functional Class & GPS Latitude & GPS Longitude & \begin{tabular}{|l|} 
Pole \\
Circumference \\
(ft)
\end{tabular} & $\begin{array}{l}\text { Pole Height } \\
(\mathrm{ft})\end{array}$ \\
\hline \multirow[t]{3}{*}{ UIC-021 } & UIC-021-PP1 & 3055-B-027 & 0.504 & SUMPED & NO & ARTERIAL & $\mathrm{N} 45^{\circ} 31.279^{\prime}$ & W122 $24.775^{\prime}$ & 3.5 & 45 \\
\hline & UIC-021-PP2 & & & & & & $\mathrm{N} 45^{\circ} 31.255^{\prime}$ & W122²4.758' & 3.83 & 45 \\
\hline & UIC-021-PP3 & & & & & & $\mathrm{N} 45^{\circ} 31.223^{\prime}$ & W122 $24.744^{\prime}$ & 3.83 & 45 \\
\hline \multirow[t]{2}{*}{ UIC-022 } & UIC-022-PP1 & 3153-F-021 & 0.147 & SUMPED & NO & ARTERIAL & $\mathrm{N} 45^{\circ} 31.067^{\prime}$ & W122²6.040' & 3.5 & 45 \\
\hline & UIC-022-PP2 & & & & & & N45 $31.103^{\prime}$ & W122²6.037' & 4.08 & 45 \\
\hline UIC-023 & UIC-023-PP1 & 3047-W-109 & 0.197 & SUMPED & NO & COLLECTOR & $\mathrm{N} 45^{\circ} 31.319^{\prime}$ & W122²9.194' & 3.92 & 58 \\
\hline UIC-024 & UIC-024-PP1 & 3249-W-026 & 0.0597 & SUMPED & NO & RESIDENTIAL & $\mathrm{N} 45^{\circ} 30.489^{\prime}$ & W122ํ28.835' & 2.08 & 33 \\
\hline UIC-025 & UIC-025-PPO & 3050-W-050 & 0.04 & SUMPED & NO & RESIDENTIAL & & & & \\
\hline \multirow[t]{2}{*}{ UIC-028 } & UIC-028-PP1 & 3349-W-056 & 0.123 & SUMPED & YES & ARTERIAL & $\mathrm{N} 45^{\circ} 30.268^{\prime}$ & W122²8.228' & 3 & 33 \\
\hline & UIC-028-PP2 & & & & & & $\mathrm{N} 45^{\circ} 30.259^{\prime}$ & W122²8.211' & 2.83 & 45 \\
\hline \multirow[t]{3}{*}{ UIC-029 } & UIC-029-PP1 & $3150-F-010$ & 0.133 & SUMPED & NO & RESIDENTIAL & $\mathrm{N} 45^{\circ} 30.882^{\prime}$ & W122 $27.514^{\prime}$ & 3.17 & 45 \\
\hline & UIC-029-PP2 & & & & & & $\mathrm{N} 45^{\circ} 30.892^{\prime}$ & W122²7.508' & 3.42 & 45 \\
\hline & UIC-029-PP3 & & & & & & $\mathrm{N} 45^{\circ} 30.908^{\prime}$ & W122 $27.510^{\prime}$ & 4.17 & 45 \\
\hline UIC-030 & UIC-030-PPO & 3152-F-082 & 0.04 & SUMPED & YES & RESIDENTIAL & & & & \\
\hline UIC-031 & UIC-031-PP1 & 3149-W-042 & 0.102 & SUMPED & NO & RESIDENTIAL & N45 $30.930^{\prime}$ & W122²8.259' & 2.92 & 45 \\
\hline UIC-032 & UIC-032-PPO & 2947-W-008 & 0.04 & SUMPED & NO & RESIDENTIAL & & & & \\
\hline UIC-034 & UIC-034-PPO & $3152-F-050$ & 0.04 & SUMPED & NO & RESIDENTIAL & & & & \\
\hline \multirow[t]{3}{*}{ UIC-035 } & UIC-035-PP1 & 2949-W-042 & 0.04 & SUMPED & NO & RESIDENTIAL & $\mathrm{N} 45^{\circ} 31.730^{\prime}$ & W122 $28.156^{\prime}$ & 2.83 & 45 \\
\hline & UIC-035-PP2 & & & & & & $\mathrm{N} 45^{\circ} 31.733^{\prime}$ & W122 $28.122^{\prime}$ & 2.83 & 45 \\
\hline & UIC-035-PP3 & & & & & & $\mathrm{N} 45^{\circ} 31.721^{\prime}$ & W122²8.107' & 2.92 & 33 \\
\hline UIC-036 & UIC-036-PP1 & 3149-W-015 & 0.172 & SUMPED & YES & COLLECTOR & $\mathrm{N} 45^{\circ} 30.818^{\prime}$ & W122 $28.089^{\prime}$ & & 33 \\
\hline UIC-037 & UIC-037-PPO & 3155-K-041 & 0.04 & SUMPED & YES & RESIDENTIAL & & & & \\
\hline UIC-038 & UIC-038-PPO & $3052-F-020$ & 0.04 & SUMPED & YES & RESIDENTIAL & & & & \\
\hline UIC-039 & UIC-039-PP1 & 3048-W-014 & 0.223 & SUMPED & NO & ARTERIAL & $\mathrm{N} 45^{\circ} 31.155^{\prime}$ & W122 $29.113^{\prime}$ & 3 & 58 \\
\hline UIC-040 & UIC-040-PPO & 3348-W-011 & 0.04 & SUMPED & NO & RESIDENTIAL & & & & \\
\hline UIC-041 & UIC-041-PP1 & 3149-W-019 & 2.6 & SUMPED & NO & BOULEVARD & $\mathrm{N} 45^{\circ} 31.142^{\prime}$ & W122²8.014' & 4.33 & 58 \\
\hline UIC-042 & UIC-042-PPO & $3152-F-058$ & 0.04 & SUMPED & NO & RESIDENTIAL & & & & \\
\hline UIC-043 & UIC-043-PPO & 3049-W-039 & 0.1 & SUMPED & NO & RESIDENTIAL & & & & \\
\hline \multirow[t]{2}{*}{ UIC-045 } & UIC-045-PP1 & 3050-W-019 & 6.89 / 0.659 & SUMPED & NO & BOULEVARD & $\mathrm{N} 45^{\circ} 31.151^{\prime}$ & W122 $27.672^{\prime}$ & 4.08 & 45 \\
\hline & UIC-045-PP2 & & & & & & N453․․153' & W122 27.706 & 3 & 33 \\
\hline UIC-046 & UIC-046-PPO & 3048-W-081 & 0.04 & SUMPED & NO & RESIDENTIAL & & & & \\
\hline
\end{tabular}




\begin{tabular}{|c|c|c|c|c|c|c|c|c|c|c|}
\hline GRTS Rank & $\begin{array}{l}\text { Power Pole } \\
\text { Unique ID }\end{array}$ & $\begin{array}{l}\text { Surface } \\
\text { Area (ft2) }\end{array}$ & $\begin{array}{l}\text { PGE Power } \\
\text { Pole Map }\end{array}$ & \begin{tabular}{|l} 
PGE Power \\
Pole Number
\end{tabular} & Pole Manufacturer & $\begin{array}{l}\text { Pole } \\
\text { Manufacture } \\
\text { Date }\end{array}$ & \begin{tabular}{|l} 
Last \\
Inspection
\end{tabular} & $\begin{array}{l}\text { Distance to } \\
\text { UIC Inlet (ft) }\end{array}$ & $\begin{array}{l}\text { Distance to } \\
\text { Curb }(\mathrm{ft})\end{array}$ & $\begin{array}{l}\text { Substrate } \\
\text { Surrounding } \\
\text { Pole }\end{array}$ \\
\hline \multirow{2}{*}{ UIC-021 } & UIC-021-PP2 & 172.35 & A1335C & 3370 & PENTAFIR & 1990 & 2008 & 207 & 4.67 & DIRT \\
\hline & UIC-021-PP3 & 172.35 & A1335C & 3369 & PENTAFIR & 1990 & 2008 & 426 & 4.83 & CONCRETE \\
\hline UIC-023 & UIC-023-PP1 & 227.36 & A1331C & 1610 & & 1983 & 2002 & 111 & 2.92 & CONCRETE \\
\hline UIC-024 & UIC-024-PP1 & 68.64 & D1305C & 8408 & PENTAFIR & 1971 & 1997 & 30 & 1.5 & VEGETATION \\
\hline UIC-025 & UIC-025-PPO & & & & & & & & & \\
\hline \multirow[t]{2}{*}{ UIC-028 } & UIC-028-PP1 & 99 & & & PENTAFIR & 1968 & & 66 & 1.08 & VEGETATION \\
\hline & UIC-028-PP2 & 127.35 & D138 & 1967 & PENTAFIR & 1960 & 1989 & 66 & 18.42 & VEGETATION \\
\hline UIC-031 & UIC-031-PP1 & 131.4 & D135B & 6114 & PENTAFIR & 1962 & 1989 & 15 & 1.08 & VEGETATION \\
\hline UIC-032 & UIC-032-PPO & & & & & & & & & \\
\hline UIC-034 & UIC-034-PPO & & & & & & & & & \\
\hline \multirow[t]{3}{*}{ UIC-035 } & UIC-035-PP1 & 127.35 & A1332B & 4834 & PENTAFIR & 1955 & 1993 & 321 & 1.25 & DIRT \\
\hline & UIC-035-PP2 & 127.35 & A1332 & 2268 & PENTAFIR & 1955 & 1989 & 198 & 1.25 & VEGETATION \\
\hline & UIC-035-PP3 & 96.36 & A1332B & 4835 & PENTAFIR & 1955 & 1993 & 102 & 1.25 & VEGETATION \\
\hline UIC-036 & UIC-036-PP1 & 0 & & & & & & & 16 & DIRT \\
\hline UIC-037 & UIC-037-PPO & & & & & & & & & \\
\hline UIC-038 & UIC-038-PPO & & & & & & & & & \\
\hline UIC-039 & UIC-039-PP1 & 174 & A1331D & 3087 & PENTAFIR & 1975 & 2008 & 150 & 5.92 & CONCRETE \\
\hline UIC-040 & UIC-040-PP0 & & & & & & & & & \\
\hline
\end{tabular}




\begin{tabular}{|c|c|c|c|c|c|c|c|c|c|c|}
\hline GRTS Rank & $\begin{array}{l}\text { Power Pole } \\
\text { Unique ID }\end{array}$ & $\begin{array}{l}\text { Distance to } \\
\text { Impervious } \\
\text { Surface (ft) }\end{array}$ & \begin{tabular}{|l} 
Visual Est. of \\
Product on \\
Pole
\end{tabular} & $\begin{array}{l}\text { Treatment } \\
\text { Compound on } \\
\text { Ground }\end{array}$ & \begin{tabular}{|l|} 
Radius \\
Treatment \\
Compound \\
Ground (in)
\end{tabular} & $\begin{array}{l}\text { Pole } \\
\text { Appearance }\end{array}$ & \begin{tabular}{|l} 
Diffusion \\
Plugs \\
Present
\end{tabular} & \begin{tabular}{|l|} 
Number \\
Diffusion \\
Plugs
\end{tabular} & Adjacent Land Use & $\begin{array}{l}\text { Soil } \\
\text { Complex }\end{array}$ \\
\hline \multirow[t]{3}{*}{ UIC-021 } & UIC-021-PP1 & 0.75 & MEDIUM & NO & & MATURE & PLASTIC & 3 & RESIDENTIAL & $29 A$ \\
\hline & UIC-021-PP2 & 0.25 & LOW & NO & & MATURE & PLASTIC & 5 & RESIDENTIAL & $29 A$ \\
\hline & UIC-021-PP3 & NA & MEDIUM & YES & 1 & MATURE & PLASTIC & 6 & COMMERCIAL & $29 A$ \\
\hline \multirow[t]{2}{*}{ UIC-022 } & UIC-022-PP1 & 1.33 & $\mathrm{HIGH}$ & NO & & JUVENILE & PLASTIC & 4 & COMMERCIAL & $26 \mathrm{~A}$ \\
\hline & UIC-022-PP2 & 3.17 & $\mathrm{HIGH}$ & NO & & JUVENILE & PLASTIC & 7 & COMMERCIAL & $26 \mathrm{~A}$ \\
\hline UIC-023 & UIC-023-PP1 & NA & MEDIUM & YES & 2 & MATURE & PLASTIC & 8 & RESIDENTIAL & $30 \mathrm{~A}$ \\
\hline UIC-024 & UIC-024-PP1 & 1 & $\mathrm{HIGH}$ & NO & & MATURE & WOOD & 4 & RESIDENTIAL & $30 \mathrm{~A}$ \\
\hline UIC-025 & UIC-025-PPO & & & & & & & & & $30 \mathrm{~A}$ \\
\hline \multirow[t]{2}{*}{ UIC-028 } & UIC-028-PP1 & 0.67 & MEDIUM & NO & & WEATHERED & WOOD & 1 & RESIDENTIAL & $30 \mathrm{~A}$ \\
\hline & UIC-028-PP2 & 18 & MEDIUM & NO & & WEATHERED & WOOD & 2 & RESIDENTIAL & $30 \mathrm{~A}$ \\
\hline \multirow[t]{3}{*}{ UIC-029 } & UIC-029-PP1 & 3.75 & $\mathrm{HIGH}$ & NO & & MATURE & NO & & INDUSTRIAL & $30 \mathrm{~A}$ \\
\hline & UIC-029-PP2 & 3.75 & LOW & NO & & MATURE & PLASTIC & 4 & INDUSTRIAL & $30 \mathrm{~A}$ \\
\hline & UIC-029-PP3 & 3.17 & $\mathrm{HIGH}$ & NO & & MATURE & NO & & INDUSTRIAL & $30 \mathrm{~A}$ \\
\hline UIC-030 & UIC-030-PPO & & & & & & & & & $29 \mathrm{~A}$ \\
\hline UIC-031 & UIC-031-PP1 & 0.67 & LOW & NO & & MATURE & WOOD & 4 & RESIDENTIAL & $30 \mathrm{~A}$ \\
\hline UIC-032 & UIC-032-PPO & & & & & & & & & $30 \mathrm{~A}$ \\
\hline UIC-034 & UIC-034-PPO & & & & & & & & & $26 B$ \\
\hline \multirow[t]{3}{*}{ UIC-035 } & UIC-035-PP1 & 0.75 & LOW & NO & & WEATHERED & WOOD & 3 & RESIDENTIAL & $30 \mathrm{~A}$ \\
\hline & UIC-035-PP2 & 0.75 & LOW & NO & & WEATHERED & WOOD & 3 & RESIDENTIAL & $30 \mathrm{~A}$ \\
\hline & UIC-035-PP3 & 0.75 & MEDIUM & NO & & MATURE & WOOD & 3 & RESIDENTIAL & $30 \mathrm{~A}$ \\
\hline UIC-036 & UIC-036-PP1 & 10 & $\mathrm{HIGH}$ & YES & 3 & MATURE & & & COMMERCIAL & $30 \mathrm{~A}$ \\
\hline UIC-037 & UIC-037-PPO & & & & & & & & & $29 \mathrm{~B}$ \\
\hline UIC-038 & UIC-038-PPO & & & & & & & & & $30 \mathrm{~B}$ \\
\hline UIC-039 & UIC-039-PP1 & NA & $\mathrm{HIGH}$ & YES & 4 & WEATHERED & PLASTIC & 3 & COMMERCIAL & $30 \mathrm{~A}$ \\
\hline UIC-040 & UIC-040-PPO & & & & & & & & & $30 \mathrm{~A}$ \\
\hline UIC-041 & UIC-041-PP1 & NA & $\mathrm{HIGH}$ & YES & 1 & MATURE & PLASTIC & 7 & COMMERCIAL & $30 \mathrm{~A}$ \\
\hline UIC-042 & UIC-042-PPO & & & & & & & & & $29 A$ \\
\hline UIC-043 & UIC-043-PPO & & & & & & & & & $30 \mathrm{~A}$ \\
\hline \multirow[t]{2}{*}{ UIC-045 } & UIC-045-PP1 & NA & MEDIUM & YES & 3 & MATURE & PLASTIC & 5 & COMMERCIAL & $30 \mathrm{~A}$ \\
\hline & UIC-045-PP2 & NA & MEDIUM & NO & & WEATHERED & WOOD & 2 & COMMERCIAL & $30 \mathrm{~A}$ \\
\hline UIC-046 & UIC-046-PPO & & & & & & & & & $30 \mathrm{~A}$ \\
\hline
\end{tabular}




\begin{tabular}{|c|c|c|c|c|c|c|c|c|c|c|}
\hline GRTS Rank & $\begin{array}{l}\text { Power Pole } \\
\text { Unique ID }\end{array}$ & System ID & Penta (ug/L) & $\begin{array}{l}\text { Catch Basin } \\
\text { Type }\end{array}$ & Sed Manhole & Functional Class & GPS Latitude & GPS Longitude & \begin{tabular}{|l|} 
Pole \\
Circumference \\
(ft)
\end{tabular} & $\begin{array}{l}\text { Pole Height } \\
(\mathrm{ft})\end{array}$ \\
\hline \multirow[t]{4}{*}{ UIC-047 } & UIC-047-PP1 & 3149-W-059 & 0.354 & SUMPED & YES & RESIDENTIAL & $\mathrm{N} 45^{\circ} 31.043^{\prime}$ & $\mathrm{W} 122^{\circ} 28.541^{\prime}$ & 2.92 & 45 \\
\hline & UIC-047-PP2 & & & & & & $\mathrm{N} 45^{\circ} 31.039^{\prime}$ & W122 28.543 & 3 & 15 \\
\hline & UIC-047-PP3 & & & & & & $\mathrm{N} 45^{\circ} 31.057^{\prime}$ & W122 $28.545^{\prime}$ & 3.83 & 58 \\
\hline & UIC-047-PP4 & & & & & & $\mathrm{N} 45^{\circ} 31.086^{\prime}$ & W122²8.542' & 4 & 58 \\
\hline \multirow[t]{5}{*}{ UIC-048 } & UIC-048-PP1 & 2946-W-002 & 0.947 & SUMPED & NO & ARTERIAL & $\mathrm{N} 45^{\circ} 31.591^{\prime}$ & 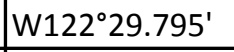 & 4.75 & 58 \\
\hline & UIC-048-PP2 & & & & & & $\mathrm{N} 45^{\circ} 31.590^{\prime}$ & W12229.835' & 4.25 & 58 \\
\hline & UIC-048-PP3 & & & & & & $\mathrm{N} 45^{\circ} 31.590^{\prime}$ & W122²9.876' & 4.75 & 58 \\
\hline & UIC-048-PP4 & & & & & & $\mathrm{N} 45^{\circ} 31.592^{\prime}$ & W122 $29.907^{\prime}$ & 4.17 & 58 \\
\hline & UIC-048-PP5 & & & & & & N45운.592' & W122²9.939' & 4.25 & 58 \\
\hline \multirow[t]{2}{*}{ UIC-049 } & UIC-049-PP1 & 3449-J-073 & 0.17 & UNSUMPED & YES & RESIDENTIAL & N45 $29.577^{\prime}$ & W122²8.447' & 2.5 & 33 \\
\hline & UIC-049-PP2 & & & & & & $\mathrm{N} 45^{\circ} 29.575^{\prime}$ & W122 $28.533^{\prime}$ & 3.5 & 45 \\
\hline UIC-050 & UIC-050-PP1 & $3250-F-007$ & 0.9 & SUMPED & NO & RESIDENTIAL & $\mathrm{N} 45^{\circ} 30.636^{\prime}$ & W122²7.507' & 3 & 45 \\
\hline \multirow[t]{2}{*}{ UIC-051 } & UIC-051-PP1 & 3047-W-027 & 5.74 & SUMPED & NO & COLLECTOR & $\mathrm{N} 45^{\circ} 31.269^{\prime}$ & W122 $29.168^{\prime}$ & 2.83 & 45 \\
\hline & UIC-051-PP2 & & & & & & $\mathrm{N} 45^{\circ} 31.244^{\prime}$ & W122²9.166' & 4.5 & 58 \\
\hline \multirow[t]{2}{*}{ UIC-052 } & UIC-052-PP1 & 3149-W-003 & 1.79 & SUMPED & NO & ARTERIAL & N45 $30.791^{\prime}$ & W122²8.539' & 4.33 & 58 \\
\hline & UIC-052-PP2 & & & & & & $\mathrm{N} 45^{\circ} 30.819^{\prime}$ & W122 $28.534^{\prime}$ & 3 & 45 \\
\hline UIC-053 & UIC-053-PP1 & 2950-W-063 & 0.04 & SUMPED & NO & RESIDENTIAL & $\mathrm{N} 45^{\circ} 31.828^{\prime}$ & W122²7.546' & 2.33 & 33 \\
\hline UIC-054 & UIC-054-PPO & $3053-F-020$ & 0.08 & SUMPED & NO & ARTERIAL & & & & \\
\hline \multirow[t]{2}{*}{ UIC-055 } & UIC-055-PP1 & 3048-W-097 & 0.216 & SUMPED & NO & COLLECTOR & $\mathrm{N} 45^{\circ} 31.309^{\prime}$ & W122 $28.859^{\prime}$ & & 58 \\
\hline & UIC-055-PP2 & & & & & & $\mathrm{N} 45^{\circ} 31.313^{\prime}$ & W122²8.817' & 4.08 & 58 \\
\hline \multirow[t]{3}{*}{ UIC-057 } & UIC-057-PP1 & 3050-W-016 & 9.1 & SUMPED & NO & BOULEVARD & $\mathrm{N} 45^{\circ} 31.155^{\prime}$ & W122 $27.734^{\prime}$ & 3.67 & 58 \\
\hline & UIC-057-PP2 & & & & & & $\mathrm{N} 45^{\circ} 31.163^{\prime}$ & W122 $27.773^{\prime}$ & 3.5 & 45 \\
\hline & UIC-057-PP3 & & & & & & $\mathrm{N} 45^{\circ} 31.152^{\prime}$ & W122 $27.782^{\prime}$ & 4.17 & 58 \\
\hline UIC-059 & UIC-059-PPO & 3049-W-069 & 0.0862 & SUMPED & NO & BOULEVARD & & & & \\
\hline \multirow[t]{4}{*}{ UIC-060 } & UIC-060-PP1 & 3047-W-096 & 0.518 & SUMPED & NO & COLLECTOR & $\mathrm{N} 45^{\circ} 31.327^{\prime}$ & W122 $29.711^{\prime}$ & 4.17 & 58 \\
\hline & UIC-060-PP2 & & & & & & $\mathrm{N} 45^{\circ} 31.323^{\prime}$ & W122 $29.744^{\prime}$ & 2.5 & 58 \\
\hline & UIC-060-PP3 & & & & & & $\mathrm{N} 45^{\circ} 31.318^{\prime}$ & W122 $29.754^{\prime}$ & 4.08 & 58 \\
\hline & UIC-060-PP4 & & & & & & $\mathrm{N} 45^{\circ} 31.320^{\prime}$ & W122 $29.772^{\prime}$ & 2.5 & 58 \\
\hline UIC-061 & UIC-061-PP1 & 3150-F-043 & 0.118 & SUMPED & NO & COLLECTOR & $\mathrm{N} 45^{\circ} 30.911^{\prime}$ & W122 $27.310^{\prime}$ & 4.17 & 58 \\
\hline UIC-062 & UIC-062-PP1 & 3047-W-047 & 0.163 & SUMPED & NO & COLLECTOR & $\mathrm{N} 45^{\circ} 31.466^{\prime}$ & W122 $29.177^{\prime}$ & 2.5 & 45 \\
\hline UIC-070 & UIC-070-PP1 & 3153-F-025 & 0.149 & SUMPED & NO & ARTERIAL & $\mathrm{N} 45^{\circ} 30.968^{\prime}$ & W122 $26.037^{\prime}$ & 3 & 33 \\
\hline UIC-071 & UIC-071-PP1 & 3047-W-103 & 0.139 & SUMPED & NO & COLLECTOR & $\mathrm{N} 45^{\circ} 31.334^{\prime}$ & W122²9.407' & 3.17 & 45 \\
\hline
\end{tabular}




\begin{tabular}{|c|c|c|c|c|c|c|c|c|c|c|}
\hline GRTS Rank & $\begin{array}{l}\text { Power Pole } \\
\text { Unique ID }\end{array}$ & $\begin{array}{l}\text { Surface } \\
\text { Area }(\mathrm{ft} 2)\end{array}$ & $\begin{array}{l}\text { PGE Power } \\
\text { Pole Map }\end{array}$ & $\begin{array}{l}\text { PGE Power } \\
\text { Pole Number }\end{array}$ & Pole Manufacturer & $\begin{array}{l}\text { Pole } \\
\text { Manufacture } \\
\text { Date }\end{array}$ & \begin{tabular}{|l} 
Last \\
Inspection
\end{tabular} & $\begin{array}{l}\text { Distance to } \\
\text { UIC Inlet (ft) }\end{array}$ & $\begin{array}{l}\text { Distance to } \\
\text { Curb (ft) }\end{array}$ & $\begin{array}{l}\text { Substrate } \\
\text { Surrounding } \\
\text { Pole }\end{array}$ \\
\hline \multirow{2}{*}{ UIC-047 } & UIC-047-PP2 & 45 & & & & & 1997 & 138 & 5.42 & DIRT \\
\hline & UIC-047-PP3 & 222.14 & D135B & 1084 & PENTAFIR & 1976 & 2008 & 27 & 7.83 & DIRT \\
\hline \multirow{4}{*}{ UIC-048 } & UIC-048-PP2 & 246.5 & A1236 & 2758 & TAYLOR TREATING & 1999 & 2008 & 167 & 1 & CONCRETE \\
\hline & UIC-048-PP3 & 275.5 & A1236 & 2757 & & 1948 & 2008 & 314 & 1.33 & DIRT \\
\hline & UIC-048-PP4 & 241.86 & A1236 & 2756 & TAYLOR TREATING & 1992 & 2008 & 452 & 1.17 & CONCRETE \\
\hline & UIC-048-PP5 & 246.5 & A1236 & 2992 & PENTAFIR & 1987 & 2008 & 593 & 3 & VEGETATION \\
\hline UIC-049 & UIC-049-PP1 & 82.5 & D138 & 11365 & & 1976 & 1993 & 297 & 1 & VEGETATION \\
\hline \multirow[t]{2}{*}{ UIC-052 } & UIC-052-PP1 & 251.14 & D135B & 579 & PENTAFIR & 1976 & 2008 & 150 & 1.17 & CONCRETE \\
\hline & UIC-052-PP2 & 135 & D135 & 578 & PENTAFIR & 1968 & 1989 & 15 & 1 & CONCRETE \\
\hline UIC-053 & UIC-053-PP1 & 76.89 & A1332A & 6326 & PENTAFIR & 1978 & 1993 & 105 & 1.25 & DIRT \\
\hline UIC-054 & UIC-054-PPO & & & & & & & & & \\
\hline \multirow[t]{2}{*}{ UIC-055 } & UIC-055-PP1 & 0 & & 1233 & & & & 252 & & DIRT \\
\hline & UIC-055-PP2 & 236.64 & A1331 & 1232 & PENTAFIR & 1988 & 2002 & 72 & 14.08 & DIRT \\
\hline \multirow[t]{3}{*}{ UIC-057 } & UIC-057-PP1 & 212.86 & A1332D & 1207 & PENTAFIR & 1989 & 2002 & 126 & 1.33 & CONCRETE \\
\hline & UIC-057-PP2 & 157.5 & A1332D & 64 & MCFARLANE CASCADE & 2008 & & 24 & 1.67 & CONCRETE \\
\hline & UIC-057-PP3 & 241.86 & A1332D & 6867 & PENTAFIR & 1989 & 2002 & 69 & 1.92 & CONCRETE \\
\hline UIC-059 & UIC-059-PPO & & & & & & & & & \\
\hline UIC-060 & UIC-060-PP1 & 241.86 & A1331C & 3815 & PENTAFIR & 1983 & 2002 & 36 & 2.67 & DIRT \\
\hline
\end{tabular}




\begin{tabular}{|c|c|c|c|c|c|c|c|c|c|c|}
\hline GRTS Rank & $\begin{array}{l}\text { Power Pole } \\
\text { Unique ID }\end{array}$ & $\begin{array}{l}\text { Distance to } \\
\text { Impervious } \\
\text { Surface (ft) }\end{array}$ & $\begin{array}{l}\text { Visual Est. of } \\
\text { Product on } \\
\text { Pole }\end{array}$ & $\begin{array}{l}\text { Treatment } \\
\text { Compound on } \\
\text { Ground }\end{array}$ & \begin{tabular}{|l} 
Radius \\
Treatment \\
Compound \\
Ground (in)
\end{tabular} & $\begin{array}{l}\text { Pole } \\
\text { Appearance }\end{array}$ & $\begin{array}{l}\text { Diffusion } \\
\text { Plugs } \\
\text { Present }\end{array}$ & $\begin{array}{l}\text { Number } \\
\text { Diffusion } \\
\text { Plugs }\end{array}$ & Adjacent Land Use & $\begin{array}{l}\text { Soil } \\
\text { Complex }\end{array}$ \\
\hline \multirow[t]{4}{*}{ UIC-047 } & UIC-047-PP1 & 1.25 & MEDIUM & YES & 3 & MATURE & PLASTIC & 3 & RESIDENTIAL & $30 \mathrm{~A}$ \\
\hline & UIC-047-PP2 & 0.08 & LOW & NO & & WEATHERED & WOOD & 5 & RESIDENTIAL & $30 \mathrm{~A}$ \\
\hline & UIC-047-PP3 & 2.42 & $\mathrm{HIGH}$ & YES & 2 & WEATHERED & PLASTIC & 6 & RESIDENTIAL & $30 \mathrm{~A}$ \\
\hline & UIC-047-PP4 & 5.67 & HIGH & NO & & MATURE & PLASTIC & 8 & RESIDENTIAL & $30 \mathrm{~A}$ \\
\hline \multirow[t]{5}{*}{ UIC-048 } & UIC-048-PP1 & NA & MEDIUM & NO & & WEATHERED & PLASTIC & 8 & COMMERCIAL & $30 \mathrm{~A}$ \\
\hline & UIC-048-PP2 & NA & LOW & YES & 4 & MATURE & PLASTIC & 3 & MIXED & $30 \mathrm{~A}$ \\
\hline & UIC-048-PP3 & 0.92 & LOW & NO & & WEATHERED & PLASTIC & 8 & RESIDENTIAL & $30 \mathrm{~A}$ \\
\hline & UIC-048-PP4 & NA & $\mathrm{HIGH}$ & YES & 2 & MATURE & PLASTIC & 5 & RESIDENTIAL & $30 \mathrm{~A}$ \\
\hline & UIC-048-PP5 & 2.5 & $\mathrm{HIGH}$ & YES & 3 & MATURE & PLASTIC & 8 & MIXED & $30 \mathrm{~A}$ \\
\hline \multirow[t]{2}{*}{ UIC-049 } & UIC-049-PP1 & 0.5 & LOW & NO & & WEATHERED & NO & & RESIDENTIAL & $29 B$ \\
\hline & UIC-049-PP2 & NA & $\mathrm{HIGH}$ & YES & 1 & MATURE & PLASTIC & 4 & COMMERCIAL & $29 B$ \\
\hline UIC-050 & UIC-050-PP1 & NA & MEDIUM & YES & 2 & MATURE & NO & & INDUSTRIAL & $30 \mathrm{~A}$ \\
\hline \multirow[t]{2}{*}{ UIC-051 } & UIC-051-PP1 & NA & $\mathrm{HIGH}$ & NO & & WEATHERED & PLASTIC & 5 & RESIDENTIAL & $30 \mathrm{~A}$ \\
\hline & UIC-051-PP2 & NA & $\mathrm{HIGH}$ & YES & 2 & MATURE & PLASTIC & 4 & RESIDENTIAL & $30 \mathrm{~A}$ \\
\hline \multirow[t]{2}{*}{ UIC-052 } & UIC-052-PP1 & NA & $\mathrm{HIGH}$ & YES & 6 & MATURE & PLASTIC & 8 & RESIDENTIAL & $29 A$ \\
\hline & UIC-052-PP2 & NA & $\mathrm{HIGH}$ & YES & 6 & MATURE & WOOD & 4 & MIXED & $29 A$ \\
\hline UIC-053 & UIC-053-PP1 & 0.75 & $\mathrm{HIGH}$ & YES & 2 & MATURE & WOOD & 3 & RESIDENTIAL & $30 \mathrm{~A}$ \\
\hline UIC-054 & UIC-054-PPO & & & & & & & & & $26 \mathrm{~A}$ \\
\hline \multirow[t]{2}{*}{ UIC-055 } & UIC-055-PP1 & NA & MEDIUM & NO & & MATURE & PLASTIC & & RESIDENTIAL & $30 \mathrm{~A}$ \\
\hline & UIC-055-PP2 & 5.75 & $\mathrm{HIGH}$ & YES & 4 & MATURE & PLASTIC & 8 & RESIDENTIAL & $30 \mathrm{~A}$ \\
\hline \multirow[t]{3}{*}{ UIC-057 } & UIC-057-PP1 & NA & MEDIUM & YES & 1 & MATURE & PLASTIC & 6 & COMMERCIAL & $30 \mathrm{~A}$ \\
\hline & UIC-057-PP2 & NA & MEDIUM & YES & 3 & JUVENILE & NO & & COMMERCIAL & $30 \mathrm{~A}$ \\
\hline & UIC-057-PP3 & NA & MEDIUM & YES & 2 & MATURE & PLASTIC & 8 & COMMERCIAL & $30 \mathrm{~A}$ \\
\hline UIC-059 & UIC-059-PPO & & & & & & & & & $30 \mathrm{~A}$ \\
\hline \multirow[t]{4}{*}{ UIC-060 } & UIC-060-PP1 & 2.17 & $\mathrm{HIGH}$ & YES & 4 & MATURE & PLASTIC & 8 & RESIDENTIAL & $30 \mathrm{~A}$ \\
\hline & UIC-060-PP2 & NA & MEDIUM & NO & & WEATHERED & WOOD & 4 & RESIDENTIAL & $30 \mathrm{~A}$ \\
\hline & UIC-060-PP3 & NA & $\mathrm{HIGH}$ & YES & 8 & MATURE & PLASTIC & 8 & RESIDENTIAL & $30 \mathrm{~A}$ \\
\hline & UIC-060-PP4 & NA & $\mathrm{HIGH}$ & YES & 2 & MATURE & WOOD & 3 & MIXED & $30 \mathrm{~A}$ \\
\hline UIC-061 & UIC-061-PP1 & NA & MEDIUM & YES & 3 & MATURE & PLASTIC & 7 & COMMERCIAL & $30 \mathrm{~A}$ \\
\hline UIC-062 & UIC-062-PP1 & 7.58 & MEDIUM & YES & 5 & MATURE & NO & & RESIDENTIAL & $30 \mathrm{~A}$ \\
\hline UIC-070 & UIC-070-PP1 & 0.58 & LOW & NO & & WEATHERED & NO & & RESIDENTIAL & $26 \mathrm{~A}$ \\
\hline UIC-071 & UIC-071-PP1 & 0.33 & $\mathrm{HIGH}$ & YES & 4 & WEATHERED & PLASTIC & 5 & RESIDENTIAL & $30 \mathrm{~A}$ \\
\hline
\end{tabular}




\begin{tabular}{|c|c|c|c|c|c|c|c|c|c|c|}
\hline GRTS Rank & $\begin{array}{l}\text { Power Pole } \\
\text { Unique ID }\end{array}$ & System ID & Penta (ug/L) & $\begin{array}{l}\text { Catch Basin } \\
\text { Type }\end{array}$ & Sed Manhole & Functional Class & GPS Latitude & GPS Longitude & $\begin{array}{l}\text { Pole } \\
\text { Circumference } \\
\text { (ft) }\end{array}$ & $\begin{array}{l}\text { Pole Height } \\
(\mathrm{ft})\end{array}$ \\
\hline \multirow[t]{3}{*}{ UIC-086 } & UIC-086-PP1 & 3153-F-017 & 5.96 & UNSUMPED & NO & ARTERIAL & $\mathrm{N} 45^{\circ} 31.138^{\prime}$ & W122 $25.978^{\prime}$ & 5 & 58 \\
\hline & UIC-086-PP2 & & & & & & $\mathrm{N} 45^{\circ} 31.144^{\prime}$ & W122 $26.016^{\prime}$ & 3.83 & 45 \\
\hline & UIC-086-PP3 & & & & & & $\mathrm{N} 45^{\circ} 31.122^{\prime}$ & W122 $26.019^{\prime}$ & 3.17 & 45 \\
\hline \multirow[t]{2}{*}{ UIC-093 } & UIC-093-PP1 & 3150-F-047 & 2.04 & SUMPED & NO & ARTERIAL & N45운.143' & W122 $27.393^{\prime}$ & 3.42 & 45 \\
\hline & UIC-093-PP2 & & & & & & $\mathrm{N} 45^{\circ} 31.143^{\prime}$ & W122 $27.431^{\prime}$ & 3.67 & 45 \\
\hline \multirow[t]{5}{*}{ UIC-094 } & UIC-094-PP1 & $3254-F-072$ & 0.449 & SUMPED & NO & COLLECTOR & $\mathrm{N} 45^{\circ} 30.505^{\prime}$ & W122 $25.267^{\prime}$ & 2.5 & 33 \\
\hline & UIC-094-PP2 & & & & & & $\mathrm{N} 45^{\circ} 30.486^{\prime}$ & W122 $25.273^{\prime}$ & 2.33 & 33 \\
\hline & UIC-094-PP3 & & & & & & $\mathrm{N} 45^{\circ} 30.460^{\prime}$ & W122 $25.270^{\prime}$ & 2.33 & 33 \\
\hline & UIC-094-PP4 & & & & & & $\mathrm{N} 45^{\circ} 30.436^{\prime}$ & W122 $25.270^{\prime}$ & 2.33 & 33 \\
\hline & UIC-094-PP5 & & & & & & $\mathrm{N} 45^{\circ} 30.406^{\prime}$ & W122 $25.274^{\prime}$ & 2.83 & 33 \\
\hline UIC-100 & UIC-100-PPO & $3248-W-020$ & 0.0926 & SUMPED & NO & ARTERIAL & & & & \\
\hline \multirow[t]{2}{*}{ UIC-103 } & UIC-103-PP1 & 3048-W-091 & 0.204 & SUMPED & NO & COLLECTOR & $\mathrm{N} 45^{\circ} 31.338^{\prime}$ & W122 $29.042^{\prime}$ & 3 & 45 \\
\hline & UIC-103-PP2 & & & & & & $\mathrm{N} 45^{\circ} 31.346^{\prime}$ & W122 $29.065^{\prime}$ & 2.83 & 45 \\
\hline
\end{tabular}




\begin{tabular}{|c|c|c|c|c|c|c|c|c|c|c|}
\hline GRTS Rank & $\begin{array}{l}\text { Power Pole } \\
\text { Unique ID }\end{array}$ & $\begin{array}{l}\text { Surface } \\
\text { Area }(\mathrm{ft} 2)\end{array}$ & $\begin{array}{l}\text { PGE Power } \\
\text { Pole Map }\end{array}$ & $\begin{array}{l}\text { PGE Power } \\
\text { Pole Number }\end{array}$ & Pole Manufacturer & $\begin{array}{l}\text { Pole } \\
\text { Manufacture } \\
\text { Date }\end{array}$ & \begin{tabular}{|l} 
Last \\
Inspection
\end{tabular} & $\begin{array}{l}\text { Distance to } \\
\text { UIC Inlet (ft) }\end{array}$ & $\begin{array}{l}\text { Distance to } \\
\text { Curb }(\mathrm{ft})\end{array}$ & $\begin{array}{l}\text { Substrate } \\
\text { Surrounding } \\
\text { Pole }\end{array}$ \\
\hline \multirow{2}{*}{ UIC-086 } & UIC-086-PP2 & 172.35 & D1303B & 7169 & TAYLOR TREATING & 1996 & 2007 & 1 & 4.67 & CONCRETE \\
\hline & UIC-086-PP3 & 142.65 & D133B2 & 7846 & PENTAFIR & 1968 & 2007 & 123 & 1.08 & CONCRETE \\
\hline \multirow[t]{5}{*}{ UIC-094 } & UIC-094-PP1 & 82.5 & D1303D & 77 & SJI NW & 2010 & & 3 & & ASPHALT \\
\hline & UIC-094-PP2 & 76.89 & & & & & 1989 & 72 & 1.92 & CONCRETE \\
\hline & UIC-094-PP3 & 76.89 & & & PENTAFIR & 1967 & 1989 & 228 & 1.83 & CONCRETE \\
\hline & UIC-094-PP4 & 76.89 & & & PENTAFIR & 1967 & 1989 & 381 & 1.92 & CONCRETE \\
\hline & UIC-094-PP5 & 93.39 & & & PENTAFIR & 1964 & 1989 & 546 & 4 & CONCRETE \\
\hline
\end{tabular}




\begin{tabular}{|c|c|c|c|c|c|c|c|c|c|c|}
\hline GRTS Rank & $\begin{array}{l}\text { Power Pole } \\
\text { Unique ID }\end{array}$ & $\begin{array}{l}\text { Distance to } \\
\text { Impervious } \\
\text { Surface (ft) }\end{array}$ & $\begin{array}{l}\text { Visual Est. of } \\
\text { Product on } \\
\text { Pole }\end{array}$ & $\begin{array}{l}\text { Treatment } \\
\text { Compound on } \\
\text { Ground }\end{array}$ & $\begin{array}{l}\text { Radius } \\
\text { Treatment } \\
\text { Compound } \\
\text { Ground (in) }\end{array}$ & \begin{tabular}{|l} 
Pole \\
Appearance
\end{tabular} & $\begin{array}{l}\text { Diffusion } \\
\text { Plugs } \\
\text { Present }\end{array}$ & $\begin{array}{l}\text { Number } \\
\text { Diffusion } \\
\text { Plugs }\end{array}$ & Adjacent Land Use & $\begin{array}{l}\text { Soil } \\
\text { Complex }\end{array}$ \\
\hline \multirow[t]{3}{*}{ UIC-086 } & UIC-086-PP1 & NA & $\mathrm{HIGH}$ & YES & 3 & MATURE & PLASTIC & & 8 COMMERCIAL & $26 \mathrm{~A}$ \\
\hline & UIC-086-PP2 & NA & $\mathrm{HIGH}$ & YES & 4 & MATURE & PLASTIC & 8 & 8 COMMERCIAL & $26 \mathrm{~A}$ \\
\hline & UIC-086-PP3 & NA & MEDIUM & YES & 6 & MATURE & PLASTIC & 4 & 4 COMMERCIAL & $26 \mathrm{~A}$ \\
\hline \multirow[t]{2}{*}{ UIC-093 } & UIC-093-PP1 & NA & MEDIUM & YES & 5 & MATURE & NO & & COMMERCIAL & $30 \mathrm{~A}$ \\
\hline & UIC-093-PP2 & NA & LOW & NO & & WEATHERED & WOOD & & 4 COMMERCIAL & $30 \mathrm{~A}$ \\
\hline \multirow[t]{5}{*}{ UIC-094 } & UIC-094-PP1 & NA & $\mathrm{HIGH}$ & NO & & JUVENILE & NO & & RESIDENTIAL & $30 \mathrm{~A}$ \\
\hline & UIC-094-PP2 & NA & MEDIUM & NO & & WEATHERED & WOOD & & 2 RESIDENTIAL & $30 \mathrm{~A}$ \\
\hline & UIC-094-PP3 & NA & MEDIUM & NO & & MATURE & WOOD & & 2 COMMERCIAL & $30 \mathrm{~A}$ \\
\hline & UIC-094-PP4 & NA & LOW & NO & & WEATHERED & WOOD & & 3 COMMERCIAL & $30 \mathrm{~A}$ \\
\hline & UIC-094-PP5 & NA & MEDIUM & NO & & MATURE & WOOD & & 2 COMMERCIAL & $30 \mathrm{~A}$ \\
\hline UIC-100 & UIC-100-PPO & & & & & & & & & $30 \mathrm{~A}$ \\
\hline \multirow[t]{2}{*}{ UIC-103 } & UIC-103-PP1 & 2.33 & LOW & NO & & MATURE & PLASTIC & & 5 RESIDENTIAL & $30 \mathrm{~A}$ \\
\hline & UIC-103-PP2 & NA & $\mathrm{HIGH}$ & YES & 8 & WEATHERED & PLASTIC & & \begin{tabular}{l|l}
5 & RESIDENTIAL
\end{tabular} & $30 \mathrm{~A}$ \\
\hline
\end{tabular}




\begin{tabular}{llllll}
\hline $\begin{array}{l}\text { Soil } \\
\text { Complex }\end{array}$ & Soil Complex Name & Slope & $\begin{array}{l}\text { A Horizon Soil } \\
\text { Profile }\end{array}$ & $\begin{array}{l}\text { B Horizon Soil } \\
\text { Profile }\end{array}$ & C Horizon Soil Profile \\
\hline 25B & Latourell Loam & $3-8 \%$ & Silt loam & Silt loam & Very gravelly sand \\
26A & Latourell Urban Land Complex & $0-3 \%$ & Loam & Loam & Very gravelly sandy loam \\
26B & Latourell Urban Land Complex & $3-8 \%$ & Loam & Loam & Very gravelly sandy loam \\
29A & Multnomah Silt Loam & $0-3 \%$ & Silt loam & Silt loam & Very gravelly sand \\
29A & Multnomah Silt Loam & $3-8 \%$ & Silt loam & Silt loam & Very gravelly sand \\
30A & Multnomah Urban Land Complex & $0-3 \%$ & Silt loam & Silt loam & Very gravelly sand \\
30A & Multnomah Urban Land Complex & $3-8 \%$ & Silt loam & Silt loam & Very gravelly sand \\
\hline
\end{tabular}




\section{WORKS CITED}

Anselin, L. 1995. Local indicators of spatial association-LISA. Geographical Analysis, 27: 93-115.

Choudhury, H., Coleman, J., DeRosa, CT., and Stara, JF. 1986. Pentachlorophenol: health and environmental effects profile. Toxicology and Industrial Health, 2(4): 483-571.

Christodoulatos, C, Korfiatis, GP, Talimcioglu, NM, Mohiuddin, M. 1994. Adsorption of pentachlorophenol by natural soils. Journal of Environmental Science \& Health A29(5): 883-898.

City of Gresham. 2007. Volume I: overview of the City of Gresham's point and non-point source TMDL implementation plans. Prepared by City of Gresham, Department of Environmental Services. Gresham, Oregon.

City of Gresham. 2009. Gresham UIC priority pollutant study proposal: wet weather season 2009-2010. Prepared by City of Gresham, Department of Environmental Services. Gresham, Oregon.

City of Gresham. 2011a. Stormwater management plan. Prepared by City of Gresham, Department of Environmental Services. Gresham, Oregon.

City of Gresham. 2011b. Stormwater monitoring and quality assurance plan. Prepared by City of Gresham, Department of Environmental Services. Gresham, Oregon.

City of Gresham. Water quality information. Retrieved May 14, 2012 from http://greshamoregon.gov/city/city-departments/environmental-services/water

City of Portland. 2006a. Underground injection control management plan: stormwater underground injection control. Prepared by City of Portland, Bureau of Environmental Services for WPCF Permit 102830. Portland, Oregon.

City of Portland. 2006b. Sampling and analysis plan: stormwater underground injection control system monitoring. Prepared by City of Portland, Bureau of Environmental Services for WPCF Permit 102830. Portland, Oregon.

City of Portland. 2009. Underground injection control management plan annual report no. 4 Fiscal Year 2008-2009. Prepared by City of Portland, Bureau of Environmental Services for WPCF Permit 102830. Portland, Oregon.

Clean Water Act of 1972. 33 USC § 1251 (1987). 
Cole, RH., Frederick, RE., Healy, RP., and Rolan, RG. 1984. Preliminary findings of the priority pollutant monitoring project of the nationwide urban runoff program. Journal (Water Pollution Control Federation), 56(7): 898-908.

ESRI. 2006. ArcGIS Spatial Analyst: Advanced raster spatial analysis. Redlands, CA: Environmental Systems Research Institute.

ESRI. 2011a. ArcGIS Desktop: Release 10. Redlands, CA: Environmental Systems Research Institute.

ESRI. 2012a. ArcGIS Desktop 10 Help Library: Spatial analyst toolbox, hydrology toolset. Retrieved on May 19, 2012 from http://help.arcgis.com/en/arcgisdesktop/10.0/help/index.html

ESRI. 2012b. ArcGIS Desktop 10 Help Library: Spatial statistics toolbox. Retrieved on May 19, 2012 from http://help.arcgis.com/en/arcgisdesktop/10.0/help/index.html

Getis, A. and Ord, JK. 1992. The analysis of spatial association by use of distance statistics. Geographical Analysis, 24: 189-206.

Gotelli, NJ. and Ellison, AM. 2004. A Primer of Ecological Statistics. Sunderland, Massachusetts: Sinauer Associates, Inc.

Griffin, DM., Grizzard, TJ., Randall, CW., Helsel, DR., and Hartigan, JP. 1980. Analysis of nonpoint pollution export from small catchments. Journal (Water Pollution Control Federation), 52(4): 780-790.

GSI Water Solutions, Incorporated. 2011a. Technical memorandum: DRAFT Statistical evaluation of the relationship between utility poles and PCP concentrations in storm water at UICs. Portland, Oregon.

GSI Water Solutions, Incorporated. 2011b. Technical memorandum: pollutant fate and transport model results in support of the City of Gresham UIC WPCF Permit - proposed EDLs. Portland, Oregon.

Kennedy/Jenks Consultants. 2009. Compilation and evaluation of existing stormwater quality data from Oregon (K/J Project No. 0891020.00). Portland, Oregon.

Loh, W. 2008. Classification and regression tree methods. In Ruggeri, Kenett, and Faltin (Eds.), Encyclopedia of statistics in quality and reliability (315-323). Hoboken, New Jersey: Wiley

Maindonald, J. and Braun, J. 2007. Data analysis and graphics using R: An example-based approach (Cambridge series in statistical and probabilistic mathematics) ( $2^{\text {nd }}$ ed.). New York: Cambridge University Press. 
McFarland, W.D. and Morgan, D.S. 1996. Description of the ground-water flow system in the Portland basin, Oregon and Washington: U.S. Geological Survey Water Supply Paper 2470A.

Mills, T., Arnold, B., Sivakumaran, S., Northcott, G., Vogeler, I., Robinson, B., Norling, C., and Leonil, L. 2006. Phytoremediation and long-term site management of soil contaminated with pentachlorophenol (PCP) and heavy metals. Journal of Environmental Management, 79: 232-241.

Oregon Association of Clean Water Agencies. 2003. Underground injection wells for stormwater: best management practices manual. Portland, Oregon.

Oregon Department of Environmental Quality. Underground injection control program. Retrieved October 13, 2011 from http://www.oregondeq.org/wq/uic/overview

Oregon Department of Human Services. 2006. Technical bulletin health effects information: Pentachlorophenol. Portland, Oregon.

Pignatello, JJ., Martinson, MM., Steiert, JG., Carlson, RE., and Crawford, RL. 1983. Biodegradation and photolysis of pentachlorophenol in artificial freshwater systems. Applied and Environmental Microbiology, 46(5): 1024-1031.

Pitt, R., Clark, S., and Field, R. 1999. Groundwater contamination potential from stormwater infiltration practices. Urban Water, 1:217-236.

R Development Core Team. 2011. R: A language and environment for statistical computing. $\mathrm{R}$ Foundation for Statistical Computing, Vienna, Austria.

Roche, JN. 1965. Wood preservation: An important factor in conservation. Proc. of the Am. Wood Preservers' Assoc. 61:11-15. AWPA. Granbury, TX.

Sloto, RA. 1988. Effects of urbanization on storm-runoff volume and peak discharge of Valley Creek, eastern Chester County, Pennsylvania: U.S. Geological Survey Water Resources Investigation Report 87-4196.

Snyder, D.T. 2008. Estimated depth to ground water and configuration of the water table in the Portland, Oregon area: U.S. Geological Survey Scientific Investigations Report 2008-5059.

Stevens, DL. and Olsen, AR. 2004. Spatially balanced sampling of natural resources. Journal of the American Statistical Association, 99(465):262-278. 
Swanson, R.D., McFarland, W.D., Gonthier, J.B., and Wilkinson, J.W. 1993. A description of hydrogeologic units in the Portland Basin, Oregon and Washington: U.S. Geological Survey Water-Resources Investigations Report 90-4196.

Therneau, TM. and Atkinson, B. 2011a. rpart: Recursive Partitioning. R package version 3.1-50.

Therneau, TM. and Atkinson, B. 2011b. An introduction to recursive partitioning using the RPART routines (Update to Orion Technical Report 21). Mayo Foundation.

Tsihrintzis, VA. And Hamid, R. 1997. Modeling and management of urban stormwater runoff quality: a review. Water Resources Management, 11:137-164.

US Environmental Protection Agency. 1990. National water quality inventory - 1988 report to Congress. Office of the Water Program Operations, Water Planning Division, Washington, D.C., USA.

US Environmental Protection Agency. Basic information about pentachlorophenol in drinking water. Retrieved October 13, 2011 from http://water.epa.gov/drink/contaminants/basicinformation/pentachlorophenol

US Environmental Protection Agency. Underground injection control program. Retrieved October 13, 2011 from http://water.eps.gov/type/groundwater/uic/index

US Environmental Protection Agency. Office of Ground Water and Drinking Water. Class V UIC study fact sheet: storm water drainage wells. Retrieved April 17, 2012 from http://water.epa.gov/type/groundwater/uic/class5/upload/study_uicclass5_classvstudy_fs_storm_wells.pdf

Wilkinson, JG. 1979. Industrial Timber Preservation. Associated Business Press, London, UK.

Wong, AS. and Crosby, DG. (1981). Photodecomposition of pentachlorophenol in water. Journal of Agricultural Food Chemistry, 29: 125-130. 